\title{
A COMPARISON STUDY OF COMPOSITE LAMINATED PLATES WITH HOLES UNDER TENSION
}

\author{
A Thesis \\ presented to \\ the Faculty of California Polytechnic State University, \\ San Luis Obispo
}

\author{
In Partial Fulfillment \\ of the Requirements for the Degree \\ Masters of Science in Aerospace Engineering
}

by

Joun S. Kim

October 2017 
(c) 2017

Joun S. Kim

ALL RIGHTS RESERVED 
COMMITTEE MEMBERSHIP

\author{
TITLE: A Comparison Study of Composite \\ Laminated Plates with Holes under \\ Tension \\ AUTHOR: Joun S. Kim \\ DATE SUBMITTED: October 2017
}

\author{
COMMITTEE CHAIR: Dr. Faysal Kolkailah, Ph.D. \\ Professor of Aerospace Engineering \\ COMMITTEE MEMBER: Dr. Dianne DeTurris, Ph.D. \\ Professor of Aerospace Engineering \\ COMMITTEE MEMBER: Dr. Eltahry Elghandour, Ph.D. \\ Associate Professor of Mechanical \\ Engineering \\ COMMITTEE MEMBER: ThOMas WOO \\ Composite Engineer at General Atomic
}


ABSTRACT

A Comparison Study of Composite Laminated Plates

with Holes under Tension

-Joun S. Kim-

A study was conducted to quantify the accuracy of numerical approximations to deem sufficiency in validating structural composite design, thus minimizing, or even eliminating the need for experimental test. Error values for stress and strain were compared between Finite Element Analysis (FEA) and analytical (Classical Laminated Plate Theory), and FEA and experimental tensile test for two composite plate designs under tension: a cross-ply composite plate design of $\left[(0 / 90)_{4}\right]_{s}$ and a quasi-isotropic layup design of $\left[0_{2} /+45 /-45 / 90_{2}\right]$ s, each with a single, centered hole of 1/8" diameter, and 1/4" diameter (four sets total). The intent of adding variability to the ply sequences and hole configurations was to gauge the sensitivity and confidence of the FEA results and to study whether introducing enough variability would, indeed, produce greater discrepancies between numerical and experimental results, thus necessitating a physical test. A shell element numerical approximation method through ABAQUS was used for the FEA.

Mitsubishi Rayon Carbon Fiber and Composites (formerly Newport Composites) unidirectional pre-preg NCT301-2G150/108 was utilized for manufacturing-which was conducted and tested to conform to ASTM D3039/D3039M standards.

A global seed size of 0.020 , or a node count on the order of magnitude of 30,000 nodes per substrate, was utilized for its sub-3\% error with efficiency in run-time.

The average error rate for FEA strain from analytical strain at a point load of $10001 \mathrm{bf}$ was $2 \%$, while the FEA-to-experimental strains averaged an error of $4 \%$; FEA-to-analytical and FEA-to-tensile test stress 
values at $1000 \mathrm{lbf}$ point load both averaged an error value of $6 \%$. Suffice to say, many of these strain values were accurate up to ten-thousandths and hundred-thousandths of an in/in, and the larger stress/strain errors between FEA and test may have been attributed to the natural variables introduced from conducting a tensile test: strain gauge application methods, tolerance stacks from load cells and strain gauge readings. Despite the variables, it was determined that numerical analysis could, indeed, replace experimental testing. It was observed through this thesis that a denser, more intricate mesh design could provide a greater level of accuracy for numerical solutions, which proves the notion that if lower error rates were necessitated, continued research with a more powerful processor should be able to provide the granularity and accuracy in output that would further minimize error rates between FEA and experimental. Additionally, design margins and factors of safety would generally cover the error rates expected from numerical analysis.

Future work may involve utilizing different types of pre-preg and further varied hole dimensions to better understand how the FEA correlates with analytical and tensile test results. Other load types, such as bending, may also provide insight into how these materials behave under loading, thus furthering the conversation of whether numerical approximations may one day replace testing all together.

Keywords: Composites, Finite Element Analysis, Tensile Tests, Holes in Plates 
ACKNOWLEDGMENTS

I would like to express my utmost gratitude to Dr. Faysal Kolkailah, Dr. Eltahry Elghandour, Dr. Dianne DeTurris, and Thomas Woo for their guidance, unconditional support, and mentorship throughout my thesis. 
TABLE OF CONTENTS

\begin{tabular}{|c|c|}
\hline LIST OF TABLES & ix \\
\hline LIST OF FIGURES & $x i$ \\
\hline NOMENCLATURE & $x v i$ \\
\hline I. INTRODUCTION & 1 \\
\hline Motivation for study & 1 \\
\hline Previous Works & 5 \\
\hline Thesis Overview & 12 \\
\hline II. Manufacturing and Test & 15 \\
\hline Manufacturing for Pull Test & 15 \\
\hline Prepping for Tensile Test & 24 \\
\hline Tensile Test Challenges - Tabs & 28 \\
\hline Tensile Test Challenges - Strain Gauges & 33 \\
\hline III.Material Properties & 35 \\
\hline IV. The Analytical Method: Cross and Quas & 40 \\
\hline Cross-ply & 42 \\
\hline Quasi-isotropic & 43 \\
\hline V. The Homogenous Baseline & 44 \\
\hline Building a Homogenous FEA Baseline & 47 \\
\hline Validating the Homogenous Baseline & 52 \\
\hline VI. Finite Element Analysis Methodology & 53 \\
\hline VII. Results Discussion & 59 \\
\hline VIII.Closing Discussion & 74 \\
\hline Conclusion & 74 \\
\hline Future Work & 76 \\
\hline Bibliography & 78 \\
\hline
\end{tabular}


Classical Laminated Plate Theory Equations

Creating an FEA Model in ABAQUS

Finite Element Models

Previous Works Summary 
TABLE 1 - CROSS AND QUASI-ISOTROPIC LAYUP CONFIGURATION REQUIREMENTS

TABLE 2 - LAYUP DESIGNS FOR IDENTIFYING MATERIAL PROPERTIES 13

TABLE 3 - RISK RATINGS DETERMINED FOR LAB TASKS PERFORMED; THIS STEP WILL HELP IDENTIFY THE HIGHER RISK STEPS THAT WILL BE TAKEN THROUGHOUT MANUFACTURING AND TEST, BRINGING TO FOCUS SAFETY

TABLE 4 - SPECIMEN REQUIREMENTS COMPARED TO ACTUAL DIMENSIONS

TABLE 5 - STRAIN GAUGES IDENTIFIED FOR REACH PLY DESIGN 26

TABLE $6-[0]_{6}$ ATTRIBUTES 36

$\begin{array}{lll}\text { TABLE } 7-[90]_{12} \text { ATTRIBUTES } & 37\end{array}$

$\begin{array}{lll}\text { TABLE } 8-[+/ 45]_{8} \text { ATTRIBUTES } & 38\end{array}$

TABLE 9 - MATERIAL PROPERTIES OF UNIDIRECTIONAL PRE-PREG NCT301-2G150/108 39

TABLE 10 - SPECIMEN DIMENSIONS $\quad 44$

TABLE 11 - MATERIAL CHARACTERISTICS OF LOW CARBON STEEL 45

TABLE 12 - TRUE STRESS/STRAIN FROM TEST RESULTS 50

TABLE 13 - NODE VARIATIONS FOR 1/8" CROSS-PLY SUBSTRATE

TABLE 14 - CROSS-PLY, CENTERED 1/8" hOLE, TENSILE TEST RESUltS

$\begin{array}{ll}\text { AT } 1000 \mathrm{LBF} & 60\end{array}$

TABLE 15 - CROSS-PLY, CENTERED 1/4" HOLE, TENSILE test RESUltS

AT $1000 \mathrm{LBF} \quad 62$

TABLE 16 - QUASI-ISOTROPIC, CENTERED 1/8" HOLE, TENSILE TEST

$\begin{array}{lll}\text { RESULTS AT 1000LBF } & 64\end{array}$

TABLE 17 - QUASI-ISOTROPIC, CENTERED 1/4" HOLE, TENSILE TEST

RESULTS AT 1000LBF 66

TABLE 18 - FEA RESULTS COMPARED WITH ANALYTICAL 71

TABLE 19 - FEA RESUltS COMPARED WITH TENSILE TEST 
TABLE 20 - TENSILE RESULTS COMPARED WITH ANALYTICAL

TABLE 21 - FEA-TO-ANALYTICAL AND FEA-TO-TENSILE TEST STRAIN, WITH CORRELATING ERROR RATES

TABLE 22 - FEA-TO-ANALYTICAL AND FEA-TO-TENSILE TEST STRESS, WITH CORRELATING ERROR RATES 
LIST OF FIGURES

FIGURE 1 - ELECTRON WAS INTRODUCED AS THE FIRST CARBON-COMPOSITE LAUNCH VEHICLE BACK IN 2014, PER AUCKLAND-BASED AEROSPACE COMPANY, ROCKET LAB (HENDERSON, 2014)

FIGURE 2 - SPECIMEN GEOMETRY REQUIREMENTS FROM ASTM D3039/D3039M (ASTM, 2014)

FIGURE 3 - FREQUENCY OF ERROR RATES IDENTIFIED FROM THE 175 INSTANCES OF NUMERICAL AND EXPERIMENTAL COMPARISONS

FIGURE 4 - ACETONE IS USED TO SMOOTH THE SURFACE OF THE ALUMINUM TOOLING PLATE; RESIDUE WILL CREATE POINTS OF STRESS CONCENTRATION ON THE RESULTING COMPOSITE PLATES

FIGURE 5 - THE PRE-PREG IS ROLLED FLAT AND LAID ON TOP OF FLOW MEDIA; CORRECT SPACING WAS ENSURED TO REDUCE IMPINGEMENT WITH THE REGION WHERE VAC-BAG TAPE WILL BE APPLIED TO THE ALUMINUM PLATE

FIGURE 6 - THE VAC-BAG IS SEALED WITH THE LAYUP SECURED ON THE PLATE, WITH THE VACUUM CONNECTOR RESTING ON TOP OF THE LAYUP, SITUATED IN PLACE

FIGURE 7 - VACUUM IS PULLED THROUGH THE VACUUM CONNECTOR TO PERFORM A VISUAL INSPECTION FOR LEAKS PRIOR TO ENTERING THE AUTOCLAVE

FIGURE 8 - LAYUP IS INSERTED INTO AND CONNECTED TO THE AUTOCLAVE'S VACUUM PUMP (GREEN HOSE)

FIGURE 9 - VISUAL INSPECTION CONDUCTED TO ENSURE BLEMISHES CONDUCIVE TO FORMING STRESS CONCENTRATIONS ARE MEDIATED FIGURE 10 - RISK RATING MATRIX TAKES LIKELIHOOD OF AN OCCURRENCE OCCURRING WITH THE SEVERITY OF ITS CONSEQUENCES AND ASSIGNS A RATING OF “LOW" (BLUE), “MEDIUM" (GREEN), “HIGH” (YELLOW), AND “VERY HIGH” (RED) 
FIGURE 11 - THE LAMINATE PLATE WAS MEASURED TO CUT FOR EACH RESPECTIVE TEST COUPON DIMENSIONS 22

FIGURE 12 - BLUE PAINTER'S TAPE WAS USED AS A GUIDELINE FOR CUTTING, ALLOWING THE FOCUS TO REMAIN ON SAFETY IN USING THE TILE SAW

FIGURE 13 - COUPONS WERE PREPPED FOR THE DRILL-PRESS FOR THOSE REQUIRING HOLES

FIGURE 14 - DRILL PRESS USED TO PUT 1/8" AND 1/4" HOLES IN THE APPLICABLE TEST COUPONS

FIGURE 15 - INSTRON 8801 UTILIZED FOR PULL TESTS

FIGURE 16 - UNI COUPONS, 0 AND 90 WITH OMEGA STRAIN GAUGES

FIGURE 17 - ANGLE-PLY TEST COUPONS WITH OMEGA STRAIN GAUGES 26

FIGURE 18 - CROSS-PLY WITH HBM STRAIN GAUGES 27

FIGURE 19 - QUASI-ISOTROPIC COUPONS WITH MICRO-MEASUREMENTS $\begin{array}{lr}\text { STRAIN GAUGES } & 27\end{array}$

FIGURE 20 - DIFFERENT WHEATSTONE BRIDGES USED TO MEASURE STRAIN 28

FIGURE 21 - WEST SYSTEM'S SIX10 THICKENED EPOXY ADHESIVE'S TECHNICAL DATA SHEET DID NOT PROVIDE SHEAR STRENGTH PROPERTIES; A SUBSTITUTE EPOXY WOULD NEED TO BE IDENTIFIED FIGURE 22 - SIX10 EPOXY PREPPED TO BE APPLIED TO TEST COUPONS AND CARBON COMPOSITE TABS

FIGURE 23 - WEIGHTED PLATES WERE USED TO APPLY PRESSURE WHILE EPOXY CURED

FIGURE 24 - UNIDIRECTIONAL 90 TEST COUPON MOUNTED FOR TENSILE TEST

FIGURE 25 - A TAB IS SLIPPING ON THE UNIDIRECTIONAL 0 TEST COUPON-STRONGER EPOXY REQUIRED

FIGURE 26 - 3M SCOTCH-WELD'S DP460NS TWO-PART EPOXY DEVELOPED SPECIFICALLY FOR HIGH-SHEAR STRESS APPLICATIONS 
FIGURE 27 - REMAINING TEST COUPONS APPLIED WITH 3M SCOTCH-WELD'S DP460NS

FIGURE 28 - STRAIN GAUGES WERE SECURED TO TEST COUPONS WITH SUPER GLUE; LEAD WIRES WERE MOLDED TO SIT ON THE SOLDER PADS OF THE STRAIN GAUGES AND THEN TAPED DOWN TO THE TEST COUPON TO SECURE ITS POSITION-SOLDER WAS THEN APPLIED TO SECURE THE ELECTRICAL CONNECTION

FIGURE 29 - UNIDIRECTIONAL 0 TENSILE FAILURE MODE 35

FIGURE 30 - STRESS/STRAIN CURVE FOR THE [0]6 TENSILE TEST 36

FIGURE 31 - STRESS/STRAIN CURVE FOR THE [90]12 TENSILE TEST 37

FIGURE 32 - STRESS/STRAIN CURVE FOR [+/-45] 8 TENSILE TEST 38

FIGURE 33 - STANDARD TENSILE SPECIMENS, ACCORDING TO ASTM E8 44

FIGURE 34 - TEST SPECIMENS FOR HOMOGENOUS BASELINE FEA VALIDATION 45

FIGURE 35 - FAILED SPECIMENS UNDER TENSILE LOADING 46

FIGURE 36 - SPECIMEN WITH 1OMM THICKNESS 46

FIGURE 37 - ABAQUS OUTPUT SCREENSHOT: HOMOGENOUS BASELINE FEA 48

FIGURE 38 - ABAQUS OUTPUT SCREENSHOT: STRESS AND STRAIN PORTRAYED AS DEPENDENT ON TIME FOR HOMOGENOUS BASELINE (STRESS: N/MM², STRAIN : MM/MM, TIME: SEC) 48

FIGURE 39 - ABAQUS OUTPUT SCREENSHOT: STRESS DEPENDENT ON STRAIN OF 1OMM SPECIMEN FOR HOMOGENOUS BASELINE FEM (STRESS: N/MM², STRAIN : MM/MM)

FIGURE 40 - TABULATED STRESS AND STRAIN FROM ABAQUS FOR HOMOGENOUS BASELINE FEM (STRESS: N/MM², STRAIN: MM/MM) 50

FIGURE 41 - DETERMINING PLASTIC E, THROUGH SLOPE OF STRESS AND STRAIN

FIGURE 42 - LOW CARBON STEEL 1OMM THICKNESS SPECIMEN FEA COMPARED TO TENSILE TEST RESULTS 
FIGURE 43 - FOR THE FIRST ITERATION OF FEA, THE GLOBAL SEED SIZE WAS SET TO 0.05 , OR A NODE COUNT OF 4541

FIGURE 44 - FEA RESULT FOR 1/8" CROSS-PLY SUBSTRATE

FIGURE 45 - STRAIN GAUGE AREAS WERE HIGHLIGHTED FOR AVERAGE STRESSES AND STRAINS

FIGURE 46 - THE STRAIN (IN/IN) OF HIGHLIGHTED NODES, AS A FUNCTION OF TIME (SEC)

FIGURE 47 - HIGHLIGHTED NODES SELECTED TO CALCULATE AVERAGE STRAIN (IN/IN) USING ABAQUS COMBINE/AVG FUNCTIONS

FIGURE 48 - AVERAGE STRAIN (IN/IN) PLOTTED AS A FUNCTION OF TIME (SEC)

FIGURE 49 - CROSS-PLY, CENTERED 1/8" HOLE, TENSILE TEST RESULTS AT FAILURE

FIGURE 50 - CROSS-PLY, CENTERED 1/8" HOLE, FEA COMPARED WITH TEST AND ANALYTICAL AT 1000LBF

FIGURE 51 - CROSS-PLY, CENTERED 1/4" HOLE, TENSILE TEST RESULTS TO FAILURE

FIGURE 52 - CROSS-PLY, CENTERED 1/4" HOLE, FEA COMPARED WITH TEST AND ANALYTICAL AT 1000LBF

FIGURE 53 - QUASI-ISOTROPIC, CENTERED 1/8" HOLE, TENSILE TEST RESULTS AT FAILURE

FIGURE 54 - QUASI-ISOTROPIC, CENTERED 1/8" HOLE, FEA COMPARED WITH TEST AND ANALYTICAL AT 1000LBF

FIGURE 55 - QUASI-ISOTROPIC, CENTERED 1/4" HOLE, TENSILE TEST RESULTS AT FAILURE

FIGURE 56 - QUASI-ISOTROPIC, CENTERED 1/4" HOLE, FEA COMPARED WITH TEST AND ANALYTICAL AT 1000LBF 
FIGURE 59 - JUXTAPOSITION OF ANALYTICAL STRAIN WITH TENSILE AND FEA STRAIN AT 1000LBF

FIGURE 60 - JUXTAPOSITION OF ANALYTICAL STRESS WITH TENSILE AND FEA STRESS AT 1000LBF

FIGURE 61 - JUXTAPOSITION OF ANALYTICAL STAIN WITH TENSILE AND FEA STRAIN AT 3000LBF 
NOMENCLATURE

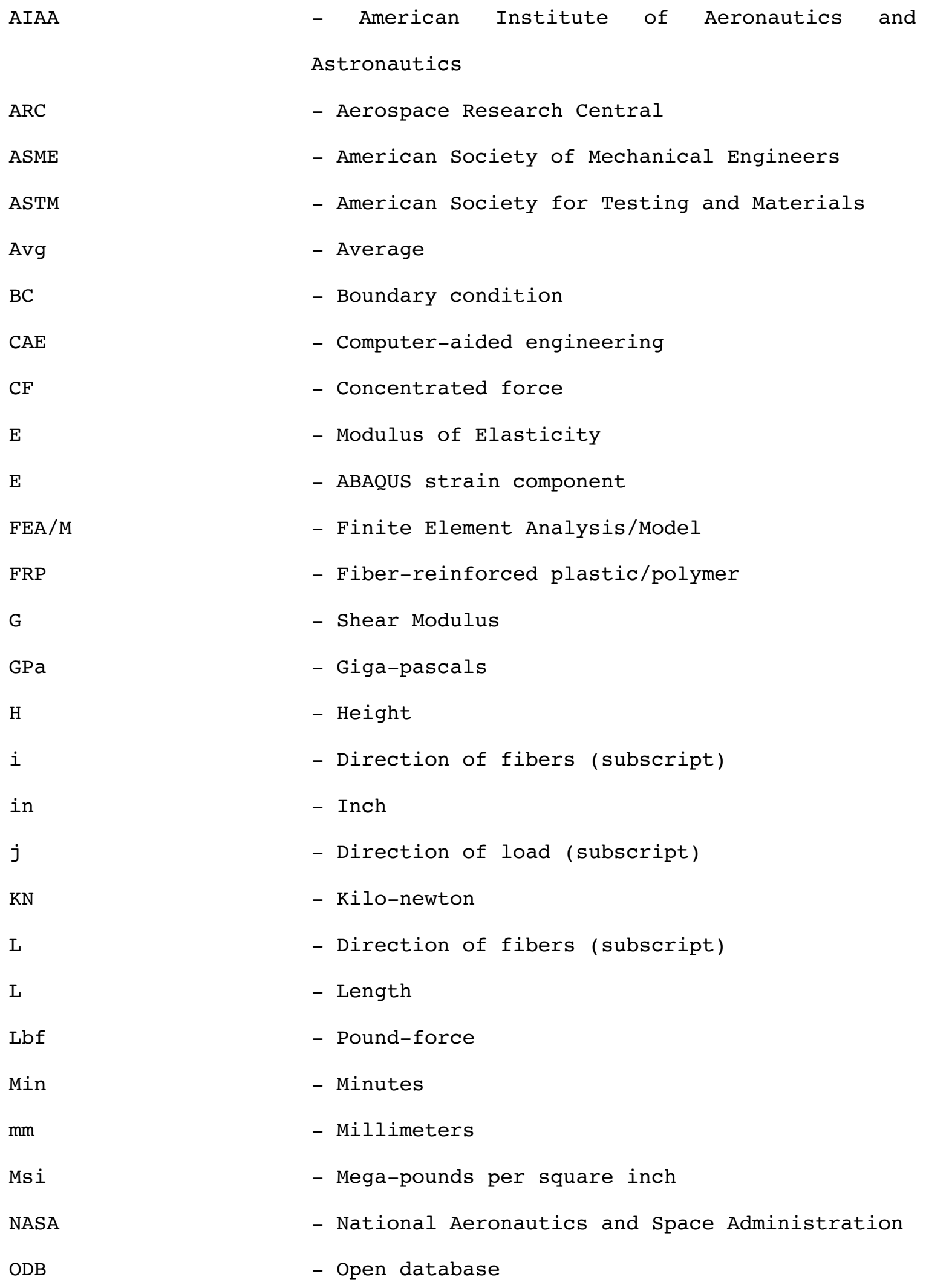




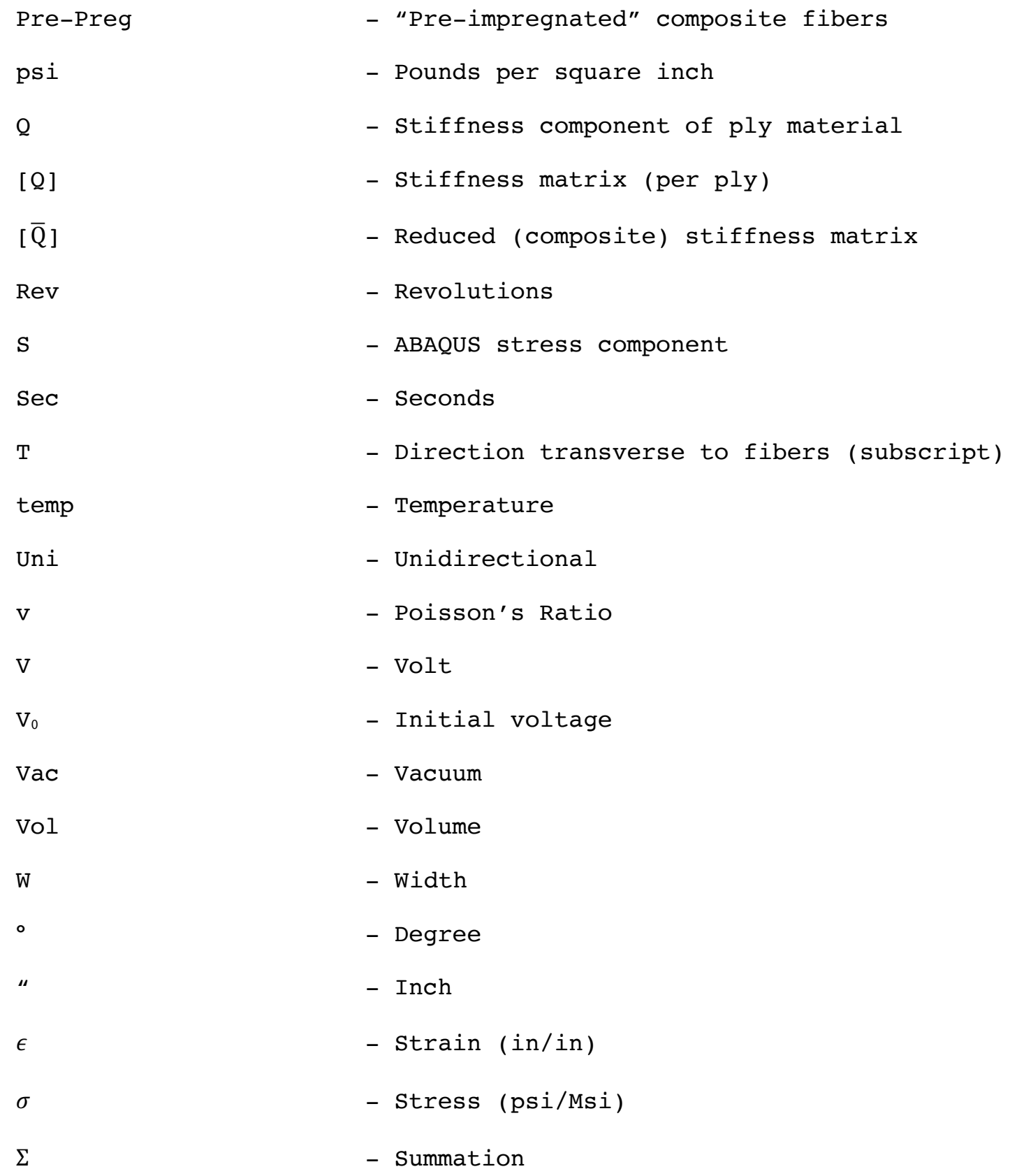


I.

INTRODUCTION

Motivation for study

Fiber-reinforced polymer (FRP) materials were first introduced in the early 1930s, spurring a new age of manufacturing and mechanical design based on a Mesopotamian practice of mixing straw into mud to provide structural reinforcement to bricks and pottery. Today, the concept of combining various materials to produce a new discrete material with its own set of properties is not a novel concept; however, the latest advancements made in composites have proven to be invaluable in situations where low strength-and-stiffness-to-weight ratios, resistance to fatigue, or an inability to rust are found to be mission critical. As a result, composites, specifically FRP, have been widely adopted by the defense, aerospace, automobile, and sports-technology industries, where FRP materials are seen everywhere from bicycle frames to launch vehicle fuselages; reference Figure 1's Electron as an example.

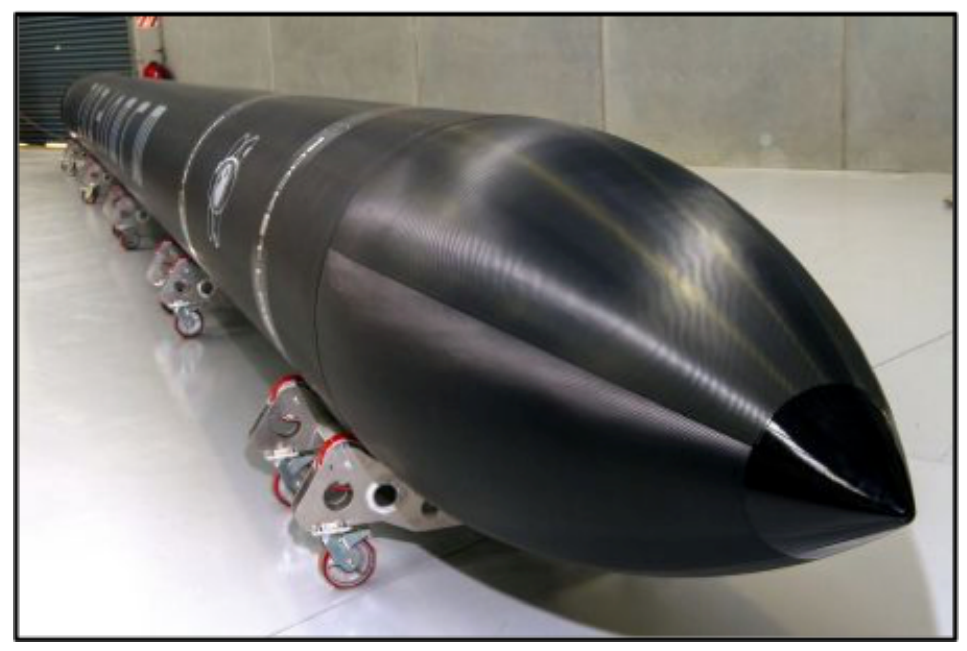

Figure 1 - Electron was introduced as the first carbon-composite launch vehicle back in 2014, per Auckland-based aerospace company, Rocket Lab (Henderson, 2014) 
The stark differences in manufacturing FRP from traditional metalsprocuring the raw fiber and matrix materials, the lay-up processes, the special tooling necessary for molding and testing fabricated specimensdrive up and front-load the production and testing costs. Studies have been conducted to show how high-speed drilling of FRP structures (tested up to $38,650 \mathrm{rev} / \mathrm{min}$ in a particular study), a significant source of tool wear, is considered to be a notable problem in the composites manufacturing world, especially since composites-compatible drill bits are upwards of ten times the cost of traditional drill bits.

Additionally, due to the inherent variability in manufacturing heterogeneous materials, structural analysis of composite materials have introduced different levels of complexity when compared to the analyses of isotropic, homogenous materials. Due to these intricacies, a level of unpredictability was to be expected of these results. Hence, researchers have relied heavily on testing different configurations of composite designs to build the fidelity of their numerical methods, such as Finite Element Analysis (FEA) models, to better predict how certain designs, holes, and cracks would behave under varying loading and environmental conditions.

Now, with decades of research and advancements in analytical and numerical tools, the motivation for this thesis is to better understand how the results of these numerical methods, specifically FEA, compare to the results of traditional analytical methods and tensile test results. With the high-cost of resources and knowledge-base required for manufacturing and testing composite specimens, the question to be ultimately answered is: have the advancements in numerical methods progressed enough such that its results are accurate enough to deem experimental testing superfluous in validating structural design?

To begin this discussion, databases such as American Institute of 
Aeronautics and Astronautics (AIAA), National Aeronautics and Space Administration (NASA) Technical Reports Server, American Society of Mechanical Engineers (ASME), and Aerospace Research Central (ARC) were thoroughly researched with the focus on how error rates trended between numerical methods and testing results, regardless of test/specimen design. If a strong correlation existed, it could make way to begin the discussion that perhaps numerical methods could be sufficient in validating structural design. If a strong correlation did not exist, each study was further investigated to identify what worked well for their research, and what may have contributed to a higher error rate; these lessons-learned were folded into the design and numerical methods of this thesis.

To contribute to the substantiation of this discussion, two composite laminate plate designs with different ply orientations, with two different hole dimensions per set, were studied for stress and strain under tensile loading at a point local to the hole; reference Table 1 . Additionally, mesh designs were varied to consider how the number of nodes in a Finite Element Model (FEM) may affect the accuracy of the results, and how that accuracy may change depending on varied ply orientations and hole configurations-"configurations" defined as the quantity and geometry of the holes in the specimens of interest. The intent of adding variability to the study was to gauge the confidence of the FEA results: would introducing enough variability eventually necessitate a physical test? Coupling the findings from this thesis with the conducted research should provide a better understanding of to what extent varying structural designs, with their correlative mesh designs, impacts the accuracy and robustness of an FEM, providing structural design engineers more confidence and better insight into their FEA results.

ASTM D3039/D3039M, or Standard Test Method for Tensile Properties 


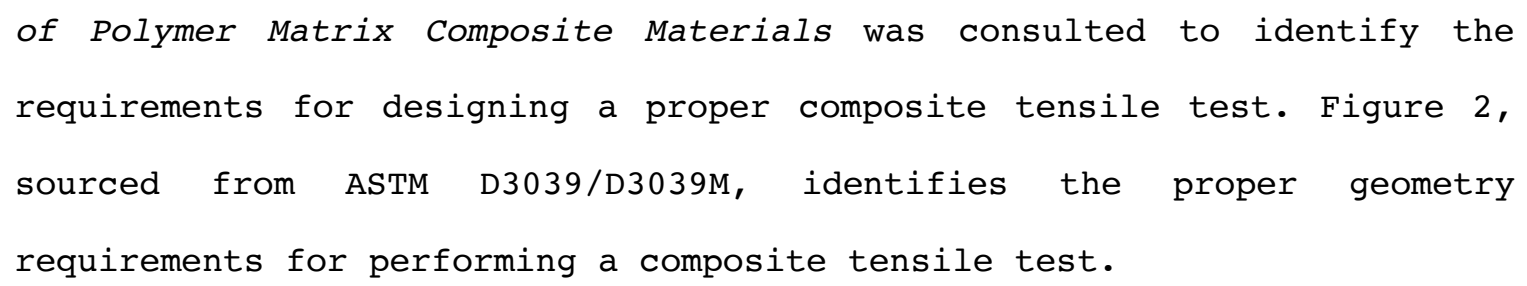

\begin{tabular}{|ll|}
\hline \multicolumn{1}{c|}{ Tensile Specimen Geometry Requirements } \\
\hline \multicolumn{1}{c|}{ Parameter } & \multicolumn{1}{c|}{ Requirement } \\
\hline $\begin{array}{l}\text { Coupon Requirements: } \\
\text { shape }\end{array}$ & constant rectangular cross-section \\
minimum length & gripping +2 times width + gage length \\
specimen width & as needed \\
specimen width tolerance & $\pm 1 \%$ of width \\
specimen thickness & as needed \\
specimen thickness tolerance & $\pm 4 \%$ of thickness \\
specimen flatness & flat with light finger pressure \\
Tab Requirements (if used): & as needed \\
tab material & as needed \\
fiber orientation (composite tabs) & as needed \\
tab thickness & $\pm 1 \%$ tab thickness \\
tab thickness variation between & \\
tabs & 5 to $90^{\circ}$, inclusive \\
tab bevel angle & feathered without damaging specimen \\
tab step at bevel to specimen & \\
\hline
\end{tabular}

Figure 2 - Specimen Geometry Requirements from ASTM D3039/D3039M (ASTM, 2014 ) 
In light of these requirements, Table 1 identifies the test specimens' design and geometry requirements:

Table 1 - Cross and Quasi-isotropic layup configuration requirements

\begin{tabular}{|c|c|c|}
\hline & $\begin{array}{c}\text { Single Hole, } \\
1 / 8{ }^{\prime \prime}, \frac{1}{4} "\end{array}$ & $\begin{array}{c}\text { Single Hole, } \\
1 / 8 ", \frac{1}{4} "\end{array}$ \\
\hline $\begin{array}{l}\text { Ply Designs } \\
\frac{\text { Cross : }}{\left[(0 / 90)_{4}\right]_{\mathrm{s}}} \\
\text { Quasi: } \\
{\left[0_{2} /\right.} \\
\left.+/-45 / 90_{2}\right]_{\mathrm{s}}\end{array}$ & \#\# & 1 \\
\hline $\begin{array}{l}\text { Test Coupons } \\
\left(\begin{array}{lllll}L & \mathrm{x} & \mathrm{W} & \mathrm{x} & \mathrm{H}\end{array}\right)\end{array}$ & $\begin{array}{l}10^{\prime \prime} \mathrm{x} 1.0 " \mathrm{x} \\
0.12^{\prime \prime} \\
\text { ( } 5 \text { pieces per } \\
\text { hole size, } 10 \\
\text { pieces total) }\end{array}$ & $\begin{array}{c}10 " x 1 " \mathrm{x} \\
0.10^{\prime \prime} \\
\text { ( } 5 \text { pieces per } \\
\text { hole size, } 10 \\
\text { pieces total) }\end{array}$ \\
\hline
\end{tabular}

Mitsubishi Rayon Carbon Fiber and Composites, formerly known as Newport Composites, unidirectional pre-preg NCT301-2G150/108 was utilized to manufacture these substrates.

Previous Works

With the growing popularity of composite applications over the last half-century, there have been countless studies conducted to better understand the structural behavior of composite laminates and how they're analyzed.

The initial set of previous works researched was inclusive of all variations of test parameters and objectives to better understand what has been studied in the world of composite research, and to what extent; 
this would provide a scope of understanding of where this thesis would fall in the context of composite research.

The nature of the research conducted includes in-plane tensile and compressive loading, such as Ercin, G.H.'s Size Effects on the Tensile and Compressive Failure of Notched Composite Laminates, published in 2013, while ensuring variations in the types of composite materials studied, such as Haque, A.'s Stress Concentrations and Notch Sensitivity in Woven Ceramic Matrix Composites Containing a Circular Hole - An Experimental, Analytical, and Finite Element Study, published in 2005. More popular material selections of carbon-carbon, or carbon-epoxy, were also researched, i.e., Hatta, H.'s 2004 study Fracture Behavior of CarbonCarbon Composites with Cross-ply Lamination, and Gan, K.W.'s 2013 study on the Effect of High Through-Thickness Compressive Stress on Fibre Direction Tensile Strength of Carbon/Epoxy Composite Laminates.

Some studies included specimens with holes and notches, such as Arslan, H.M.'s 2009 Effect of Circular Holes on Cross-ply Laminated Composite Plates - sometimes multiple holes and notches, as seen from Dan-Jumbo, E's 2009 research Strength of Composite Laminate with Multiple Holes. At times, studies focused on holes filled with pins - Atas, A.'s Failure Analysis of Laminated Composite Plates with Two Parallel PinLoaded Holes from 2008, and others in different temperature environments, such as Watanabe, S.'s Evaluation of Tensile Strength of Woven Carbon/Epoxy Composite Laminates at Cryogenic Temperatures Using the Open Hole Specimens from 2011.

Regardless of the test parameters selected for each study, the focus was placed on how the error rates trended between numerical results and experimental test. Hence, from the 30 sources that were studied in detail for this thesis, a concerted effort was made to include research that had attained both numerical and experimental results; ten of the research 
reports had clear and reliable instances for comparison, providing a total of 175 data points of numerical-to-experimental comparisons that were able to be made. These sources can be found in the Works Referenced section of the thesis, as well as the appendix. Reference Figure 3 to see the frequency of error rates that was identified from these 175 instances.

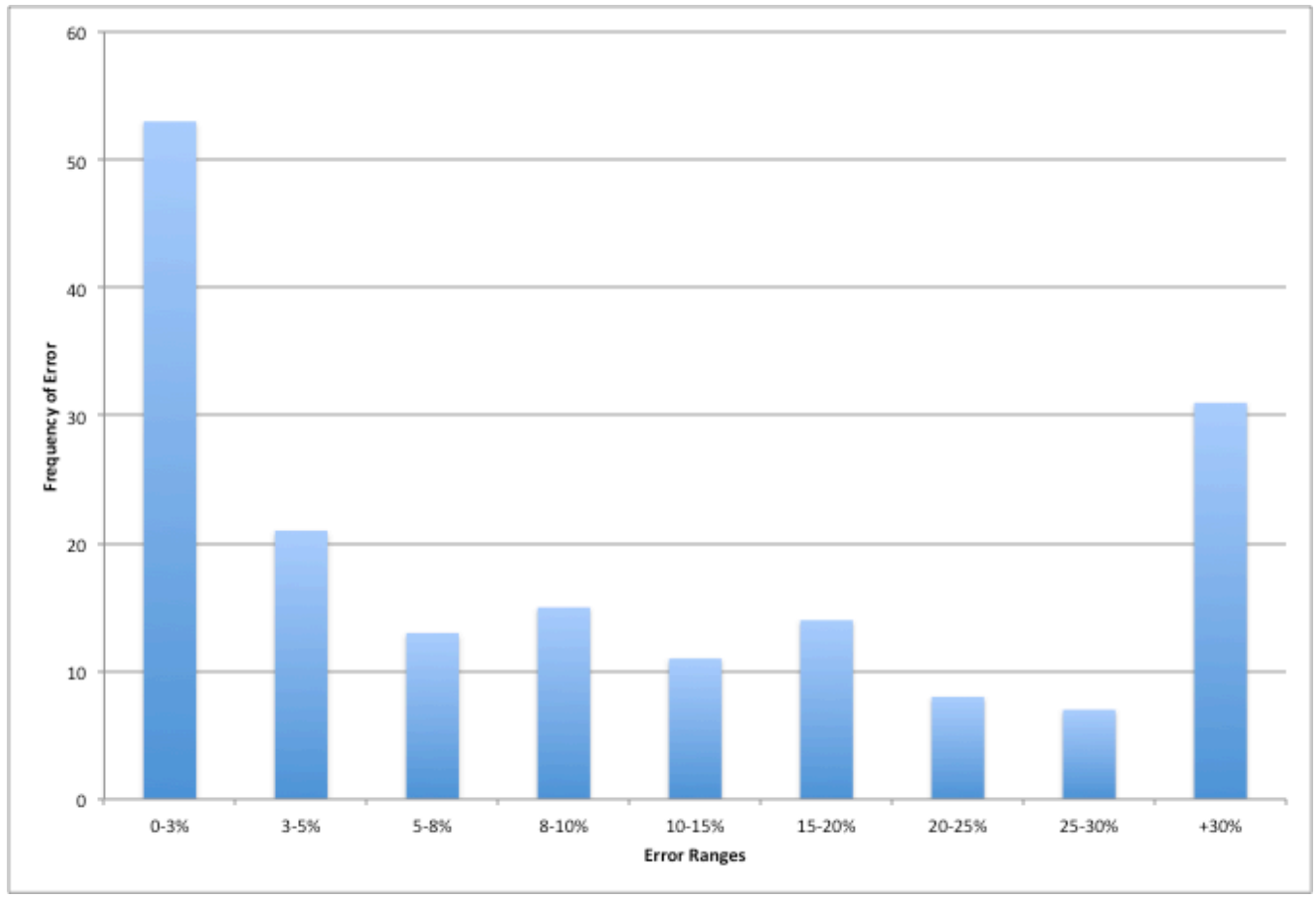

Figure 3 - Frequency of error rates identified from the 175 instances of numerical and experimental comparisons

102 of the 175 instances, or 59\% of the all comparisons, resulted in error rates less than $10 \%$. Of those 102,53 instances, or $30 \%$ of the 175 comparisons resulted in error rates less than $3 \%$. However, 31 projects, or $18 \%$ of the total 175 comparisons, did experience error rates greater than $30 \%$.

And although this small sample-size of 175 instances over 10 research projects may be insufficient to draw an adequate conclusion 
regarding numerical-to-experimental error rates for every research conducted in composites, it can be an indicator of the capabilities of numerical methods.

Diving deeper into the greater-than-30\% error comparisons, two sources stood out: Zhen, W.'s 2009 study Stress Analysis of Laminated Composite Plates with a Circular Hole According to a Single-layer Higherorder Model, and Xu, W.'s 2015 study Experimental and Numerical Study on Cross-ply Woven Textile Composite with Notches and Cracks.

Zhen's intent in this 2009 study was to study how current numerical methods could be improved by using a single-layer, higher-order numerical model instead for predicting stresses at curved free boundaries of laminated composite plates. His error rates ranged from $15-47 \%$ for his cross-ply substrates, and 15-43\% for his quasi-isotropic substrates. Xu's 2015 study focused on validating the accuracy of the Cohesive Zone Model, comparing experimental results with predictions based on Max Strain, Max Stress, and Tsai-Wu criteria: the Max Strain approach averaged 8\% error in tension, 21\% error in compression, the Max Stress averaged 28\% error in tension, $31 \%$ error in compression, and Tsai-Wu averaged $30 \%$ error in tension, $40 \%$ in compression.

It was inferred that when an author's objective was to study the accuracy of a new numerical approach, or a new numerical model, the error rates generally seemed to be larger - which contributed to the 31 projects at $+30 \%$ error, per Figure 3. However, in the following example, Wang, Callus, and Bannister found the opposite to be true.

J. Wang, P.J. Callus, and M.K. Bannister performed a study evaluating the differences between experimental and numerical analysis of the tension and compression strength of un-notched and notched quasiisotropic laminates. Using quasi-isotropic AS4/3501-6 pre-preg at [45/0/45/90]2s laminates in their study, Wang and company used two distinct 
approaches to numerical methods: linear elastic and progressive damage. They discovered their linear elastic model either significantly underestimated (first-ply failure approach) or overestimated (last-ply failure approach) the strength of un-notched laminates, and that the progressive damage approach was able to better predict the un-notched specimens' strength, provided that the non-linear shear behavior was accounted for and that the appropriate failure criteria used (Wang, 2003). What was discovered to be the more accurate numerical method through Wang's research could be implemented through the shell element model with basic material degradation laws found in commercially available FEM software, such as ABAQUS, which is the numerical method and FEA package that was used for this thesis.

Wang's experimental and FEA averaged an error of $1.5 \%$ when predicting peak loads, which differs from the objectives of this thesis, however, the study did provide a level of confidence that ABAQUS is a reliable numerical solution to compare with the experimental results. Wang's experiment did not include an analytical solution, it would have been interesting to see how his test and ABAQUS results compared with an analytical method of his choosing-as was seen through the completion of this thesis.

Much like error rates, several of the other sources provided constructive insight and lessons-learned on how to approach the design of this thesis.

Another study, conducted by Thomas M. Hermann and James E. Locke, focused on the failure analysis of anisotropic composites utilizing FEA software. Their application was a wind turbine blade structure constructed from $12 \mathrm{k}$ tex Toray $\mathrm{T} 600$ fibers consisting of a layer of $14.81 \mathrm{oz} / \mathrm{yd}^{2}$ carbon fiber at $0^{\circ}$, a layer of $4 \mathrm{~g} / \mathrm{m}^{2}$ PES fibers at $90^{\circ}$, and 2 layers of $6 \mathrm{~g} / \mathrm{m}^{2}$ E-glass fibers oriented at $\pm 60^{\circ}$, however, it was discovered that 
the shear moduli of the composites from in-plane shear testing appeared to require correction (Hermann, 2005). Due to this, the study experienced an error average of $7.5 \%$, ranging up to $19 \%$ error, between experimental and their most accurate prediction model used (Max Strain method).

This work was specifically referenced due to the difficulties Hermann faced with his shear test. As will be seen in section III, the shear test coupons for this thesis did not fail due to the limiting capabilities of the INSTRON used. Hermann's study was instrumental to understanding how such issues with testing can affect critical test results, and was a good reminder and lessons-learned to reiterate the importance of attaining the correct material properties to reduce errors between prediction models and experimental results.

In 2007, Stephen R. Hallett, Wen-Guang Jiang, and Michael R. Wisnom conducted a study on how different ply stacking sequences can affect the open hole tensile strength of composite laminates. Using uni-directional carbon/epoxy pre-preg (Hexply IM7/8552), the strongest stack sequence was discovered to be $[-45 / 45 / 90 / 0]_{s}$, with a predicted FEA failure stress of $627 \mathrm{MPa}$, and the weakest sequence was identified to be $[-45 / 90 / 0 / 45]_{\mathrm{s}}$, with an FEA failure stress of 488MPa. It was concluded that stack sequences with $0^{\circ}$ layer(s) at the surface or centerline were the strongest configurations per FEA, as are the ply stack sequences for this thesisquasi-isotropic: $\left[0_{2} / 45 /-45 / 90_{2}\right]_{\mathrm{s}}$, and cross-ply: $\left[(0 / 90)_{4}\right]_{\mathrm{s}}$.

However, the average error between FEA and experimental was discovered to be slightly above $10 \%$, which could be attributed to the modeling technique developed specifically for their research, which was used to capture the detail of sub-critical damage development at ply level in notched tensile test specimens (Hallett, 2007). Using a more traditional analytical method such as the Classical Laminated Plate Theory (CLPT), a lower error rate was seen for this thesis, as will be discussed 
in Section VII.

In 2005, Anwarul Haque, Laboni Ahmed, and Arun Ramasetty performed a similar study to Hallett's, but focused on how stress concentrations may change based on varied ply sequences and notch configurations using a woven ceramic matrix composite; quasi-isotropic [0/90/45/-45]s and cross-ply [0/90/0/90]s laminates of woven SiC/SiNC were studied.

Per Haque and company's study, lay-up sequences were deemed to be insignificant for stress concentrations, and their notched strength data showed notch-insensitivity for specimens with smaller diameter holes (diameter-of-hole/width-of-specimen ratio of $0.2-0.3$ ), but did, indeed, show a reduction in notch-insensitivity as the holes grew larger. However, Haque's error rates were larger than most from the selected studies: $31 \%$ between FEA and analytical, and 29\% between FEA and experimental. An experiment with a more accurate FEA and/or analytical method may have delineated greater sensitivities to ply sequences and notch configurations, as was seen in the results of this thesis.

It would be expected that error rates less than $3 \%$ would be achievable if the lessons-learned from this body of research were taken into account and folded into the design of this thesis: using a point load to keep the analysis to a more predictable elastic region, using the shell element model through ABAQUS as discussed from Wang's research, and taking into account the ply-stack sequences and their effects from Hallett's and Haque's studies. Lower error rates between numerical and experimental results would provide higher confidence in numerical models, which would perpetuate and contribute to the discussion of retiring the experimental step all together. 


\section{Thesis Overview}

Section I discusses the motivation for the thesis: are numerical methods, such as FEA, accurate enough to deem testing unnecessary? In order to prove this, it was established that the shell element model would be utilized through ABAQUS FEA, and the resulting stress/strain would be compared to analytical calculations and tensile test results.

Section II provides the manufacturing and testing steps for the composite specimens. The goal for this section was to determine the material properties of the pre-preg in use by completing tensile tests for the substrates identified in Table 2 below. Subsequently, a set of tensile tests was also completed for the cross-ply and quasi-isotropic substrates, found in Table 1, in order to consolidate all manufacturing and testing needs into one step (for efficiency).

These layups were baked in an autoclave at a cure cycle of 45psi, at a ramp rate of $5^{\circ} / \mathrm{min}$, holding at $250^{\circ}$ for 90 minutes, and cooling back down to ambient.

Five pull tests were conducted per layup, as dictated by ASTM D3039/D3039M. Per Hooke's Law, $\sigma=E \epsilon$, the slope of the stress/strain curves, or $E=\frac{\sigma}{\varepsilon}$, from the pull tests for the specimens from Table 2 were leveraged to determine the Modulus of Elasticity in the direction of fibers (unidirectional $0^{\circ}$ ), $E_{L}$, the Modulus of Elasticity transverse to the direction of fibers (unidirectional $90^{\circ}$ ), $\mathrm{E}_{\mathrm{T}}$, and the Shear Modulus (angle ply, $+/-45^{\circ}$ ), $\mathrm{G}_{\mathrm{LT}}$, of the pre-preg in use. 
Table 2 - Layup designs for identifying material properties

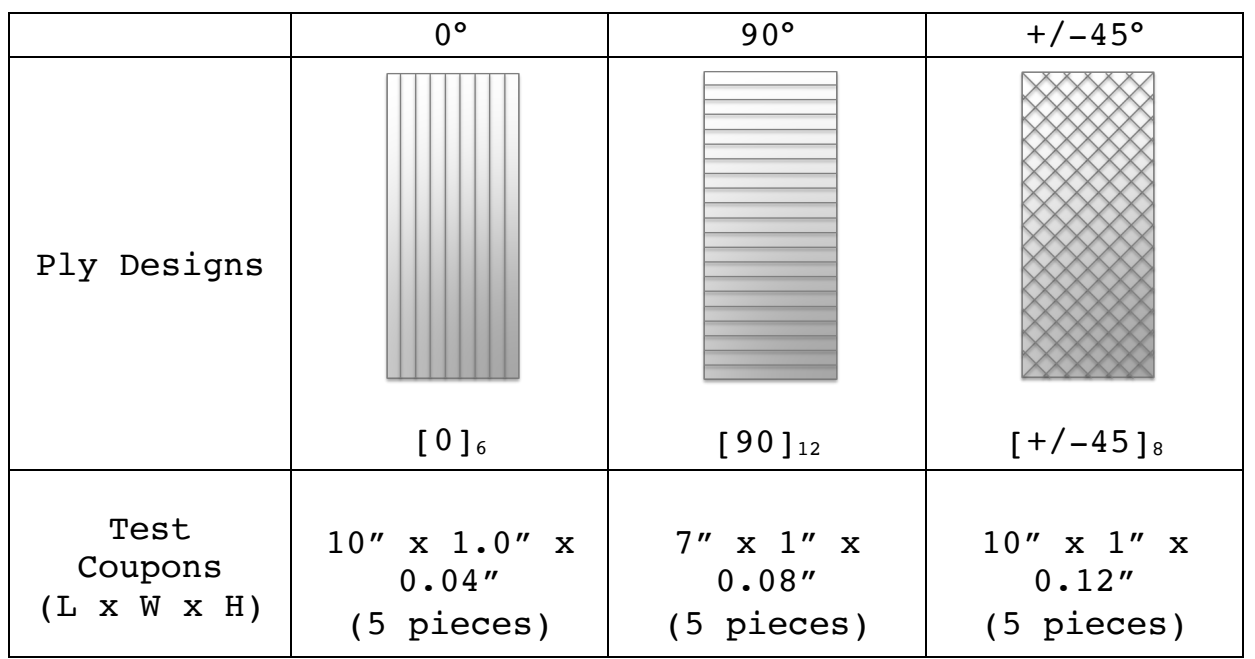

Section III reviews the results from the tensile tests for material properties. An assessment was made to determine which test results would be included, which would be discarded, and if so, why. The averages for each case were then established and used as the material properties for the analytical and FEA studies.

Results from the cross-ply and quasi-isotropic cases were saved for discussion in Section VII.

Section IV provides an overview of the Classical Laminated Plate Theory. Having a firm grasp of the theory helps establish expectations for which results seem valid when exploring the tensile test and FEA results.

Section $\mathrm{V}$ delivers a validation for a baseline FEM by modeling the boundary conditions, reference points, and other test attributes from a published tensile test. When the baseline FEA's stress/strain output matches those of the published tensile test's, the baseline FEM will have been proven and would provide the foundation to now build the composite FEMs. A homogeneous material was used to simplify the FEM; this case is referred to as the homogenous baseline. 
Section VI presents the methodology of how the FEA was run; what attributes went into the analysis, which point loads, and how postprocessing of the resulting data was conducted.

Section VII is where all results were juxtaposed, comparing FEA results with those of the analytical calculations and tensile test results.

All studies were conducted in the elastic region to ease the comparison of analytical, test, and FEA. Unless proven otherwise, a baseline point load of 1000 lbf was utilized for all analyses.

All cases studied entailed symmetrical laminates to simplify modeling and manufacturing-antisymmetric laminates require consideration of residual stresses from differences in elastic moduli and potential variations in coefficients of thermal expansion, which can also produce mid-layer, out-of-plane warping and other deformations.

This thesis builds upon decades of research on stress distribution in holes in composite structures. With seemingly endless permutations of fiber-to-matrix ratios, ply-angles, and hole configurations, there will always be value add to exploring more efficient methods of extrapolating confidence in how composite structures are analyzed and/or tested. 
II. Manufacturing and Test

Material properties for layup designs were determined by performing a series of pull-tests on the layups themselves, per ASTM D3039/D3039M. To do so, each layup design of Table 2 was crafted using Mitsubishi Rayon Carbon Fiber and Composites (formerly Newport Composites) unidirectional pre-preg NCT301-2G150/108, minimizing waste in material while still attaining the layups required to perform the appropriate tests.

Manufacturing for Pull Test

To kick off manufacturing, the following materials were required:

- One (1) roll of Mitsubishi Rayon Carbon Fiber and Composites unidirectional pre-preg NCT301-2G150/108

- One (1) roll of flow media

- One (1) roll of breather material, aero weave

- One (1) roll of vacuum bag (or, "vac-bag")

- One (1) machined aluminum plate - 36" x 24"

- Hi-temp vac-bag tape

- Acetone

- Rubber gloves

- Protective eye gear / goggles, rubber gloves

- Blue painter's tape

- Apron

- Roller

- Box cutter w/ extra cartridge-blades

- Scissors

- Paper towels

- $115 \mathrm{~V}$ vacuum pump, tubing, vacuum connector 
- Autoclave capable of accommodating pressure/temperature profiles The quality of the layup's surfaces is impacted by how clean the surfaces of the aluminum plate is made: the smoother the surface, the less bumps and nicks, which means less points for stress concentrations to build.

To begin, the proper protective eye gear, rubber gloves, and ventilation steps were all administered. Then, the aluminum plate was wiped down vigorously with acetone to ensure a smooth surface; reference Figure 4 .

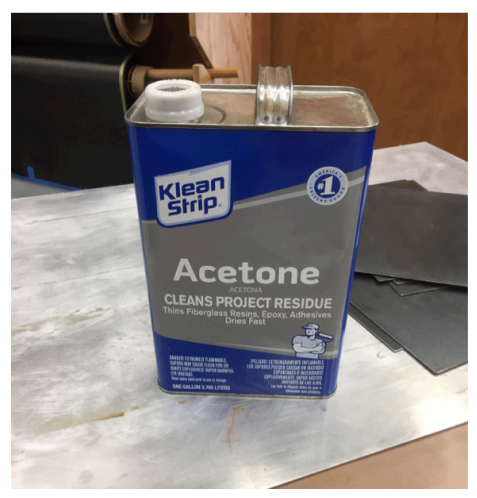

Figure 4 - Acetone is used to smooth the surface of the aluminum tooling plate; residue will create points of stress concentration on the resulting composite plates

Two layers of flow media (34" $\left.\mathrm{x} 22^{\prime \prime}\right)$ were measured and cut to fit the aluminum plate with a 1" margin around the perimeter. Blue painter's tape was used to secure the first layer of flow media to the aluminum plate. It is important to minimize impingement in the 1 " margin to provide sufficient spacing to apply the vac-bag tape; impingement increases the possibility of not securing a proper seal when pulling vacuum, which would result in warped, creased, or unusable layups. 
With the plate prepped, the layup designs from Tables 1 and 2 were cut to size using the box cutter, and layered accordingly using the roller. When rolling to flatten the layers of pre-preg, it is critical to ensure all air bubbles are pushed out between the layers, or deformations within the layers may form. It is not uncommon to briefly pull vacuum after rolling each individual layer to ensure complete flatness; reference Figure 5 .

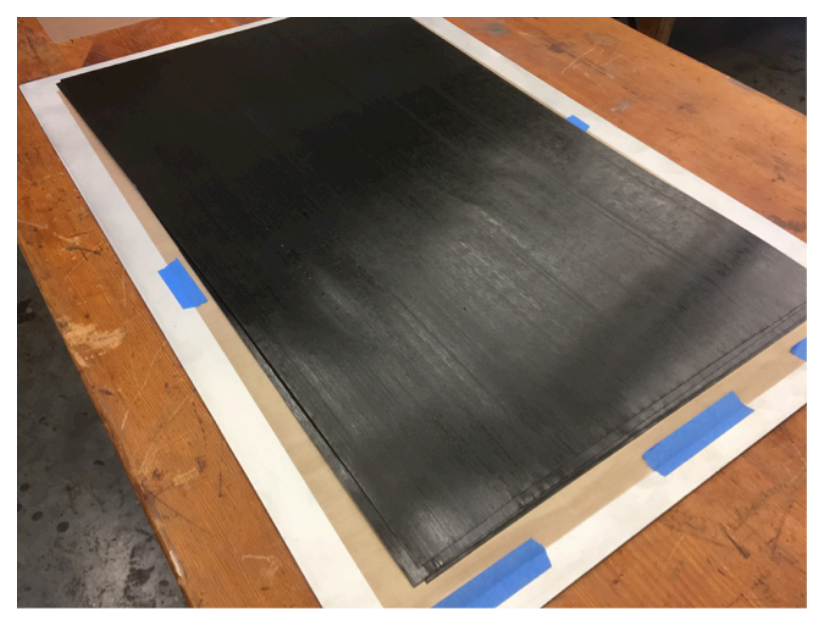

Figure 5 - The pre-preg is rolled flat and laid on top of flow media; correct spacing was ensured to reduce impingement with the region where vac-bag tape will be applied to the aluminum plate

Once the first layup was prepped, it was laid on top of the flow media secured to the aluminum plate. The second layer of flow media was then overlaid on the prepped pre-preg. Subsequently, vac-bag tape was carefully massaged on the aluminum plate along the 1" margins, focusing on the corners to ensure no air would escape when vacuum is pulled from where the layers overlap.

A sheet of vac-bag was cut to measure approximately $40 " \mathrm{x} 30 "$, and a 1" $\mathrm{x}$ 1" cross was knifed where the vacuum connector would be placed. With the connector situated, additional vac-bag tape was used to provide 
an additional seal to ensure full vacuum would be reached. As needed, a piece of breather was placed beneath the vacuum connector to prevent imprints on the layup when vacuum would be pulled. With all pieces in their respective places, the vac-bag was pulled taught over the layup configuration, and massaged into the vac-bag tape frame that was previously laid out; reference Figure 6 .

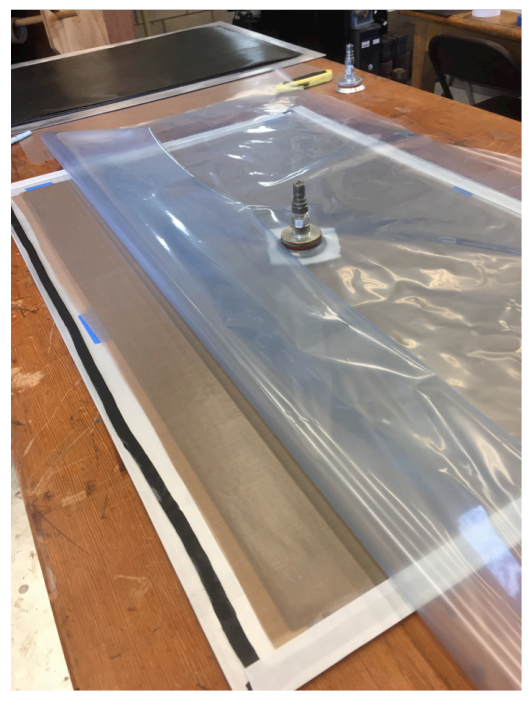

Figure 6 - The vac-bag is sealed with the layup secured on the plate, with the vacuum connector resting on top of the layup, situated in place

With the layup properly sealed, the vacuum connector was connected to the $115 \mathrm{~V}$ vacuum pump line. With the vacuum pulled, the entire layup configuration was inspected for leaks through visual inspection; additional vac-bag tape was used, where necessary, to ensure a full vacuum seal. It was important to ensure wrinkles were not created in the vacbag, particularly on the pre-preg surface, to ensure the layup would not have any creases on its surface; reference Figure 7 . 




Figure 7 - Vacuum is pulled through the vacuum connector to perform a visual inspection for leaks prior to entering the autoclave

When the vacuumed configuration was deemed acceptable, the vacuum connector was disconnected from the $115 \mathrm{~V}$ pump. Without manually releasing the vacuum from the vacuum connector, the layup configuration was transferred into the autoclave. When connecting the layup configuration to the autoclave's vacuum line, it was, once again, ensured no creases were formed on the vac-bag surface; reference Figure 8 .



Figure 8 - Layup is inserted into and connected to the autoclave's vacuum pump (green hose)

With the autoclave's chamber door shut and the appropriate temperature/pressure profile loaded, the layup was cured to match the 
requirements from the pre-preg's manufacturer's specifications: 45psi at a ramp rate of $5 \% \mathrm{~min}$, holding at $250^{\circ} \mathrm{F}$ for 90 minutes, and cooling back down to ambient. Upon completion, the layup configuration was removed from the autoclave, the vac-bag was peeled off from the aluminum plate, and a visual inspection was performed to ensure the cured layup would be fit for cutting; reference Figure 9.

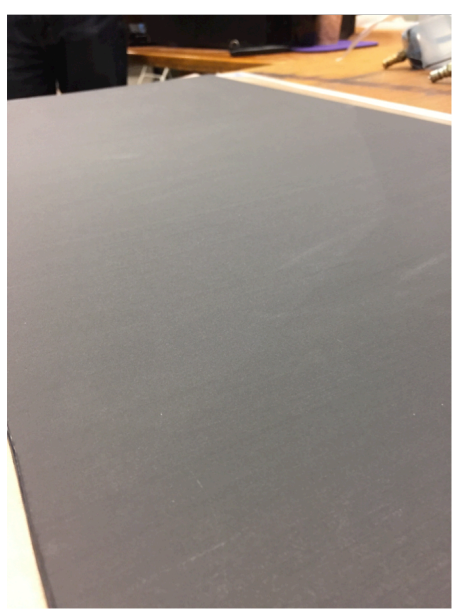

Figure 9 - Visual inspection conducted to ensure blemishes conducive to forming stress concentrations are mediated

With the layup cured, the composite plate was cut per dimensions outlined in Table 2. Prior to proceeding, the lab safety requirements of the Cal Poly Composite Structures Lab were thoroughly reviewed to place emphasis on safety. Table 3 was completed and reviewed prior to performing any manufacturing to meet lab safety requirements. Risk Ratings were determined through Figure 10, provided by the Aerospace Department; depending on the consequence and likelihood of a risky scenario unfolding, each risk is identified as "Low" (blue), “Medium" (green), "High" (yellow), and "Very High" (red). All steps were identified to be "Low" or “Medium". 
Table 3 - Risk Ratings determined for lab tasks performed; this step will help identify the higher risk steps that will be taken throughout manufacturing and test, bringing to focus safety

\begin{tabular}{|c|c|c|c|c|c|c|c|}
\hline \multirow[b]{2}{*}{ Task/Scenario } & \multirow[b]{2}{*}{ Hazard } & \multirow[b]{2}{*}{ Associated harm } & \multirow[b]{2}{*}{ Existing controls } & \multirow[b]{2}{*}{$\begin{array}{c}\text { Any } \\
\text { additional } \\
\text { controls } \\
\text { required? }\end{array}$} & \multicolumn{3}{|c|}{ Risk Rating } \\
\hline & & & & &  & 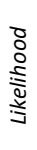 & $\underset{0}{\frac{x}{2}}$ \\
\hline Cutting test coupons & $\begin{array}{l}\text { Tile-saw imposes a hazard } \\
\text { on user and those in } \\
\text { proximity; potential cuts } \\
\text { from sharp edges of test } \\
\text { coupons }\end{array}$ & $\begin{array}{l}\text { Flying projectiles, cuts, } \\
\text { dismemberment }\end{array}$ & $\begin{array}{l}\text { - Proper-usage training, safety } \\
\text { goggles, closed-toed shoes, face } \\
\text { mask to prevent inhaling of fibers, } \\
\text { wool gloves, pre-activity } \\
\text { prep/warnings, communication }\end{array}$ & No & 4 & $D$ & $M$ \\
\hline $\begin{array}{l}\text { Drill-press for adding } \\
\text { holes to test coupon }\end{array}$ & $\begin{array}{l}\text { Drill-press imposes a hazard } \\
\text { on user and those in } \\
\text { proximity; potential cuts } \\
\text { from sharp edges of test } \\
\text { coupons }\end{array}$ & $\begin{array}{l}\text { Flying projectiles, cuts, } \\
\text { dismemberment }\end{array}$ & $\begin{array}{l}\text { - Training, safety goggles, closed- } \\
\text { toed shoes, face mask to prevent } \\
\text { inhaling of fibers, wool gloves }\end{array}$ & No & 4 & $D$ & $M$ \\
\hline Emery cloth install & $\begin{array}{l}\text { Potential cuts from sharp } \\
\text { edges of test coupons }\end{array}$ & None & $\begin{array}{l}\text { - Training, safety goggles, closed- } \\
\text { toed shoes, rubber gloves }\end{array}$ & No & 2 & $D$ & $L$ \\
\hline $\begin{array}{l}\text { Prep test coupons for } \\
\text { strain gage install }\end{array}$ & $\begin{array}{l}\text { Acetone will be used to prep } \\
\text { surface of test coupons }\end{array}$ & $\begin{array}{l}\text { Inhaling acetone is } \\
\text { hazardous; also highly } \\
\text { flammable }\end{array}$ & $\begin{array}{l}\text { - Training, safety goggles, closed- } \\
\text { toed shoes, face mask to prevent } \\
\text { inhaling of fumes, rubber gloves, } \\
\text { clean-up supplies on hand in case of } \\
\text { spillage }\end{array}$ & No & 3 & $D$ & $M$ \\
\hline Installing strain gages & $\begin{array}{l}\text { Potential cuts from sharp } \\
\text { edges of test coupons }\end{array}$ & None & $\begin{array}{l}\text { - Training, safety goggles, closed- } \\
\text { toed shoes, rubber gloves }\end{array}$ & No & 2 & $D$ & $L$ \\
\hline Performing pull-test & $\begin{array}{l}\text { Instron may malfunction; } \\
\text { installation of tooling/test } \\
\text { coupons may cause injury }\end{array}$ & \begin{tabular}{|l|} 
Flying projectiles, cuts, \\
dismemberment
\end{tabular} & $\begin{array}{l}\text { - Proper-usage training, safety } \\
\text { goggles, closed-toed shoes, rubber } \\
\text { gloves, pre-activity prep/warnings, } \\
\text { communication; plexi-glass } \\
\text { protective screen }\end{array}$ & No & 3 & $D$ & $M$ \\
\hline
\end{tabular}

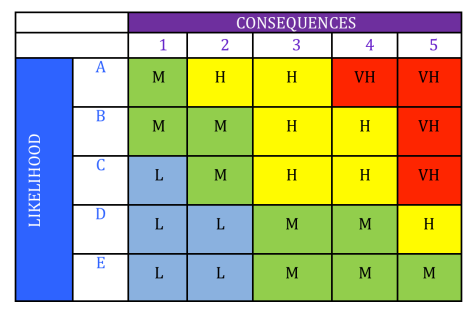

Figure 10 - Risk rating matrix takes likelihood of an occurrence occurring with the severity of its consequences and assigns a rating of "Low" (blue), "Medium" (green), "High" (yellow), and "Very High" (red)

Figure 11 shows blue tape being used to mask-off each specimen for cutting. Having the proper orientations preset using the tape allowed the focus to remain on safety in using the tile saw. Figure 12 
shows the completion of the cutting process utilizing the blue tape as guidelines:

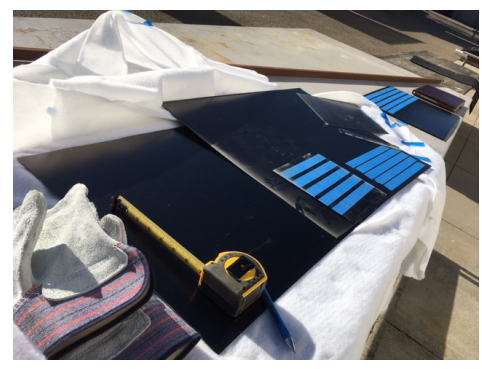

Figure 11 - The laminate plate was measured to cut for each respective test coupon dimensions

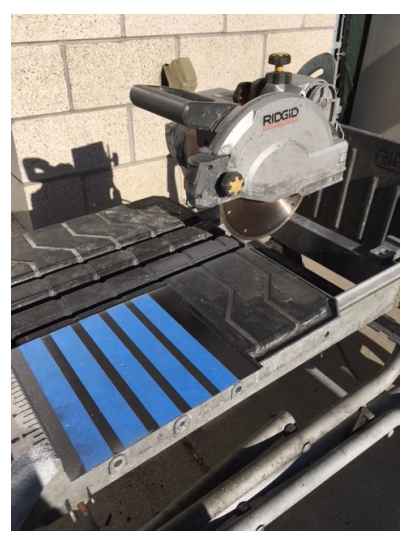

Figure 12 - Blue painter's tape was used as a guideline for cutting, allowing the focus to remain on safety in using the tile saw 
Figure 13 shows the coupons being prepped for the drill-pressthey can be seen as blue stacks in the figure from the painter's tape; Figure 14 shows a test coupon being mounted and drilled.

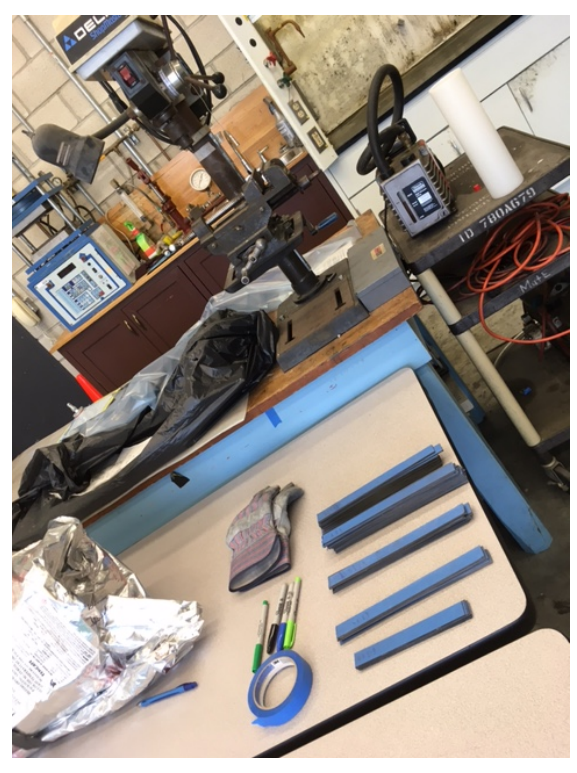

Figure 13 - Coupons were prepped for the drill-press for those requiring holes

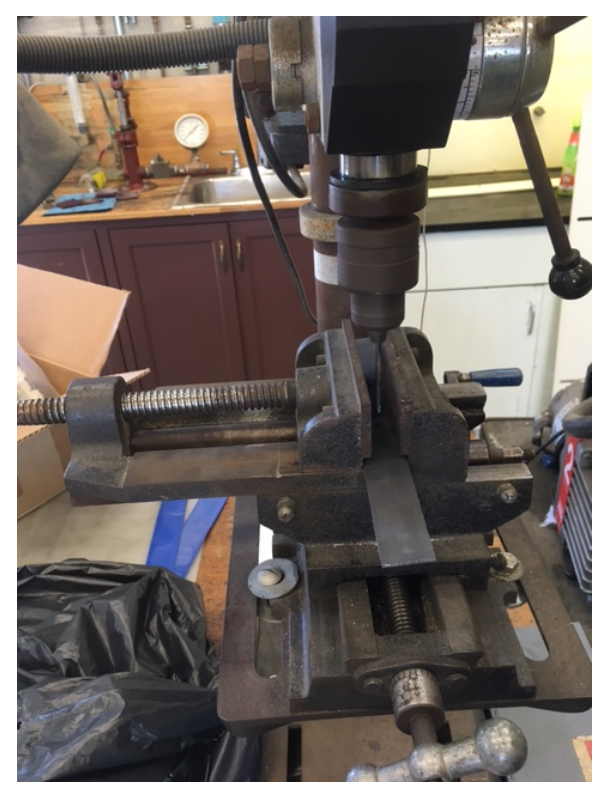

Figure 14 - Drill press used to put $1 / 8 "$ and $1 / 4 "$ holes in the applicable test coupons 
For the sake of efficiency, all manufacturing was completed at the same time. Hence, the aforementioned steps were repeated for all remaining layup designs outlined in Tables 1 and 2 . Table 4 contrasts test coupon requirements with the resulting test coupon dimensions and properties.

Table 4 - Specimen requirements compared to actual dimensions

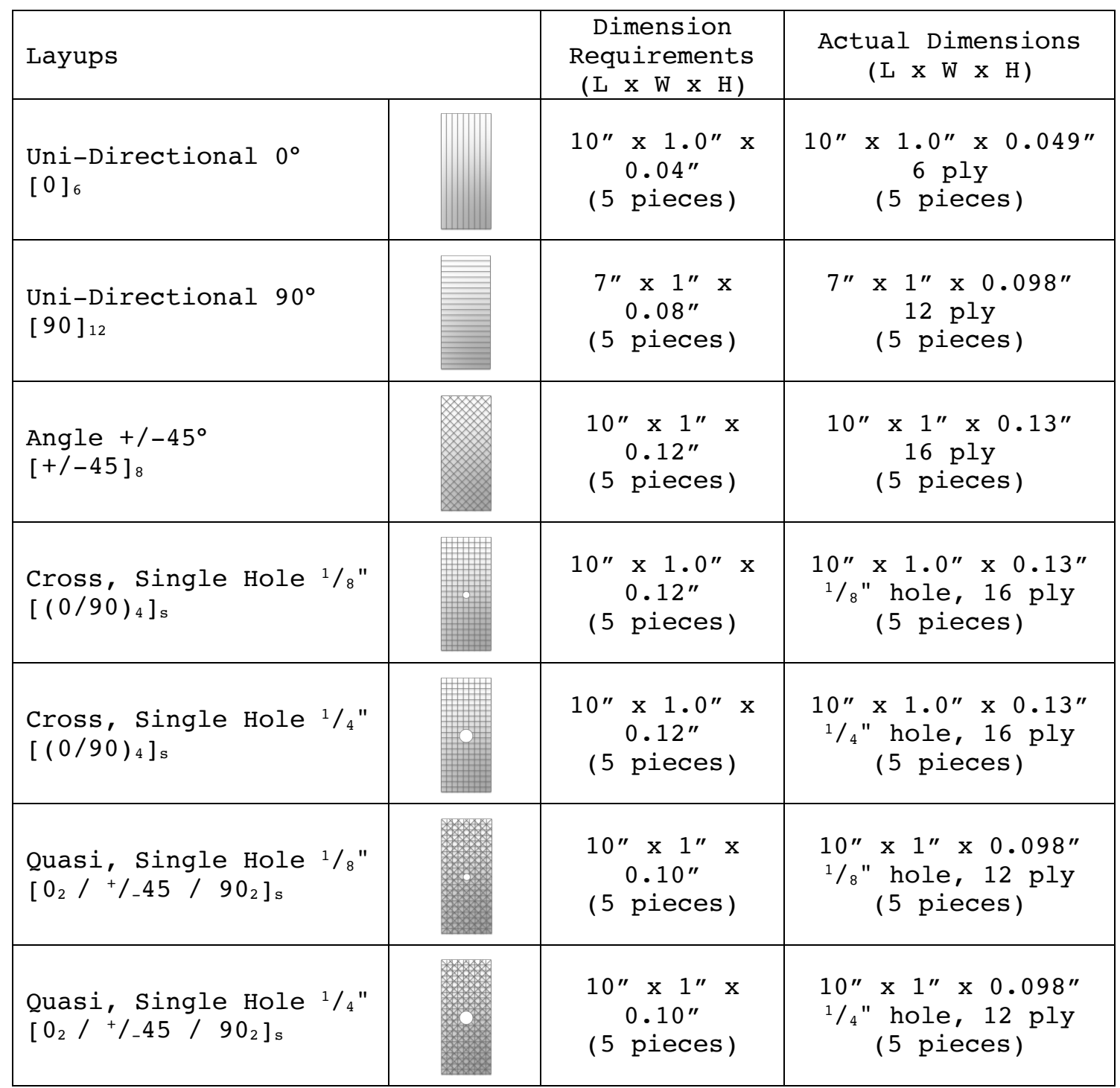

\footnotetext{
Prepping for Tensile Test

Tensile tests were conducted on an INSTRON 8801 servohydraulic testing system, located in Cal Poly's Aerospace and Mechanical
} 
Engineering's Structures lab-reference Figure 15; the Instron was verified to meet the required rate of displacement of $0.05 \mathrm{in} / \mathrm{min}$. Existing test jigs used previously for tensile tests meeting ASTM D3039/D3039M standards were installed on the INSTRON prior to testing.

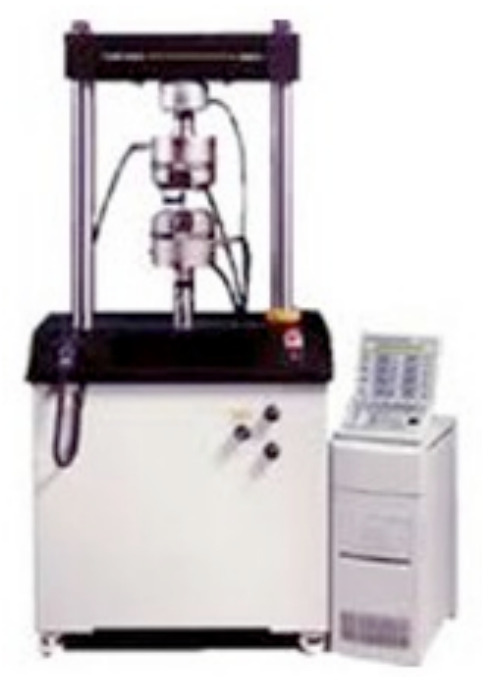

Figure 15 - INSTRON 8801 utilized for pull tests

Strain Gauges: the primary concern with the test setup contributing to varying test results is the mounting method of the strain gauges; it is important strain gauges are mounted per manufacturer's recommendation with minimized variation from test specimen to test specimen. To note, the strain gauges used for the tensile tests were as follows-reference Table 5: 
Table 5 - Strain gauges identified for reach ply design

\begin{tabular}{|c|c|c|c|}
\hline Ply Design & Strain Gage Manufacturer \& Model & Gage Factor (GF) & Resistance (Ohms) \\
\hline Uni: $[0]_{6}$ & Omega SGD-6/120-LY11 & 2.0 & $120+-0.35 \%$ \\
\hline Uni: $[90]_{12}$ & Omega SGD-6/120-LY11 & 2.0 & $120+-0.35 \%$ \\
\hline Angle: $[+-45]_{4}$ & Omega SGD-6/120-RY21 & 2.0 & $120+-0.35 \%$ \\
\hline Cross: $\left[(0 / 90)_{4}\right]_{s}$ & HBM 1-LY41-6/120 & 2.04 & $120+-0.30 \%$ \\
\hline Quasi: $\left[0_{2} /+-45 / 90_{2}\right]_{\mathrm{s}}$ & Micro-Measurements CEA-13-120FZ-120 & 2.12 & $120+-0.40 \%$ \\
\hline
\end{tabular}

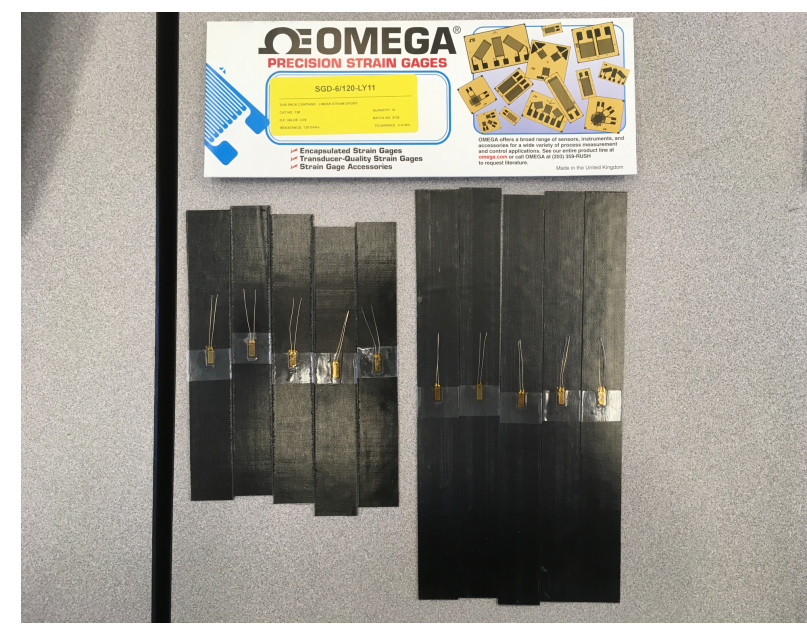

Figure 16 - Uni coupons, 0 and 90 with Omega strain gauges

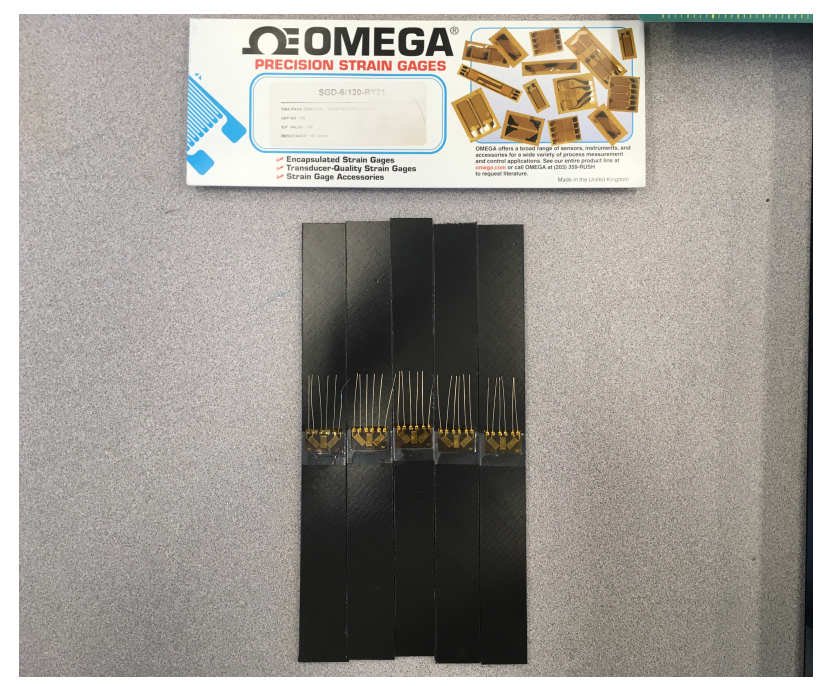

Figure 17 - Angle-ply test coupons with Omega strain gauges 


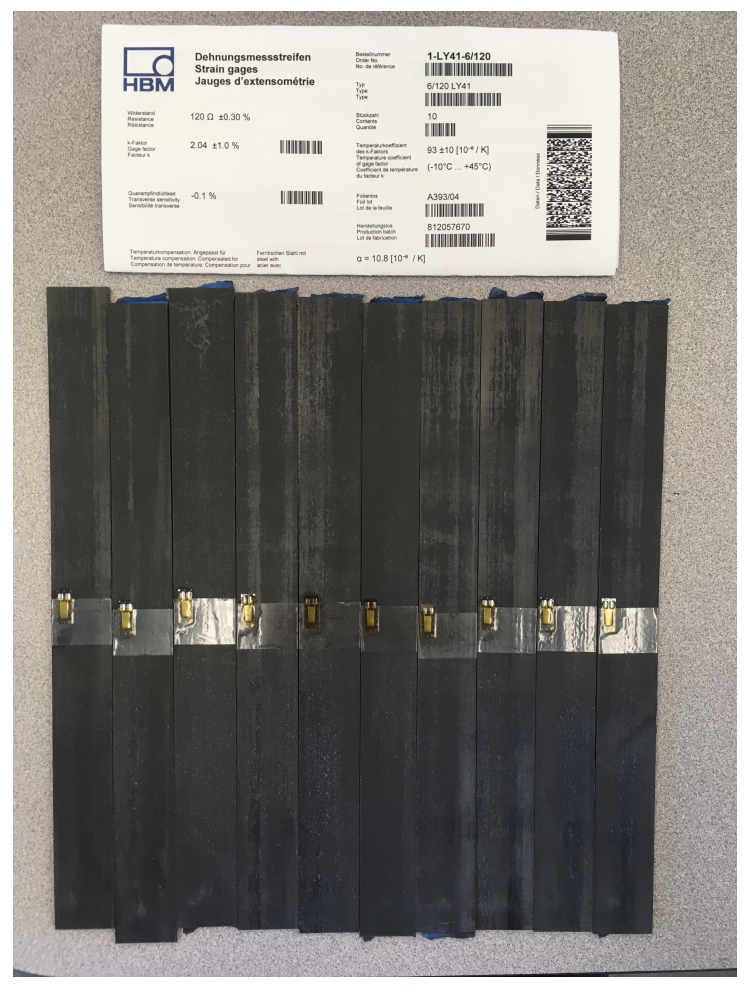

Figure 18 - Cross-ply with HBM strain gauges



Figure 19 - Quasi-isotropic coupons with Micro-Measurements strain gauges 
Recall that:

$$
V_{f}=\frac{V_{o(\text { strained })}-V_{o}(\text { unstrained })}{V_{E X}}
$$

where $V_{0}$ (unstrained) is the initial voltage at rest, $V_{\circ}$ (strained) is the measured output during strain, and $\mathrm{V}_{\mathrm{Ex}}$ is the excitation voltage; depending on the Wheatstone bridge used, Figure 20 outlines which equation to use to determine the strain measured.

Quarter-bridge strain gauge circuit

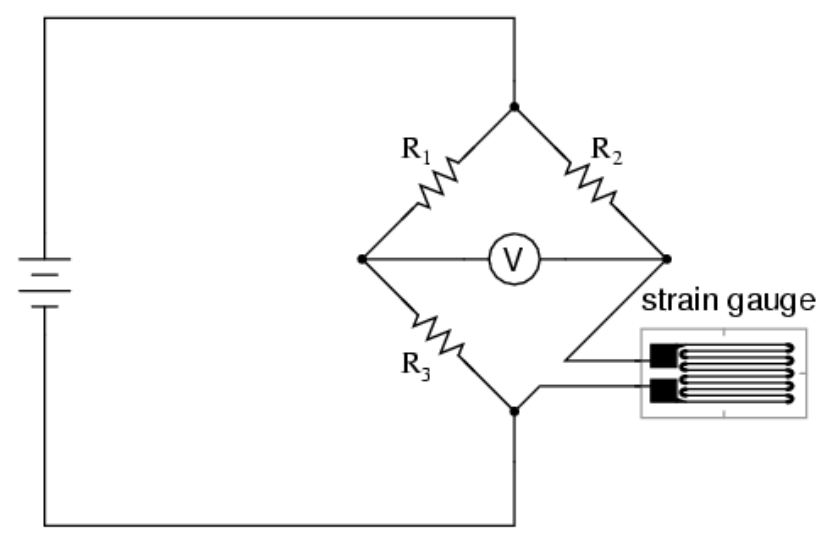

Figure 20 - Different Wheatstone bridges used to measure strain

The INSTRON has a built-in Quarter-Bridge to measure strain throughout the tensile test.

Tensile Test Challenges - Tabs

Tabs were a challenge. Initially going into the pull tests, emory cloth and/or sandpaper were recommended for use. However, the recommendation should have taken into account the maximum shear stress that would have been applied at the grips to sustain the necessary holding-power to complete the tensile tests. After a handful of failed attempts with extra sample coupons using sandpaper, the only available epoxy available in the lab, West System's Six10 thickened epoxy 
adhesive, was identified for use, Figure 21; the epoxy would be used to secure 1" x 1" carbon composite squares leftover from manufacturing.

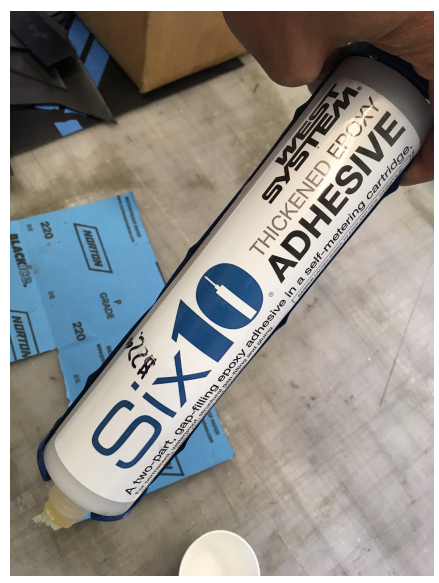

Figure 21 - West System's Six10 thickened epoxy adhesive's technical data sheet did not provide shear strength properties; a substitute epoxy would need to be identified

However, the Six10's technical data sheet did not provide specifications on the shear strength of the epoxy, thus, there was an inherent risk associated with utilizing this epoxy for all coupons. Hence, it was decided to only use the Six10 for the Unidirectional 0 and 90 coupons, as it was predicted these coupons would not require as much tensile stress to fail. Figures 22 and 23 show the application process : 


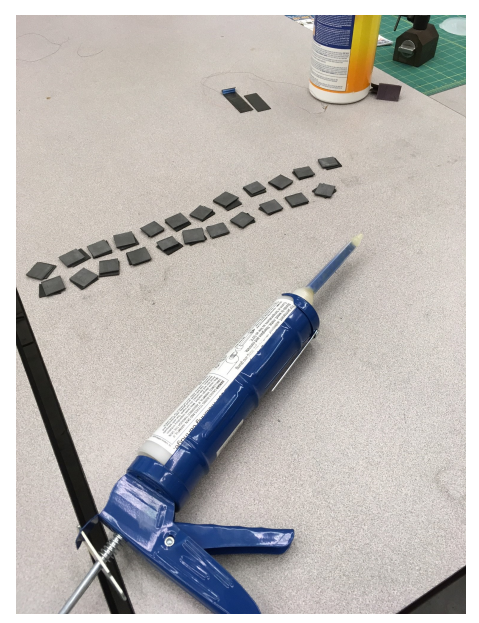

Figure 22 - Six10 epoxy prepped to be applied to test coupons and carbon composite tabs



Figure 23 - Weighted plates were used to apply pressure while epoxy cured

The recommended cure time, according to the data sheet, was one to four days. With limited time in the lab, testing had to commence after one full day of cure. Figure 24 shows the test coupon mounted in the INSTRON for a tensile test. 


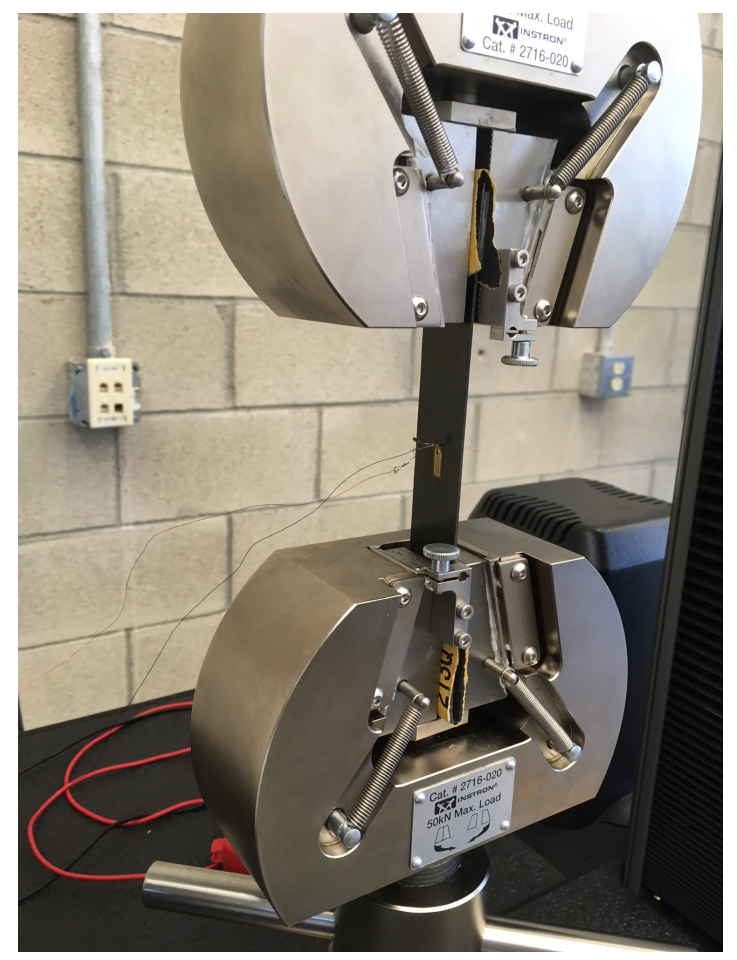

Figure 24 - Unidirectional 90 test coupon mounted for tensile test

With a successful suite of testing for the Unidirectional 90 coupons, the Unidirectional 0 test coupons were still problematic; slipping had occurred, aborting the first run of the Unidirectional 0. Figure 25 shows the slipped tabs:



Figure 25 - A tab is slipping on the Unidirectional 0 test couponstronger epoxy required 
After some research, it was discovered 3M Scotch-Weld's Off-White DP460NS two-part epoxy, Figure 26, was specifically developed for highshear applications, rated up to 1379psi for FRP at substrate failure, per 3M's specifications. Thus, a $1.250 z$ tube was ordered and was applied to the remaining test coupons, Figure 27 . Once applied, the test coupons were finally ready for tensile testing.

For future instances, aluminum or fiberglass tabs would also be explored, as it had been recommended for their ability to better imprint into the test coupons to provide a more robust grip.

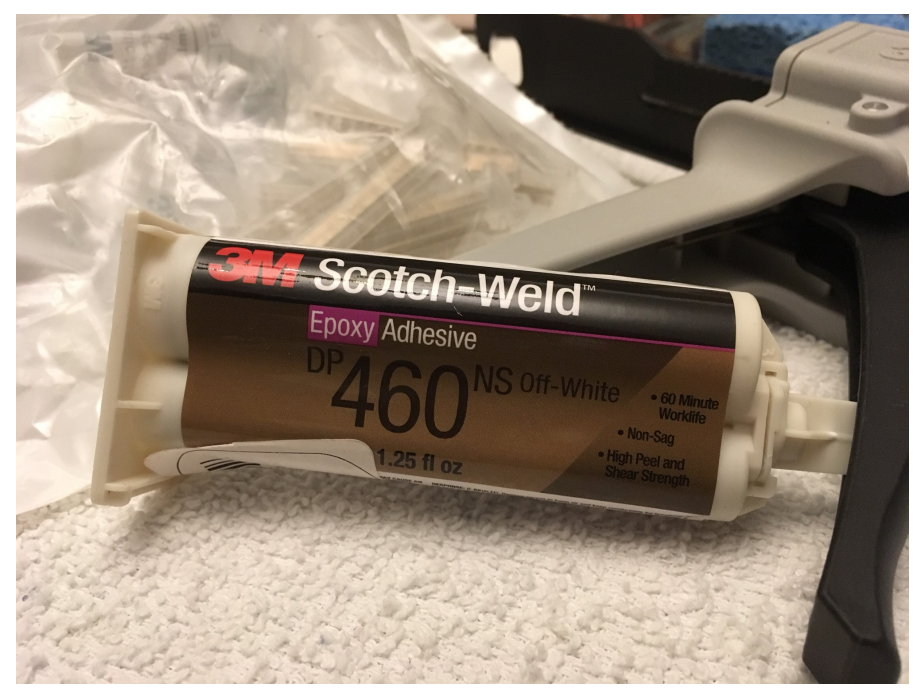

Figure 26 - 3M Scotch-Weld's DP460NS two-part epoxy developed specifically for high-shear stress applications 


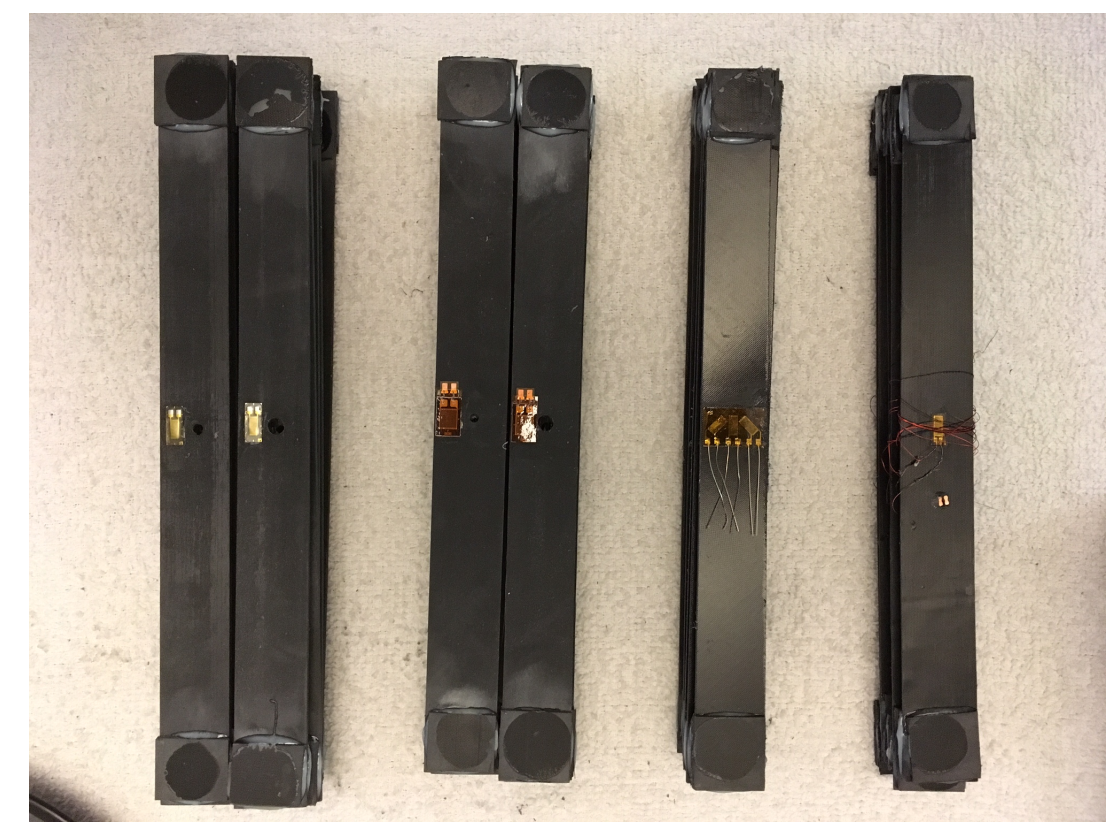

Figure 27 - Remaining test coupons applied with 3M Scotch-Weld's DP460NS

Tensile Test Challenges - Strain Gauges

Test gauges were difficult to come by. General Atomic of San Diego was gracious enough to donate 35 strain gauges for the purposes of my thesis. The most challenging aspects of the strain gauges were identifying an efficient and repeatable process to administering the gauges to the test coupons, followed by soldering on lead wires to each respective specimen's gauge, and finally, verifying electrical continuity through the leads that would connect to the quarter bridge in the INSTRON to read strain during the tensile tests. Figures 28 shows the process that was developed to secure strain gauge leads: 


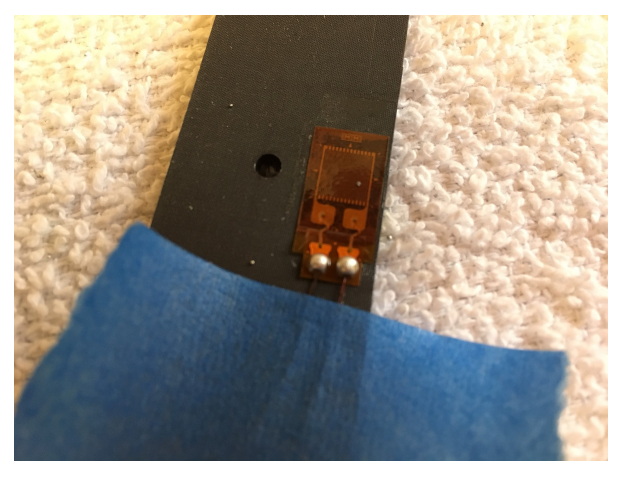

Figure 28 - Strain gauges were secured to test coupons with Super Glue; lead wires were molded to sit on the solder pads of the strain gauges and then taped down to the test coupon to secure its position-solder was then applied to secure the electrical connection

Once all strain gauges were fitted, the test coupons were ready for test. However, it was discovered during the tensile testing that the strain gauges for the quasi-isotropic test coupons were defective; their test coupons had to have their strain gauges replaced. 
III. Material Properties

Figure 29 shows the failure mode of the Unidirectional 0 ; every specimen shattered. The Unidirectional 90 coupons failed as expected, with varying failure points between the two end tabs. The Angle-ply specimens, however, never failed. It could be argued that at 16 plies and 0.13 inch thick, the Angle-ply coupons would not have failed at 0.05 in/min, since after all, the coupons elongated by up to 0.5 inches during the tensile test before the load would taper off. A point of contention for future tests, a higher capacity Instron would be recommended to induce failure.

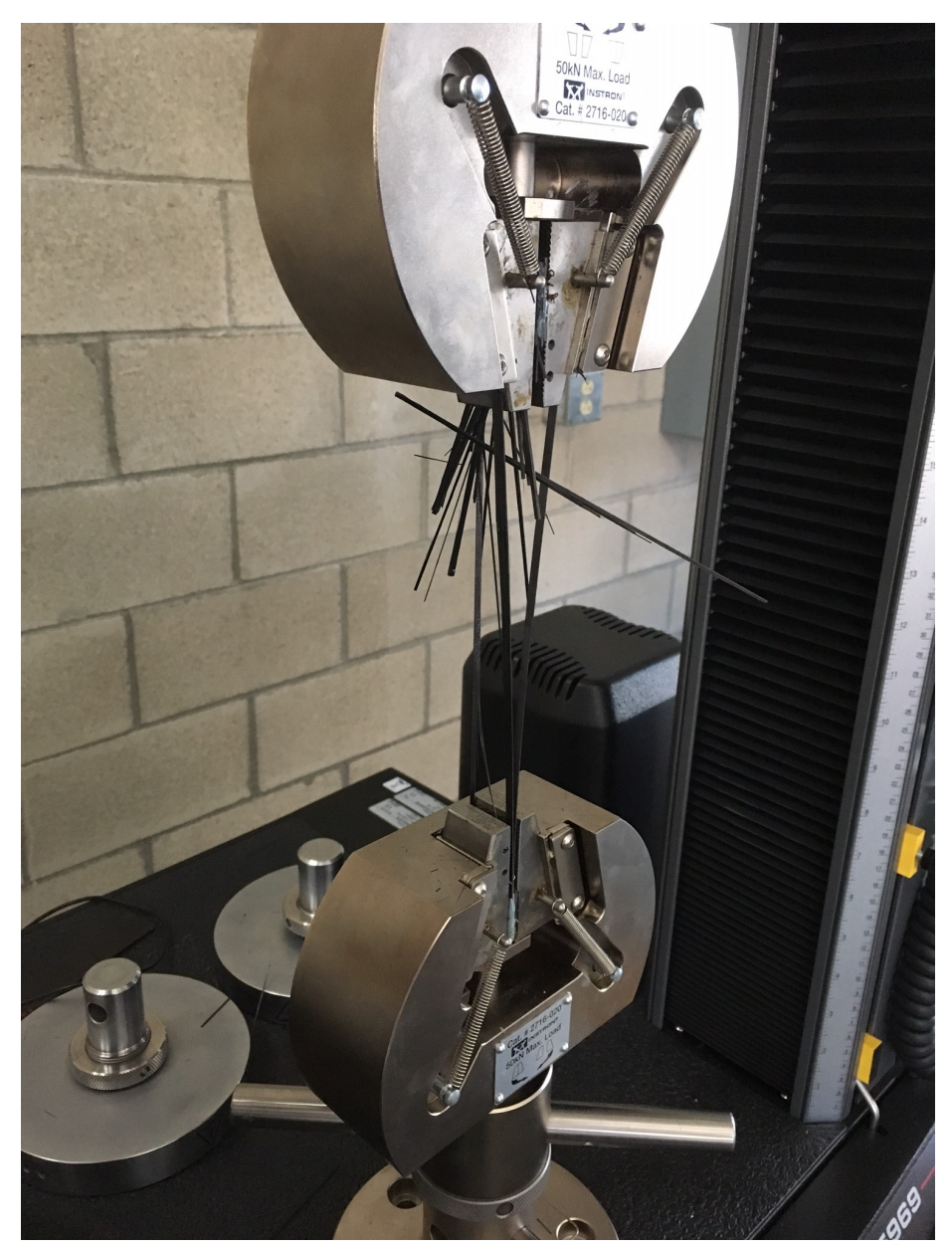

Figure 29 - Unidirectional 0 tensile failure mode 
Recall: Young's Modulus $\left(E_{L}\right)$ is the slope of the stress/strain curve, or $\mathrm{E}=\frac{\sigma}{\varepsilon}$, therefore, two additional elements are required to determine $\mathrm{E}$ : the cross-sectional area of each respective test specimen, and the force exerted over the course of each tensile test. With these points determined, Figure 30 plots the stress/strain curve for the [0]6 tensile test, and Table 6 identifies the correlating data, e.g., a Young's Modulus of $\mathrm{E}_{\mathrm{L}}=13.7 \mathrm{Msi}$ or $94.5 \mathrm{GPa}$.

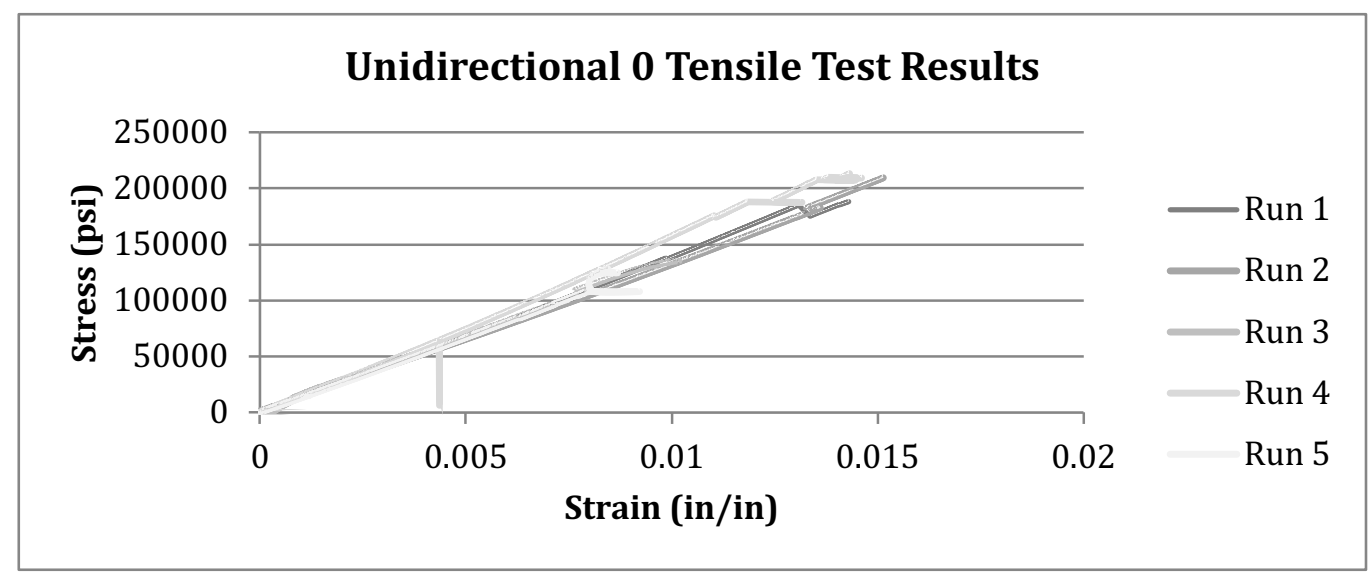

Figure 30 - Stress/strain curve for the [0]6 tensile test

The slight variation in slopes may have been an indication of slipping; however, the first three results were used in the average, as they seemed the most consistent of the five tests.

Table $6-[0]_{6}$ Attributes

$\begin{array}{llll} & \text { Max Load } & \text { Max Stress } & \text { Max Strain } \\ \text { E (Msi) } & (\text { lbf }) & (\text { Msi }) & (\text { in })\end{array}$

\begin{tabular}{rrrrr} 
Run 1 & 13.9 & 9228 & 0.1883 & 0.0143 \\
Run 2 & 13.5 & 10271 & 0.2096 & 0.0151 \\
Run 3 & 13.8 & 6630 & 0.1353 & 0.0102 \\
Run 4 & 15.5 & 10452 & 0.2133 & 0.0146 \\
Run 5 & 14.1 & 6291 & 0.1284 & 0.0092 \\
\hline Avg & 13.7 & 8710 & 0.1778 & 0.0132
\end{tabular}


The test results for Unidirectional 90, Figure 31 and Table 7, were used to determine $\mathrm{E}_{\mathrm{T}}=1 \mathrm{Msi}$ or $6.9 \mathrm{GPa}$.

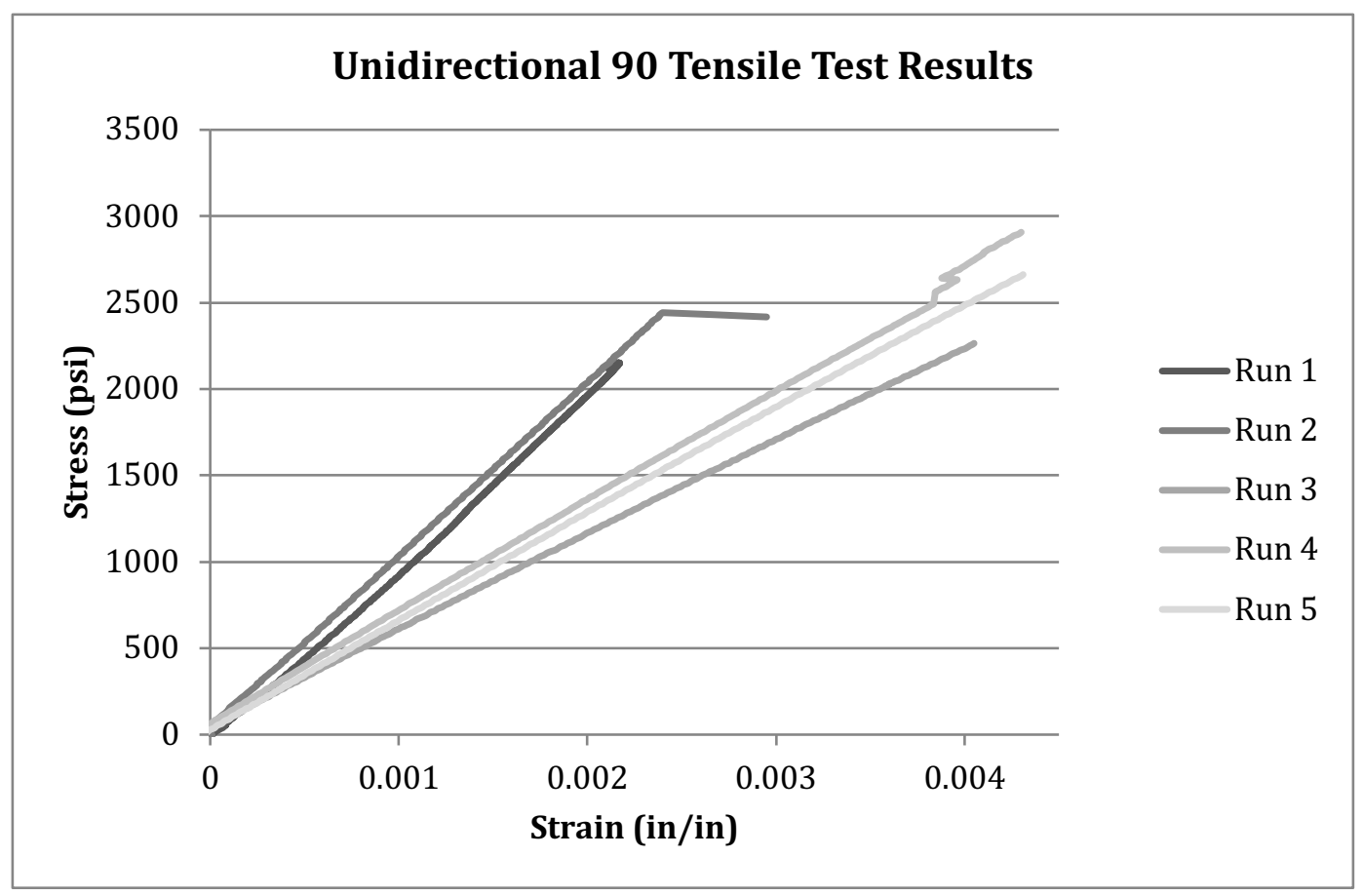

Figure 31 - Stress/Strain curve for the [90]12 tensile test

$\mathrm{E}_{\mathrm{T}}$ can generally be estimated to be roughly $1 / 10$ th of $\mathrm{E}_{\mathrm{L}} ;$ the first two runs were taken into the average to determine $E_{T}$, as they most closely resembled the expected outcome.

Table 7 - [90 $]_{12}$ Attributes

\begin{tabular}{ccrrr} 
& $\begin{array}{l}\text { E } \\
(\text { Msi })\end{array}$ & $\begin{array}{c}\text { Max Load } \\
(\text { lbf })\end{array}$ & $\begin{array}{c}\text { Max Stress } \\
(\text { psi })\end{array}$ & $\begin{array}{c}\text { Max Strain } \\
\text { (in/in) }\end{array}$ \\
Run 1 & 0.9924 & 151 & 2152 & 0.0022 \\
Run 2 & 0.9959 & 171 & 2442 & 0.0030 \\
Run 3 & 0.5479 & 158 & 2264 & 0.0041 \\
Run 5 & 0.6475 & 204 & 2907 & 0.0043 \\
\hline Avg & 1 & 186 & 2662 & 0.0051 \\
\hline
\end{tabular}


The test results for Angle-ply, Figure 32 and Table 8, were used to determine $\mathrm{G}_{\mathrm{LT}}=1.6 \mathrm{Msi}$ or $11.24 \mathrm{GPa}$.



Figure 32 - Stress/Strain curve for [+/-45]8 tensile test

Again, the test specimens for the Angle-ply did not fail, however, they pulled more consistently than the previous two sets. Run 2 had a unexpected return in the elastic region-perhaps the strain gauge connection was noisy; Run 3 did not reach the range of stress levels expected.

$$
\text { Table } 8-[+/-45]_{8} \text { Attributes }
$$

\begin{tabular}{|c|c|c|c|c|c|c|}
\hline & $E(p s i)$ & $\begin{array}{l}\text { Max Load } \\
(1 \mathrm{bf})\end{array}$ & $\begin{array}{l}\text { Shear Stress } \\
\text { Elastic } \\
\text { (psi) }\end{array}$ & $\begin{array}{l}\text { Shear Strain } \\
\text { at Elastic } \\
\text { (in/in) }\end{array}$ & $\begin{array}{l}\text { Max } \\
\text { Stress } \\
\text { (psi) }\end{array}$ & $\begin{array}{l}\text { Max } \\
\text { Strain } \\
\text { (in/in) }\end{array}$ \\
\hline Run 1 & 1.6822 & 1815 & 11018 & 0.0075 & 18147 & 0.1227 \\
\hline Run 2 & 2.8716 & 1817 & 11283 & 0.0060 & 18175 & 0.0620 \\
\hline Run 3 & 1.3772 & 1567 & 10246 & 0.0081 & 15667 & 0.1191 \\
\hline Run 4 & 1.7801 & 1697 & 11776 & 0.0074 & 16967 & 0.1263 \\
\hline Run 5 & 1.4176 & 1762 & 12266 & 0.0092 & 17625 & 0.1274 \\
\hline Avg & 1.6 & 1758 & 11686 & 0.0080 & 17579 & 0.1255 \\
\hline
\end{tabular}


Finally, Table 9 summarizes the material properties of unidirectional pre-preg NCT301-2G150/108 determined through tensile testing. Due to limitations in strain gauge availability, the Poisson's Ratio could not be measured through test, therefore it was necessary to take an estimation. Poisson's Ratio, $\mathrm{V}_{\mathrm{LT}}$, ranged anywhere from 0.1 to 0.4 in spec sheets; due to the age of the material, the pre-preg was assumed to be more brittle than its intended design, therefore, the $\mathrm{V}_{\mathrm{LT}}$ was estimated to be 0.25 .

Table 9 - Material properties of unidirectional pre-preg NCT301$2 \mathrm{G} 150 / 108$

\begin{tabular}{|l|l|r|}
\hline $\begin{array}{l}\text { Modulus of Elasticity, } \\
\text { Direction of Ply }\end{array}$ & $\mathrm{E}_{\mathrm{L}}$ & $13.7 \mathrm{Msi}$ \\
\hline $\begin{array}{l}\text { Modulus of Elasticity, } \\
\text { Transverse to Ply }\end{array}$ & $\mathrm{E}_{\mathrm{T}}$ & $94.5 \mathrm{GPa}$ \\
\hline $\begin{array}{l}\text { Shear Modulus, in Axes L/T } \\
\text { Poisson's Ratio, in Axes }\end{array}$ & $\mathrm{G}_{\mathrm{LT}}$ & $\begin{array}{l}1.9 \mathrm{GPa} \\
\text { L/T }\end{array}$ \\
\hline
\end{tabular}

These material properties were utilized for the analytical and FEA throughout the remainder of this thesis. The cross-ply and quasi-isotropic results will be discussed in section VII. 
IV. The Analytical Method: Cross and Quasi-isotropic

Hooke's Law states that force and displacement, as well as stress and strain, are linearly related $(\sigma=E \varepsilon)$. Classical Laminated Plate Theory leverages this relationship to identify the stress, strain, and/or material properties of a composite laminate plate.

When analyzing unidirectional pre-preg, a material with one plane of symmetry, or a material of "transversely isotropic" properties, the stiffness matrix, $Q$, reduces down to Equation 1 . In other words, the $Q$ matrix identifies how the material layer will behave holistically, and its components $\left(Q_{11}, Q_{12}\right.$, et al) provide specificity on how the material will behave depending on which axis the loading is applied, $i$, and in which direction the fibers are running, $j$. For example, $Q_{11}$ is the material property along the direction of fibers when the load is applied in the direction of fibers, $\mathrm{Q}_{12}$ is the material property transverse to the direction of the fibers when the load is being applied in the direction of fibers (essentially, Poisson's Ratio-how much would the width of the specimen shrink when the load is being applied along the direction of fibers, $\left.Q_{11}\right)$.

$$
\boldsymbol{Q}_{i j}=\left[\begin{array}{ccc}
Q_{11} & Q_{12} & 0 \\
Q_{12} & Q_{22} & 0 \\
0 & 0 & Q_{66}
\end{array}\right]
$$

$(\mathrm{Eq} \cdot 1)$

These stiffness components are defined by the material properties discovered through the tensile tests in Section IV, where $E_{11}$ is equivalent to $\mathrm{E}_{\mathrm{L}}, \mathrm{E}_{22}$ is equivalent to $\mathrm{E}_{\mathrm{T}}$, and $\mathrm{G}_{\mathrm{LT}}$ is equivalent to $\mathrm{Q}_{66}$; reference Equations 2 through 5 in Appendix: Classical Laminated Plate Theory Equations.

Since this study only consists of one type of pre-preg, Equations 2 through 5 need only be calculated once from the values in Table 9. Results are as follows: 


$$
\begin{aligned}
& Q_{11}=13.70 \mathrm{Msi} \\
& Q_{12}=0.25 \mathrm{Msi} \\
& Q_{22}=1.00 \mathrm{Msi} \\
& Q_{66}=1.60 \mathrm{Msi}
\end{aligned}
$$

With different ply angles, each stiffness component will now need to be translated into the direction in which the fibers are arranged; in other words: a ply's material property will shift with its orientation. Equations 6 through 11 in Appendix: Classical Laminated Plate Theory Equations calculate how each material property component transforms when placed in the ply stack at a ply angle $\theta$; assembling them all together produces the reduced stiffness matrix, Equation 12:

$$
\overline{\boldsymbol{Q}_{i j}}=\begin{array}{lll}
\overline{Q_{11}} & \overline{Q_{12}} & \overline{Q_{16}} \\
\overline{Q_{16}} & \overline{Q_{22}} & \overline{Q_{26}} \\
Q_{66}
\end{array}
$$

(Eq. 12$)$

Each ply's $\overline{Q_{l j}}$ is then summed per its proportion to the total number of plies in the stack-reference Equation 13:

$$
\left[\overline{Q_{l}}\right]_{\text {Total }}=\sum_{m=1}^{n_{\text {total }}} \frac{n_{\theta_{m}}}{n_{\text {Total }}}\left[\overline{Q_{l \jmath}}\right]_{\theta_{m}}
$$

And subsequently, the strain is determined from finding the inverse of the reduced stiffness matrix, multiplied by the stress (force/crosssectional area).

$$
\varepsilon=\left[\overline{Q_{l}}\right]_{\text {Total }}^{-1}[\sigma]
$$


Cross $-p 1 y$

Stress is defined for the two hole sizes for the cross-ply laminates :

$$
\begin{gathered}
\sigma_{\operatorname{Cross}_{1 / 8,1000 l b f}}=8,791 \text { psi } \\
\sigma_{\text {Cross }_{1 / 4,100 o l b f}}=10,256 p s i
\end{gathered}
$$

Leveraging Equations 6 through 11 from Appendix: Classical Laminated Plate Theory Equations, the following reduced Qs were determined for the 16 layer $\left[(0 / 90)_{4}\right]_{s}$ cross-ply laminate:

$$
\begin{aligned}
& {[\bar{Q}]_{\theta_{0^{\circ}}}=\left[\begin{array}{ccc}
13.70 & 0.25 & 0 \\
0.25 & 1 & 0 \\
0 & 0 & 1.6
\end{array}\right] M s i} \\
& {[\bar{Q}]_{\theta_{90^{\circ}}}=\left[\begin{array}{ccc}
1 & 0.25 & 0 \\
0.25 & 13.70 & 0 \\
0 & 0 & 1.6
\end{array}\right] M s i}
\end{aligned}
$$

Where:

$$
[\bar{Q}]_{\text {Cross }}=\left[\begin{array}{ccc}
7.35 & 0.25 & 0 \\
0.25 & 7.35 & 0 \\
0 & 0 & 1.6
\end{array}\right] M s i
$$

And its inverse:

$$
[\bar{Q}]_{\text {Cross }}^{-1}=\left[\begin{array}{ccc}
0.1362 & -0.0046 & 0 \\
-0.0046 & 0.1362 & 0 \\
0 & 0 & 0.6250
\end{array}\right] \mu s i
$$

The strains for $1 / 8 "$ and $1 / 4 "$ hole cross-ply plates:

$$
\begin{aligned}
& \varepsilon_{\operatorname{Cross}_{1 / 8^{\prime}}}=0.0012 \mathrm{in} / \mathrm{in} \\
& \varepsilon_{\operatorname{Cross}_{1 / 4^{4}}}=0.0014 \mathrm{in} / \mathrm{in}
\end{aligned}
$$


Quasi-isotropic

Stress is defined for the two hole sizes for the quasi-isotropic laminates :

$$
\begin{aligned}
& \sigma_{\text {Quasi }_{1 / 8^{\prime \prime}}}=11,662 \text { psi } \\
& \sigma_{\text {Quasi }_{1 / 4^{\prime \prime}}}=13,605 \text { psi }
\end{aligned}
$$

Leveraging Equations 6 through 11 from Appendix: Classical Laminated Plate Theory Equations, the following reduced stiffness components were solved for the 12 layer $\left[0_{2} /+45 /-45 / 90_{2}\right]_{\mathrm{s}}$ quasi-isotropic laminate to determine the strain experienced for each hole size plate. The strains for 1/8" and 1/4" hole quasi-isotropic plates:

$$
\begin{aligned}
& \varepsilon_{\text {Quasi }_{1 / 8^{\prime}}}=0.0017 \mathrm{in} / \mathrm{in} \\
& \varepsilon_{x_{\text {quasi }_{1 / 4 "}}}=0.0020 \mathrm{in} / \mathrm{in}
\end{aligned}
$$


V. The Homogenous Baseline

Research report Correlation between Engineering Stress-Strain and True Stress-Strain Curve conducted by Iman Faridmehr, Mohd Hanim Osman, and co, published in the American Journal of Civil Engineering and Architecture, 2014, Vol. 2, No. 1, 53-59, was utilized to validate the homogenous baseline; their methodology followed was in conformance to ASTM E8, reference Figure 33:


Figure 33 - Standard Tensile Specimens, according to ASTM E8

The three test specimens, developed from low carbon steel, used for validation had the following dimensions, reference Table 10, Figure 34 : Table 10 - Specimen Dimensions

\begin{tabular}{|l|r|r|r|}
\hline Specimen & \multicolumn{2}{|l|}{$\begin{array}{l}\text { Thickness } \\
(\mathrm{mm})\end{array}$} & \multicolumn{2}{l|}{$\begin{array}{l}\text { Cross Section } \\
\text { Area }(\mathrm{mm} 2)\end{array}$} & $\begin{array}{l}\text { Gauge Length } \\
(\mathrm{mm})\end{array}$ \\
\hline 1 & 10 & 380 & 50 \\
\hline 2 & 8 & 304 & 50 \\
\hline 3 & 6 & 228 & 50 \\
\hline
\end{tabular}


For the sake of the homogenous baseline, only the $10 \mathrm{~mm}$ case was considered.

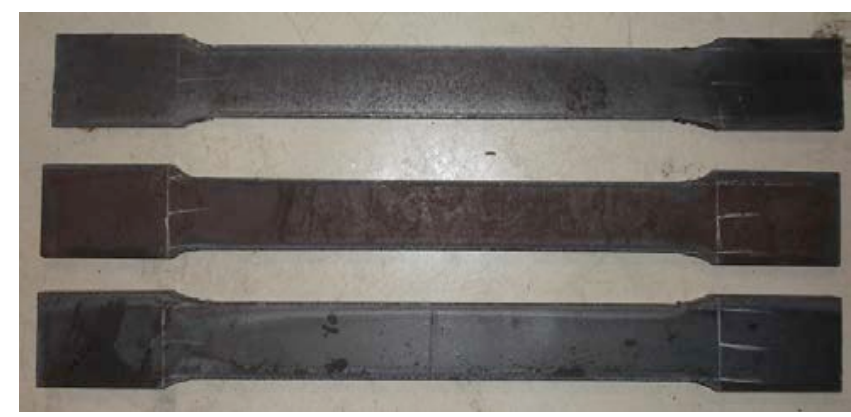

Figure 34 - Test specimens for Homogenous Baseline FEA validation

At the end of the tensile test, the following material characteristics were determined; reference Table 11 .

Table 11 - Material Characteristics of Low Carbon Steel

\begin{tabular}{|l|l|l|l|l|l|l|l|l|}
\hline Specimen & $\begin{array}{l}\text { Yield Load } \\
(\mathrm{KN})\end{array}$ & $\begin{array}{l}\text { Yield } \\
\text { Strain }\end{array}$ & $\begin{array}{l}\text { Yield } \\
\text { Strength } \\
\left(\mathrm{N} / \mathrm{mm}^{2}\right)\end{array}$ & $\begin{array}{l}\text { Young's } \\
\text { Modulus } \\
\left(\mathrm{N} / \mathrm{mm}^{2}\right)\end{array}$ & $\begin{array}{l}\text { Max } \\
\text { Load } \\
(\mathrm{KN})\end{array}$ & $\begin{array}{l}\text { Ultimate } \\
\text { Tensile } \\
\text { Strength } \\
\left(\mathrm{N} / \mathrm{mm}^{2}\right)\end{array}$ & $\begin{array}{l}\% \\
\text { Elongation }\end{array}$ & $\begin{array}{l}\text { Fracture } \\
\text { Strain } \\
(\mathrm{mm} / \\
\mathrm{mm})\end{array}$ \\
\hline 1 & 119 & 0.0013 & 279 & $2.1 \mathrm{E} 5$ & 110 & 361 & $17.5 \%$ & 0.16 \\
\hline 2 & 85 & 0.0013 & 282 & $2.1 \mathrm{E} 5$ & 106 & 351 & $18 \%$ & 0.15 \\
\hline 3 & 86 & 0.0013 & 275 & $2.1 \mathrm{E} 5$ & 108 & 358 & $18.2 \%$ & 0.15 \\
\hline
\end{tabular}

Specimen 1 was replicated in ABAQUS to validate the homogenous baseline FEA model.

The failed test specimens from the tensile loading, is shown in Figure 35: 


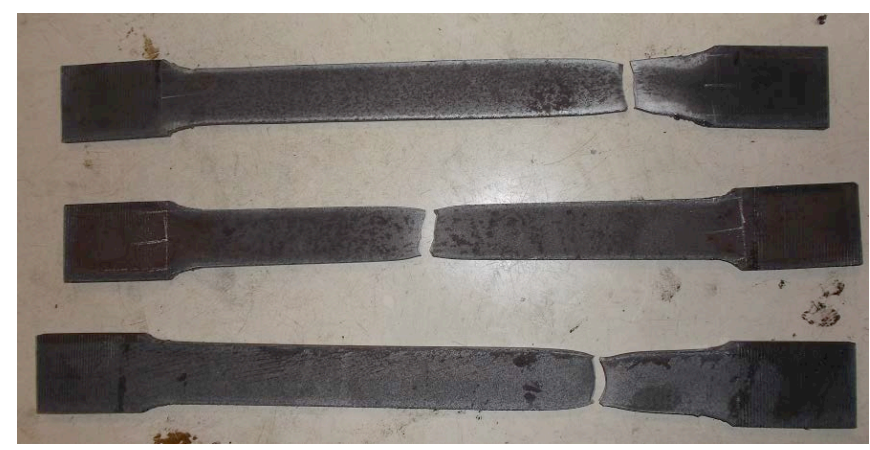

Figure 35 - Failed specimens under tensile loading

The Stress/Strain curve produced from the tensile test is shown below in Figure 36 :

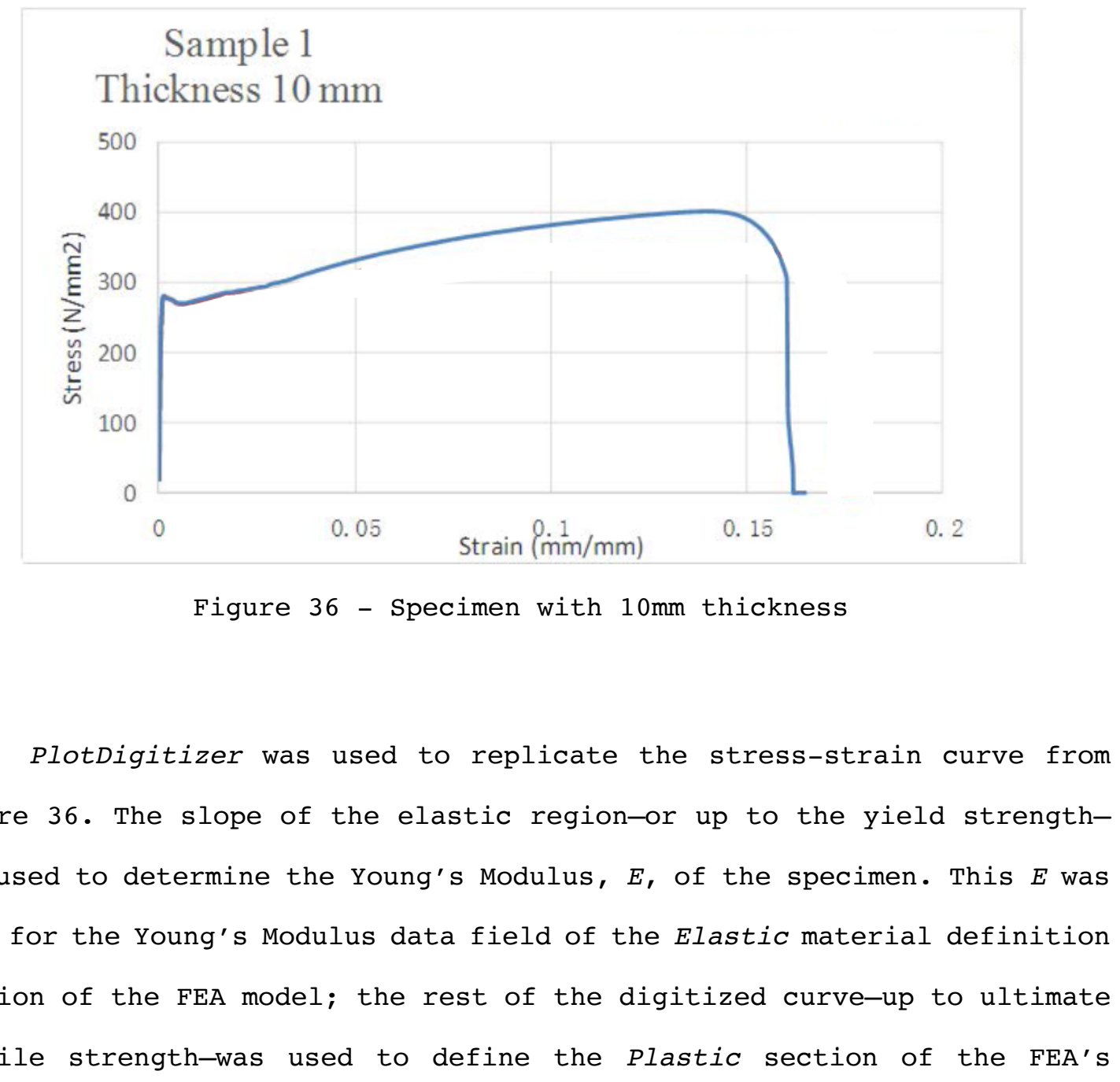


material definition. To note, it was an accepted risk that using PlotDigitizer may have introduced some inaccuracies in the resulting data.

Building a Homogenous FEA Baseline

The software used to perform FEA was ABAQUS version CAE 6.14. The steps taken to conduct the FEA can be found in Appendix B.

Analyzing the Results

To review, the following attributes went into developing this FEA model :

- Young's Modulus: $225,456 \mathrm{~N} / \mathrm{mm}^{2}$

- Poisson's Ratio: 0.29

- Plastic Yield Stress/Strain: Reference Table 5

- Step: Time Period = 2, Incrementation: Max $=100$, Initial Size = 0.05, Minimum $=2 \mathrm{E}-005$, Maximum $=0.15$

- Constraint: Coupling, Kinematic; constrain: U1, U2, U3, UR1, UR2, UR3

- Amplitude: Time (s)/Frequency (Hz) and Amplitude: 0, 0 / 1, 1

- Load: $\mathrm{CF} 2=100 \mathrm{KN}$

- Boundary Condition (BC) \#1: ENCASTRE, bottom grip

- BC \#2: Displacement/Rotation, U1, U3, UR1, UR2, UR3

- Global Seeds: Approximate global size = 3; Curvature Control = 0.1, Minimum Size Control: By fraction of global size $=0.1$

Plot Contours on Deformed Shape visualizes the effects of the load on the specimen. Though difficult to read the values, the important takeaway from Figure 37 are how the stress/strain results are visually represented, with the red regions representing the regions most stressed, and blue showing the least impacted by the load (the grips). 




Figure 37 - ABAQUS output screenshot: Homogenous Baseline FEA

ABAQUS can portray the results through a two-dimensional plot as well. To do so, click on Create $X Y$ Data $>$ ODB field output, and under the Variables tab, E: Strain components, select E22; under S: Stress Components, select Mises. Click over to the Elements/Nodes tab, Edit Selection, and highlight a node/element to plot (hold down Shift to select multiple nodes/elements). Click Plot to complete this step; reference Figure 38. Again, difficult to read values, however, the intent of Figure 38 is to emphasize the post-processing steps necessary to acquire the desired values to develop Figures 39 and 40 .



Figure 38 - ABAQUS output screenshot: Stress and Strain portrayed as dependent on time for homogenous baseline (stress: $\mathrm{N} / \mathrm{mm}^{2}$, strain: $\mathrm{mm} / \mathrm{mm}$, time: sec) 
To present the plot in Stress dependent on Strain, click on the Create $X Y$ Data button once more, but now click on the Operate on XY Data option. On the far right of the popup, under Operators, scroll down and click on combine $(X, X)$. Here, the E22 Strain and Mises Stress line items will be visible; single-clicking on each line item will populate the combine $(X, X)$ operator with the strain and stress. Clicking Plot results in Figure 39 :

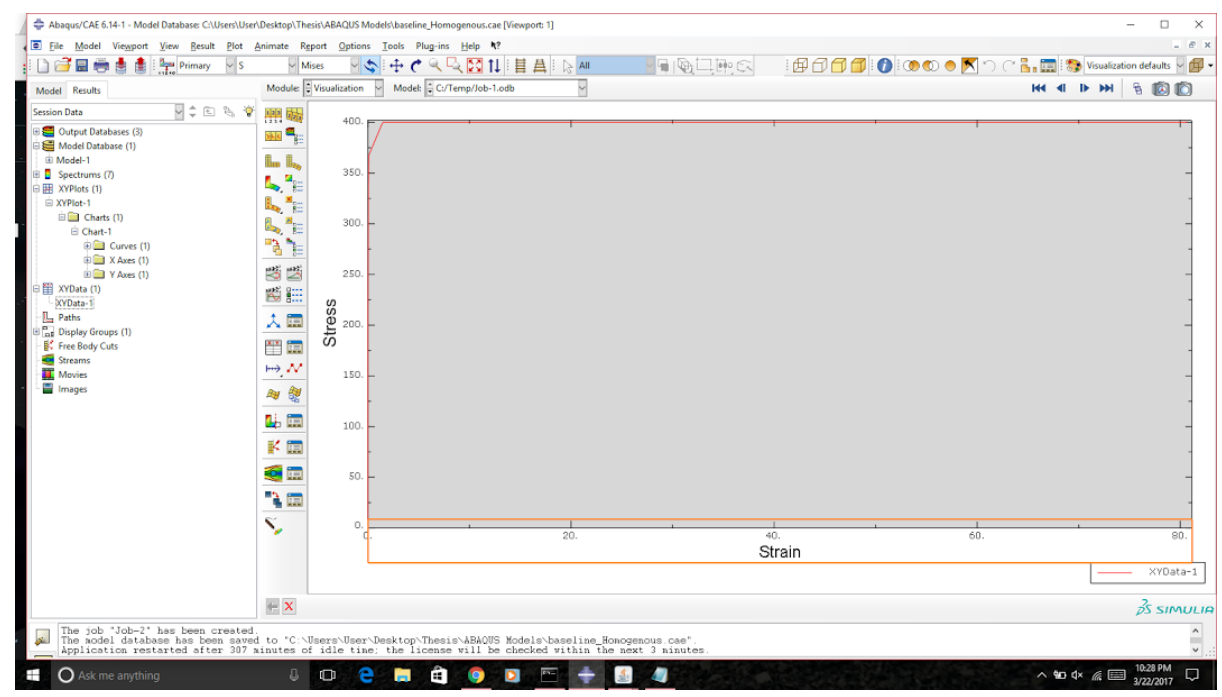

Figure 39 - ABAQUS output screenshot: Stress dependent on Strain of 10mm specimen for homogenous baseline FEM (stress: $\mathrm{N} / \mathrm{mm}^{2}$, strain: $\mathrm{mm} / \mathrm{mm}$ )

ABAQUS can also show the results in tabular form, allowing users to create their own stress/strain curve. To do this, click on XY Data Manager, and with the stress/strain curve highlighted, click Edit. A popup enumerating the stress/strain values will display; reference Figure 40: 


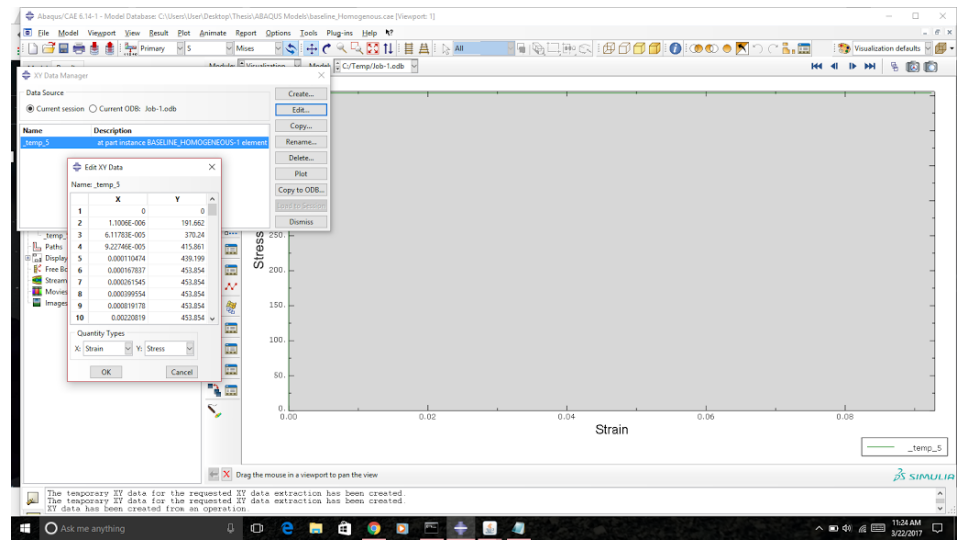

Figure 40 - Tabulated Stress and Strain from ABAQUS for homogenous baseline FEM (stress: $\mathrm{N} / \mathrm{mm}^{2}$, strain: $\mathrm{mm} / \mathrm{mm}$ )

Table 12 enumerates the true stress/strain results from the tensile test. Line items three through five were utilized to determine the slope of the elastic region, or $E$, as show in Figure 41:

Table 12 - True Stress/Strain from test results

\begin{tabular}{|c|c|}
\hline \multicolumn{2}{|c|}{ Test } \\
\hline $\begin{array}{c}\text { True } \\
\left(\mathrm{N} / \mathrm{mm}^{2}\right)\end{array}$ & $\begin{array}{c}\text { True } \\
\text { Strain } \\
(\mathrm{mm} / \mathrm{mm})\end{array}$ \\
\hline 0 & 0 \\
\hline 17.90 & 0.00064584 \\
\hline 101.43 & $6.62 \mathrm{E}-04$ \\
\hline 200.47 & $8.95 \mathrm{E}-04$ \\
\hline 282.81 & $1.13 \mathrm{E}-03$ \\
\hline 269.66 & $5.62 \mathrm{E}-03$ \\
\hline 287.48 & $1.83 \mathrm{E}-02$ \\
\hline 293.39 & $2.73 \mathrm{E}-02$ \\
\hline 302.90 & $3.37 \mathrm{E}-02$ \\
\hline 318.37 & $4.14 \mathrm{E}-02$ \\
\hline 332.64 & $5.04 \mathrm{E}-02$ \\
\hline 357.57 & $7.16 \mathrm{E}-02$ \\
\hline 376.54 & $9.26 \mathrm{E}-02$ \\
\hline 397.81 & $1.27 \mathrm{E}-01$ \\
\hline 400.11 & $1.42 \mathrm{E}-01$ \\
\hline 397.70 & $1.46 \mathrm{E}-01$ \\
\hline & \\
\hline
\end{tabular}






Figure 41 - Determining plastic $E$, through slope of Stress and Strain

The values from the FEA results were overlaid with the results from the tensile test, as shown in Table 12; reference Figure 42 . Orientation: tension through length of specimen (y-axis).

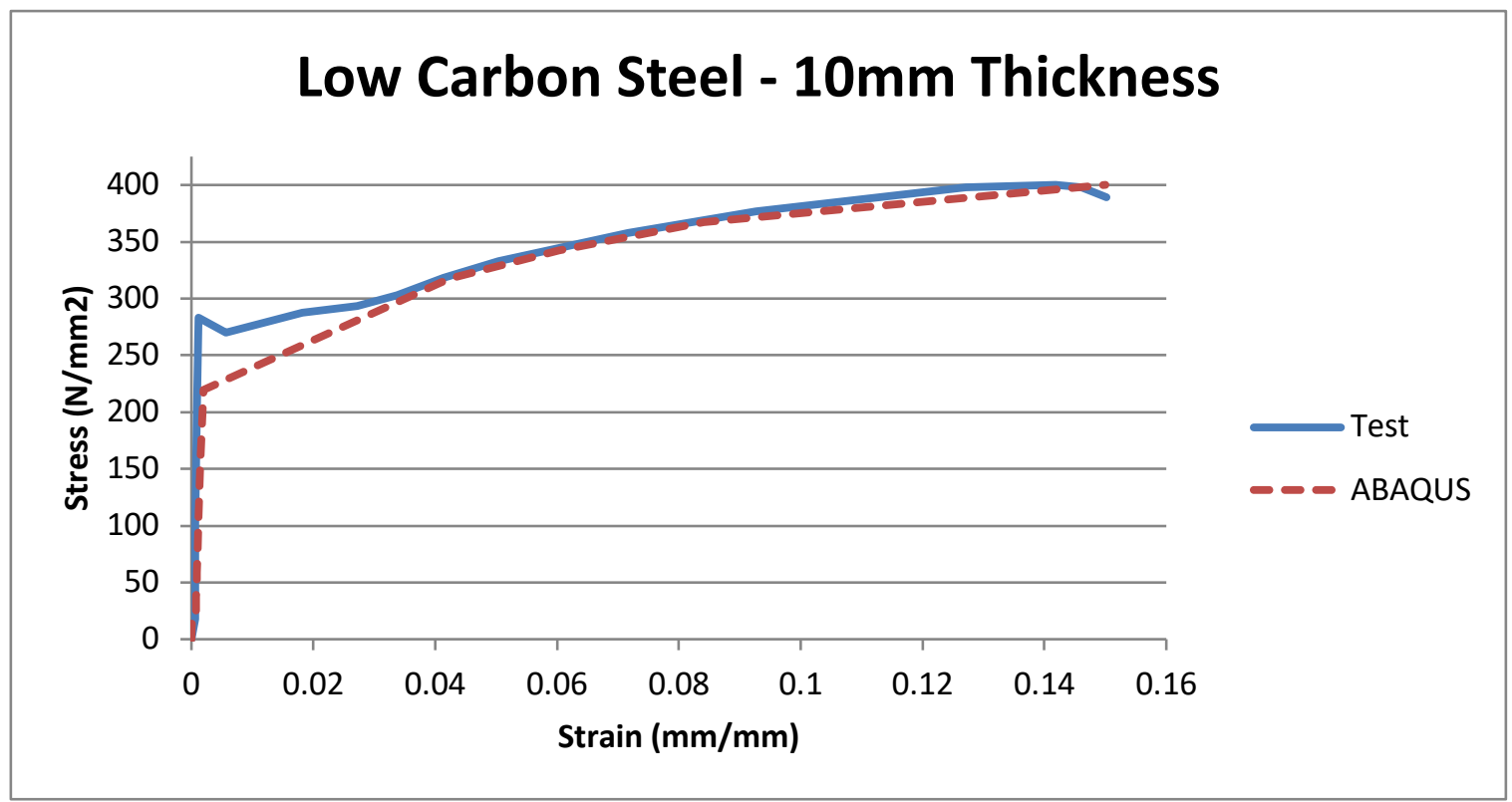

Figure 42 - Low carbon steel 10mm thickness specimen FEA compared to tensile test results 
Validating the Homogenous Baseline

The yield tensile strength was denoted as $282 \mathrm{MPa}$ for the tensile test; the ABAQUS results indicate yield strength of $220 \mathrm{MPa}$, a discrepancy of $22 \%$ from test. The ultimate tensile strength was determined to be 389MPa per test, 400MPA per FEA; a discrepancy of $3 \%$.

With the variables introduced with PlotDigitizer, and the possible differences in the test specimen compared to the one modeled in the FEA, a $22 \%$ and 3\% discrepancy were deemed acceptable for the sake of validating the FEA model. With how dynamic the elastic region is, with both the load and at what rate the load is applied contributing to the behavior of elasticity, it was less disconcerting to see the discrepancy. A $3 \%$ discrepancy at fracture provided the necessary vote of confidence in the finite element model.

These same steps were taken to develop the FEA models for the four composite laminate cases in the following section. 
VI. Finite Element Analysis Methodology

The FEA models' attributes were as follows:

- $\quad \mathrm{E}_{\mathrm{L}}: 13.7 \mathrm{Msi}$

- $\quad \mathrm{E}_{\mathrm{T}}: 1 \mathrm{Msi}$

- $\mathrm{G}_{\mathrm{LT}}: 1.6 \mathrm{Msi}$

- Poisson's Ratio: 0.25

- Step: Time Period $=1$, Incrimination: Max $=100$, Initial Size = 1, Minimum $=1 \mathrm{E}-005$, Maximum $=1$

- Constraint: Coupling, Kinematic; constrain: U1, U2, U3, UR1, UR2, UR3

- Load: $\mathrm{CF} 2=1000$ lbf at Reference Point 1 (top center node)

- Boundary Condition (BC) \#1: ENCASTRE, bottom grip

- BC \#2: Displacement/Rotation, constrain: U1, U3, UR1, UR2, UR3

- Global Seeds: Approximate global size = [0.05:0.010]; Curvature Control $=0.1$, Minimum Size Control: By fraction of global size = 0.1

The starting mesh's global seed size was set to 0.05 , or a node count of 4713, per Figure 43. Once the part was submitted for analysis, Figure 44 shows the spectrum of stresses experienced throughout the substrate, denoted by the legend in the upper left corner of the screen; reference Appendix: Creating an FEA Model in ABAQUS. 


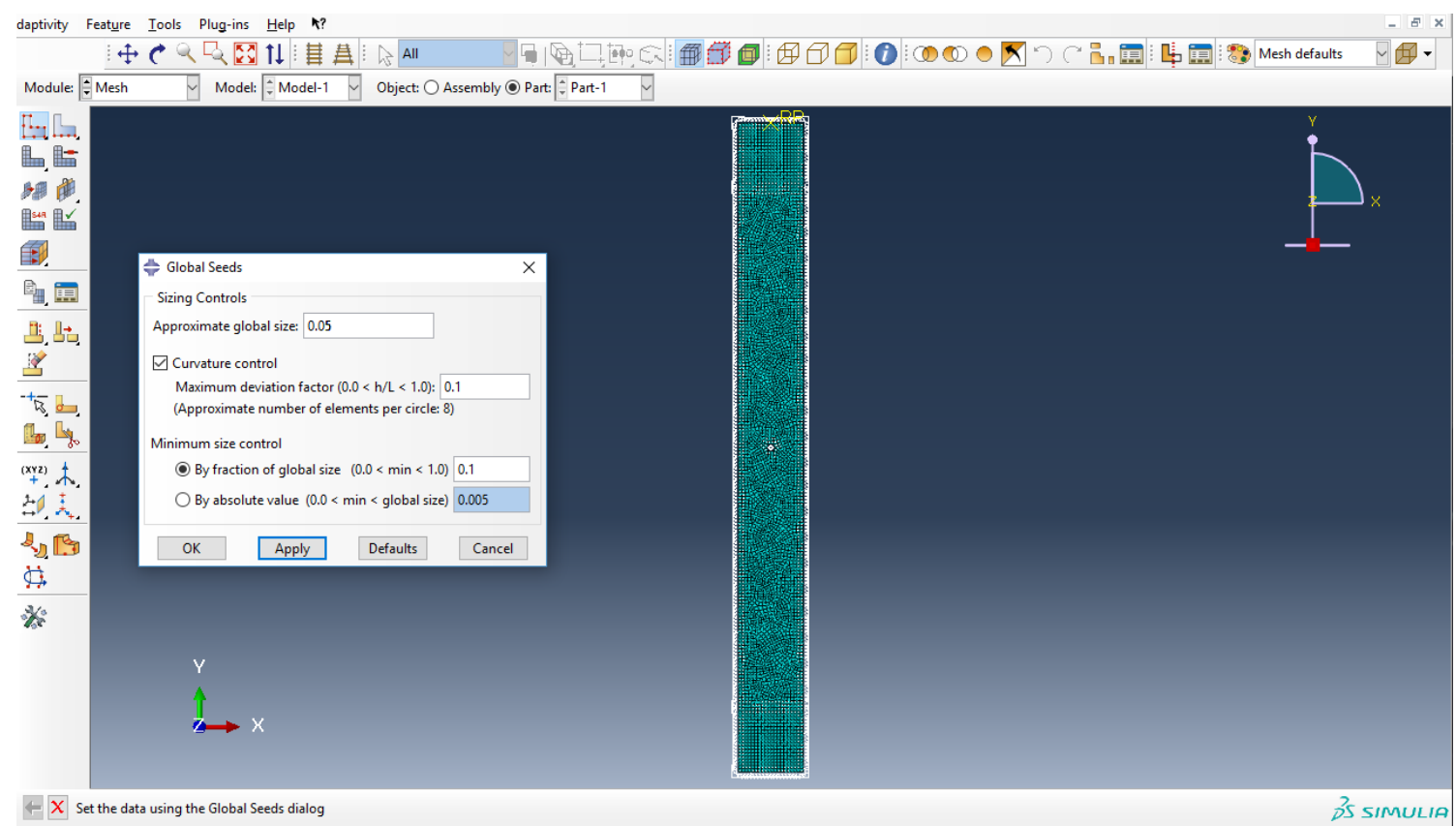

Figure 43 - For the first iteration of FEA, the global seed size was set to 0.05 , or a node count of 4541

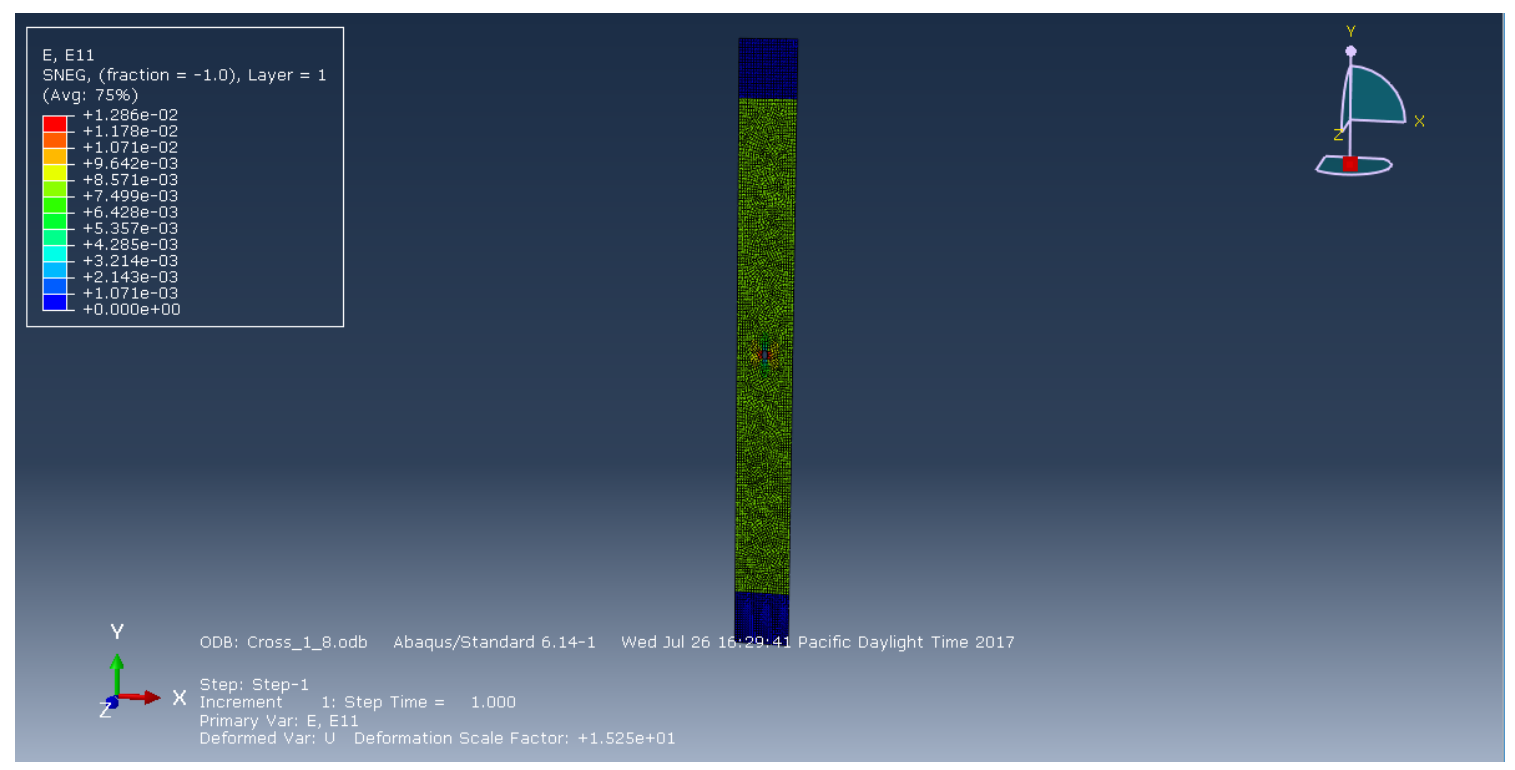

Figure 44 - FEA result for 1/8" cross-ply substrate

Table 13 delineates the node variations for the 1/8" cross-ply substrates. The ideal node count for these specimens was determined to be 29333, or a global seed size of 0.020 ; the run-time-to-accuracy factor 
was the most ideal, especially when running so many FEA scenarios. However, the advantage of conducting this study is that if the error rates are larger than expected when comparing FEA results with analytical and tensile test results, there is a solution to improve on those error rates: increase the node count.

Table 13 - Node variations for 1/8" cross-ply substrate

\begin{tabular}{|c|c|c|c|c|c|}
\hline & $\begin{array}{r}\text { Point Stress } \\
(\text { psi) }\end{array}$ & & $\begin{array}{r}\text { Point } \\
\text { Strain } \\
\text { (in/in) }\end{array}$ & & $\begin{array}{r}\text { Run-Time } \\
(\text { sec) }\end{array}$ \\
\hline Analytical & 8791 & - & 0.00120 & - & - \\
\hline
\end{tabular}

\begin{tabular}{|c|c|c|c|c|c|}
\hline $\begin{array}{l}\text { Seed } \\
\text { Size/Node } \\
\text { Count }\end{array}$ & $\begin{array}{l}\text { Avg Stress } \\
\text { at SG (psi) }\end{array}$ & $\begin{array}{r}\% \text { from } \\
\text { Analytical }\end{array}$ & $\begin{array}{r}\text { Point } \\
\text { Strain } \\
\text { (in/in) }\end{array}$ & $\begin{array}{r}\% \text { from } \\
\text { Analytical }\end{array}$ & $\begin{array}{r}\text { Run-Time } \\
(\text { sec) }\end{array}$ \\
\hline $\begin{array}{l}0.05 / \\
4541\end{array}$ & 7565 & $-13.95 \%$ & 0.00110 & $-8.38 \%$ & 45 \\
\hline $\begin{array}{l}0.03 / \\
12800\end{array}$ & 7647 & $-13.01 \%$ & 0.00111 & $-7.37 \%$ & 51 \\
\hline $\begin{array}{l}0.020 / \\
29333\end{array}$ & 8022 & $-8.74 \%$ & 0.00117 & $-2.90 \%$ & 89 \\
\hline $\begin{array}{l}0.015 / \\
51996\end{array}$ & 8005 & $-8.94 \%$ & 0.00116 & $-3.21 \%$ & 315 \\
\hline $\begin{array}{l}0.010 / \\
118006\end{array}$ & 8182 & $-6.93 \%$ & 0.00119 & $-1.01 \%$ & 450 \\
\hline
\end{tabular}

With a global seed size of 0.020 set for all finite element models, a point load of 1000 lbf was set and analyzed. Upon attaining results, the nodes in the area where the strain gauges were installed were highlighted, and the average of the stresses and strains were taken therein. An important factor to keep in mind: the sensitivity of which nodes are selected to determine the average stresses and strains is indeed a factorthis variability leaves room for a higher than desired error rate. It is crucial that the exact location of strain gauge and its nodes are analyzed. Figure 45 shows the highlighted nodes. 

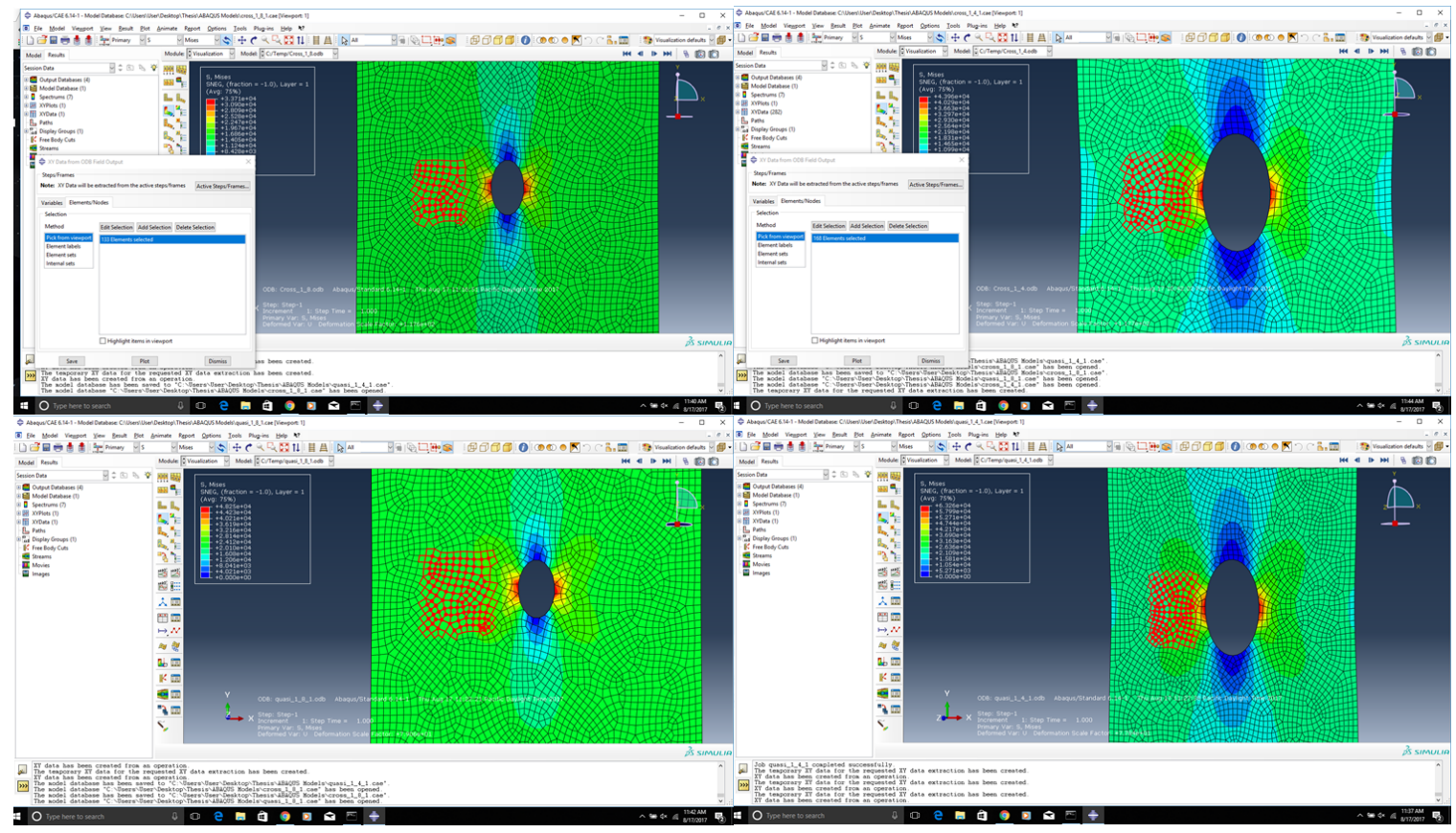

Figure 45 - Strain gauge areas were highlighted for average stresses and strains

Figure 46 shows the strain of each node highlighted, graphed as a function of time; Figure 47 shows the usage of the "combine" and "avg" functions used to plot the average of each node. 




Figure 46 - The strain (in/in) of highlighted nodes, as a function of time ( sec)



Figure 47 - Highlighted nodes selected to calculate average strain (in/in) using ABAQUS combine/avg functions 
As a result, one average curve is displayed, per Figure 48. These steps were repeated to determine the FEA Stress and FEA Strain values in Tables 14 and 15 in Section VII.

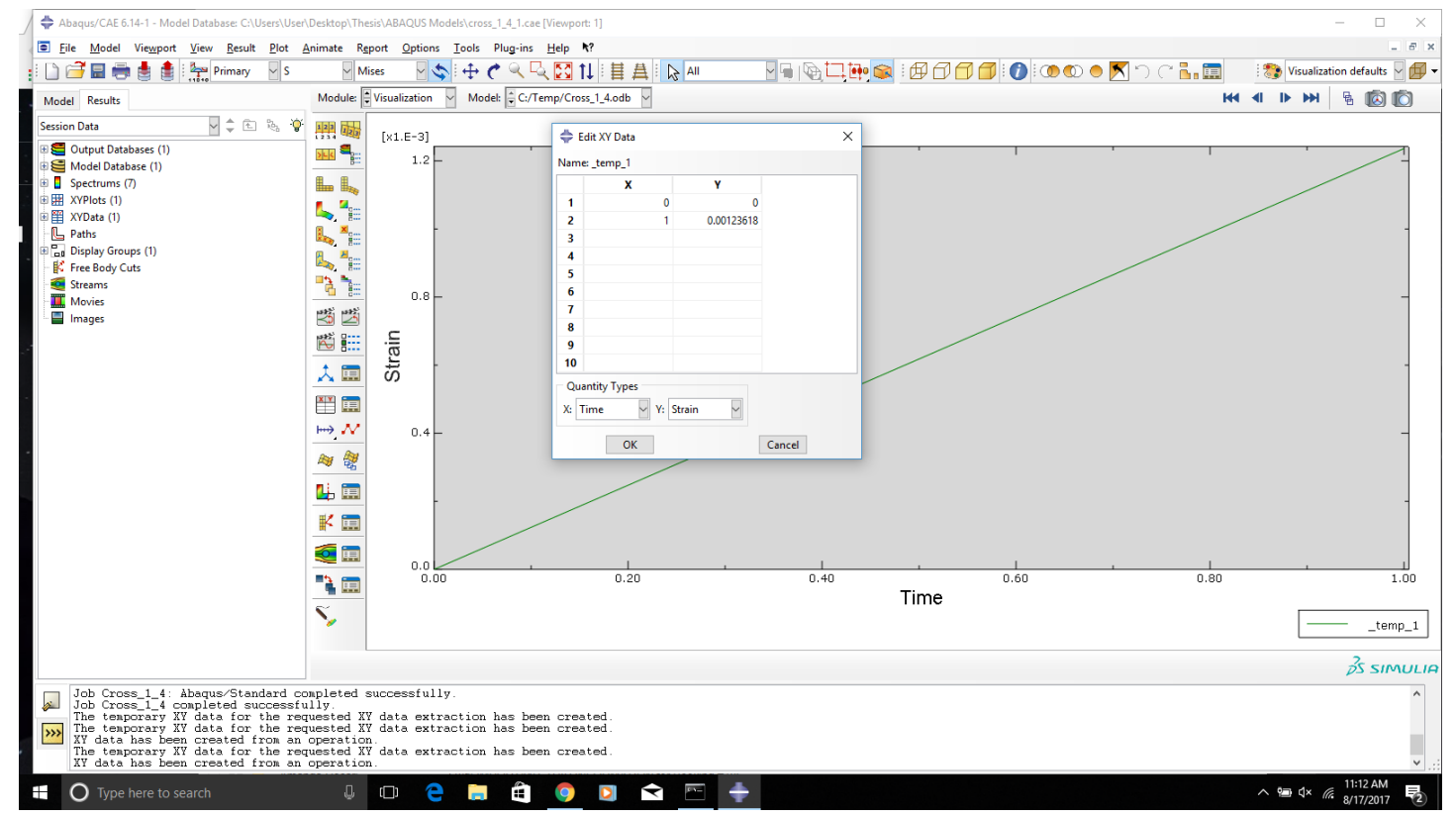

Figure 48 - Average strain (in/in) plotted as a function of time (sec) 
VII. Results Discussion

The following data represents the FEA to analytical, and FEA to tensile test results. It should be noted from the beginning that slippage was indeed an issue with several of the specimens during test, therefore, several of the runs were discarded from each set's averages. A point load of 10001 bf was studied for each case.

Cross $-p l y$

Figure 49 displays all cross-ply, 1/8" hole tensile test runs to failure. Tension orientation is along the length of the specimen (yaxis)



Figure 49 - Cross-ply, centered 1/8" hole, tensile test results at failure 
Reference Table 14 for the tensile test results for the cross-ply, centered 1/8" hole specimen at 1000 lbf point load. Run 2 was identified as anomalous and removed from the average. The analytical strain value was determined to be $0.00120 \mathrm{in} / \mathrm{in}, \mathrm{FEA}$ strain: $0.00117 \mathrm{in} / \mathrm{in}$

Table 14 - Cross-ply, centered 1/8" hole, tensile test results at $10001 \mathrm{bf}$

\begin{tabular}{lrrr} 
& $\begin{array}{c}\text { Point Stress } \\
\text { (psi) }\end{array}$ & $\begin{array}{l}\text { Point } \\
\text { Strain } \\
\text { (in/in) }\end{array}$ \\
$\operatorname{Run} 1$ & 8809 & 0.00122 \\
$\operatorname{Run} 2$ & 8810 & 0.00089 \\
$\operatorname{Run} 3$ & 8810 & 0.00110 \\
$\operatorname{Run} 4$ & 8802 & 0.00112 \\
$\operatorname{Run} 5$ & & 8801 & 0.00118 \\
\hline
\end{tabular}

Figure 50 compares FEA strain against the test and analytical strain at $10001 \mathrm{bf}$. The slightly steeper graph produced by the test results may be a product of a slight slip, however, at a minimum strain value of 0.0011 in/in (after discarding Run 2's 0.00089in/in), a tenthousandths of an inch deviation from predicted, this may be a resultant of tolerance stacks. Strain error rate of FEA to analytical: 3\%; strain error rate of FEA to test: $1 \%$ 


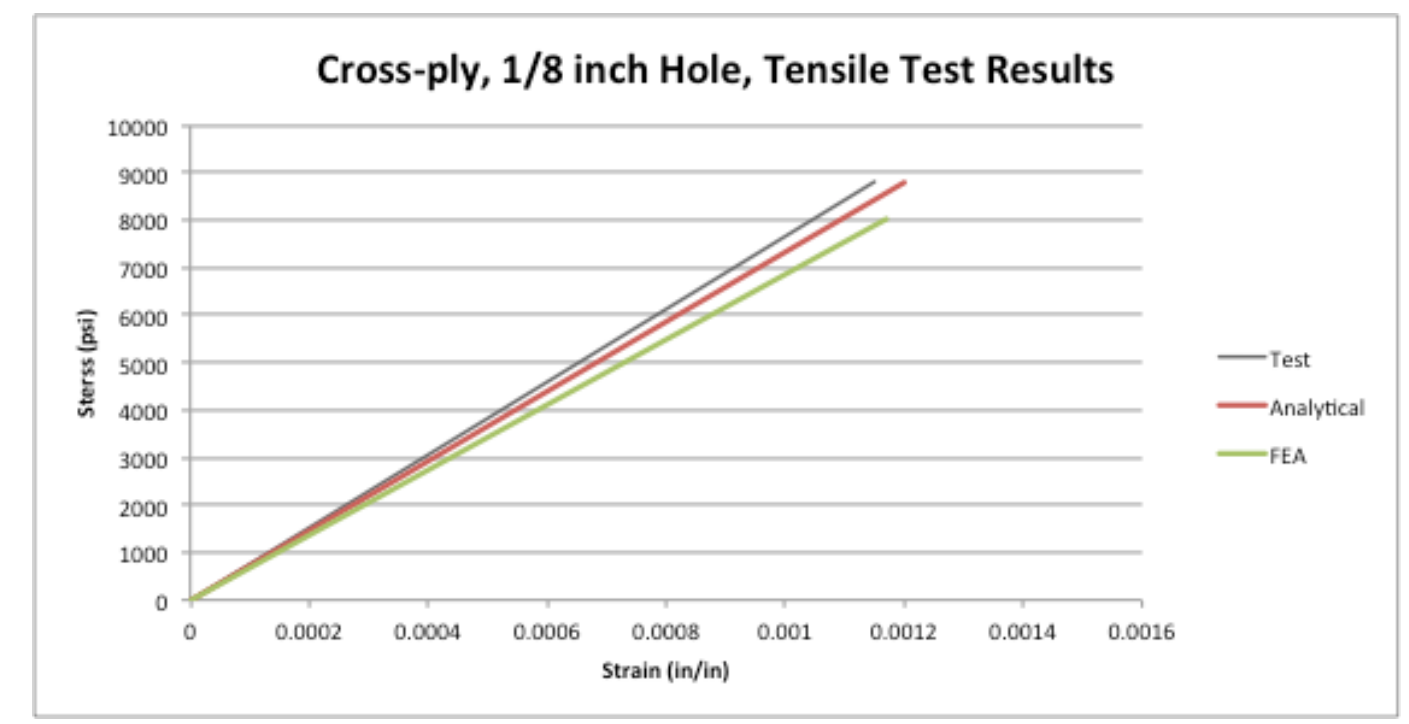

Figure 50 - Cross-ply, centered 1/8" hole, FEA compared with test and analytical at $1000 \mathrm{lbf}$

Figure 51 shows all cross-ply, centered $1 / 4 "$ hole tensile test runs to failure.

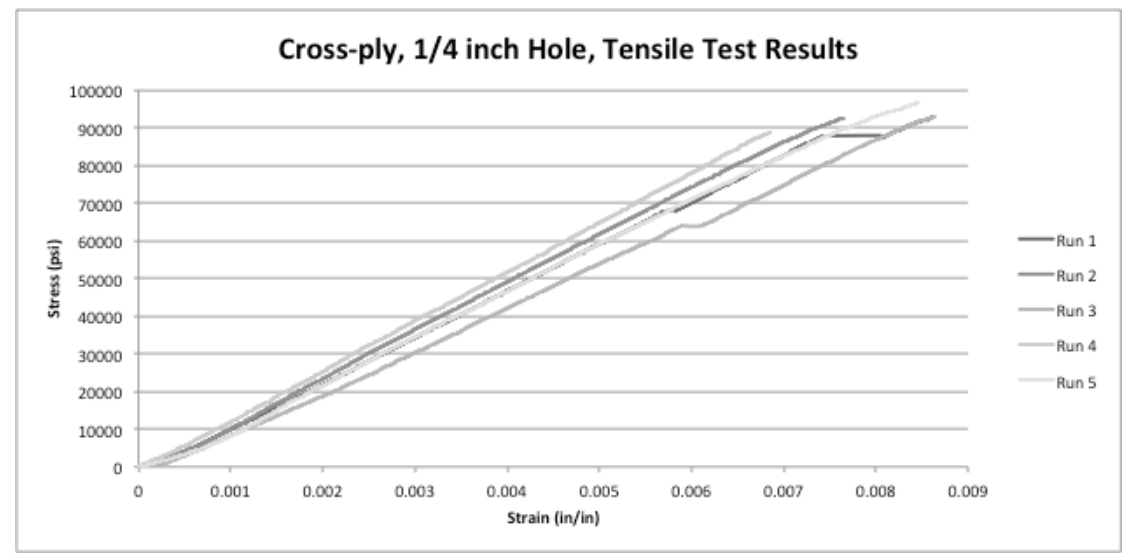

Figure 51 - Cross-ply, centered 1/4" hole, tensile test results to failure

Reference Table 15 for tensile test results at $10001 \mathrm{bf}$ point load for the cross-ply, centered 1/4" specimens under tensile loading. Runs 2 and 4 were removed from determining the average strain value for the $1 / 4$ " 
cross-ply. The analytical strain value was determined to be 0.0014 in/in, FEA strain: 0.00136 in/in.

Table 15 - Cross-ply, centered 1/4" hole, tensile test results at $10001 \mathrm{bf}$

\begin{tabular}{lrr} 
& $\begin{array}{c}\text { Point Stress } \\
\text { (psi) }\end{array}$ & $\begin{array}{l}\text { Point Strain } \\
\text { (in/in) }\end{array}$ \\
Run 1 & 10260 & 0.0013 \\
Run 2 & 10264 & 0.0012 \\
Run 3 & 10270 & 0.0015 \\
Run 4 & 10277 & 0.0012 \\
Run 5 & 10264 & 0.0014 \\
\hline \multicolumn{1}{l}{ AVERAGE } & & 0.0014
\end{tabular}

Figure 52 graphically delineates the differences of the expected analytical stress/strain curve with that of the average strain at 1000lbf. FEA to analytical strain error: 3\%; FEA to test strain error: $10 \%$. It's good to note here that the test-to-analytical error was also higher than the average at 9\%. This may be due to the natural variables introduced from performing a tensile test, such as strain gauge application methods and strain gauge/load cell tolerance stacks. 


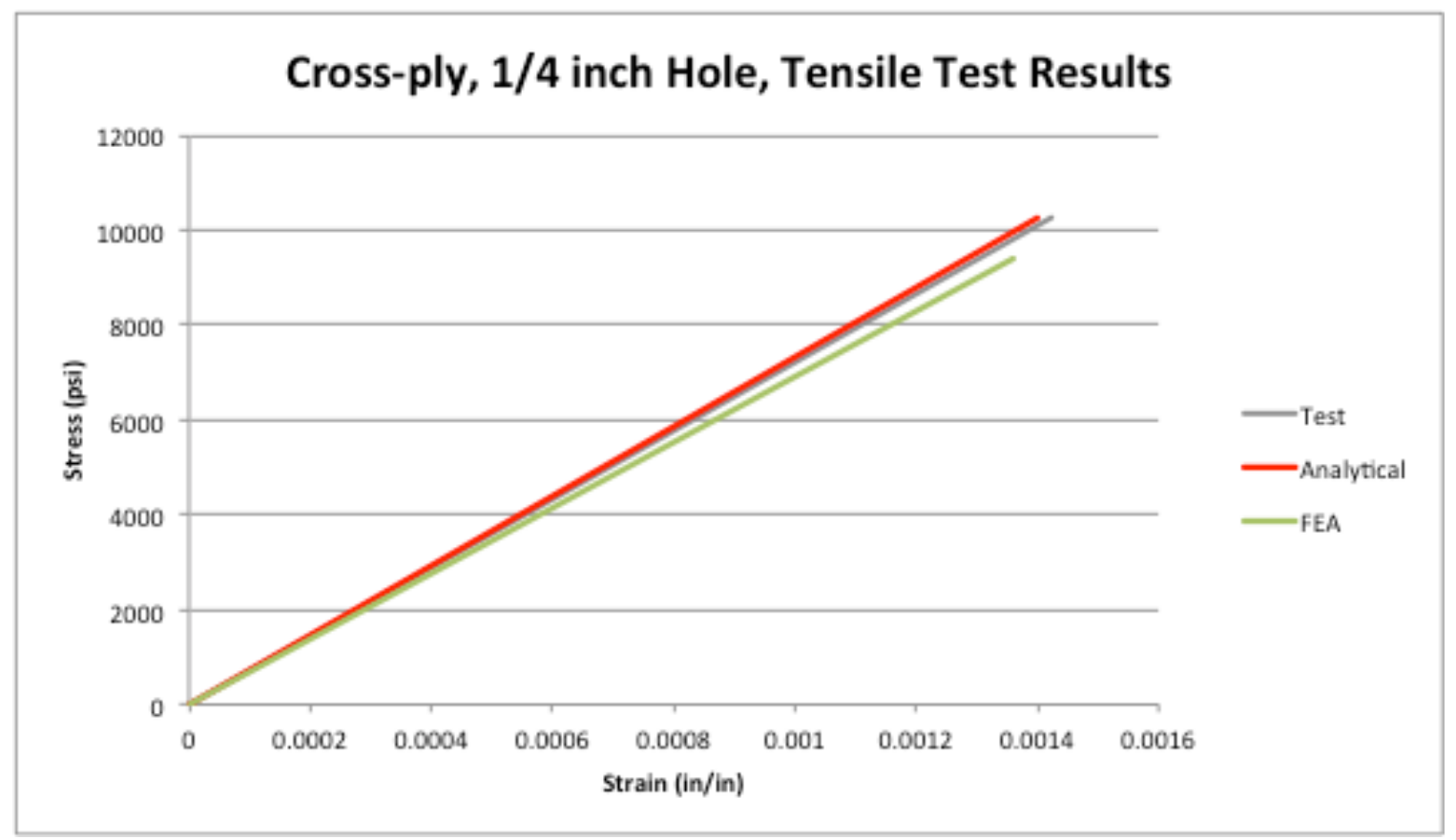

Figure 52 - Cross-ply, centered 1/4" hole, FEA compared with test and analytical at $10001 \mathrm{bf}$

Quasi-isotropic

Reference Figure 53 for tensile test results for the quasiisotropic, centered 1/8" hole specimen to failure.

It should be noted that two of the five quasi-isotropic specimens, Runs 2 and 4, behaved like a classical homogenous material, with a linear elastic region, a distinct yield point, and a sloping plastic region until fracture. The remaining three specimens resulted in less distinguished elastic-to-plastic transitions, but fractured within the expected range of strain.

Additional testing may be required to fully understand the differences in the exhibited stress/strain curves-it is most likely that the tab design/configuration, combined with the improper grips/tooling, contributed to slippage until the 70,000 psi range, causing the Instron to reduce its load rate from $0.05 \mathrm{in} / \mathrm{min}$. Due to this, one would have noticed 
minimal strain and growing stress until the $0.002 \mathrm{in} / \mathrm{in}$ range, where the Instron would have reduced its load rate, reducing the act of slipping, allowing the material to strain until failure.

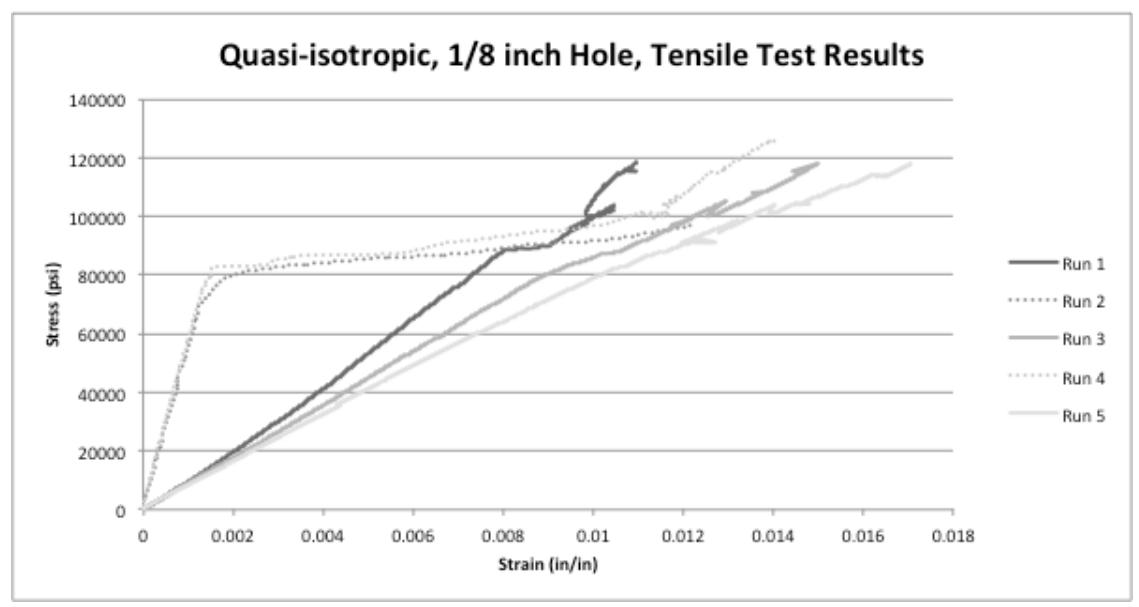

Figure 53 - Quasi-isotropic, centered 1/8" hole, tensile test results at failure

Table 16 delineates the tensile test results at $10001 b f$ point load. Runs 2 and 4 were removed from determining the average strain. The analytical strain was predicted to be 0.00170in/in, FEA strain: $0.00175 \mathrm{in} /$ in

Table 16 - Quasi-isotropic, centered 1/8" hole, tensile test results at $10001 \mathrm{bf}$

Point Stress Point Strain (psi) (in/in)

\begin{tabular}{ccc} 
Run 1 & 11675 & 0.0016 \\
Run 2 & 11669 & 0.0003 \\
Run 3 & 11668 & 0.0018 \\
Run 4 & 11670 & 0.0003 \\
Run 5 & 11662 & 0.0019 \\
\hline AVERAGE & & 0.0018
\end{tabular}


Figure 54 graphically delineates the differences of the expected analytical stress/strain curve with that of the quasi-isotropic 1/8" plate at $1000 \mathrm{lbf}$. The FEA to analytical strain error was calculated to be $3 \%$; FEA to test strain error was also calculated to be $3 \%$.



Figure 54 - Quasi-isotropic, centered 1/8" hole, FEA compared with test and analytical at $1000 \mathrm{lbf}$

Reference Figure 55 for tensile test results for the quasiisotropic, centered 1/4" hole specimen to failure. Similarly to the 1/8" hole set of quasi-isotropic specimens, the 1/4" set experienced a similar trend where three of the five runs exhibited a more distinguished yield point.

Again, it is assumed slippage had caused the Instron to reduce its load rate from $0.05 \mathrm{in} / \mathrm{min}$. Due to this, less strain was experienced than expected until reaching roughly $0.002 \mathrm{in} / \mathrm{in}$, until the Instron reduced its load rate, reducing the act of slipping, allowing the material to strain until failure. 


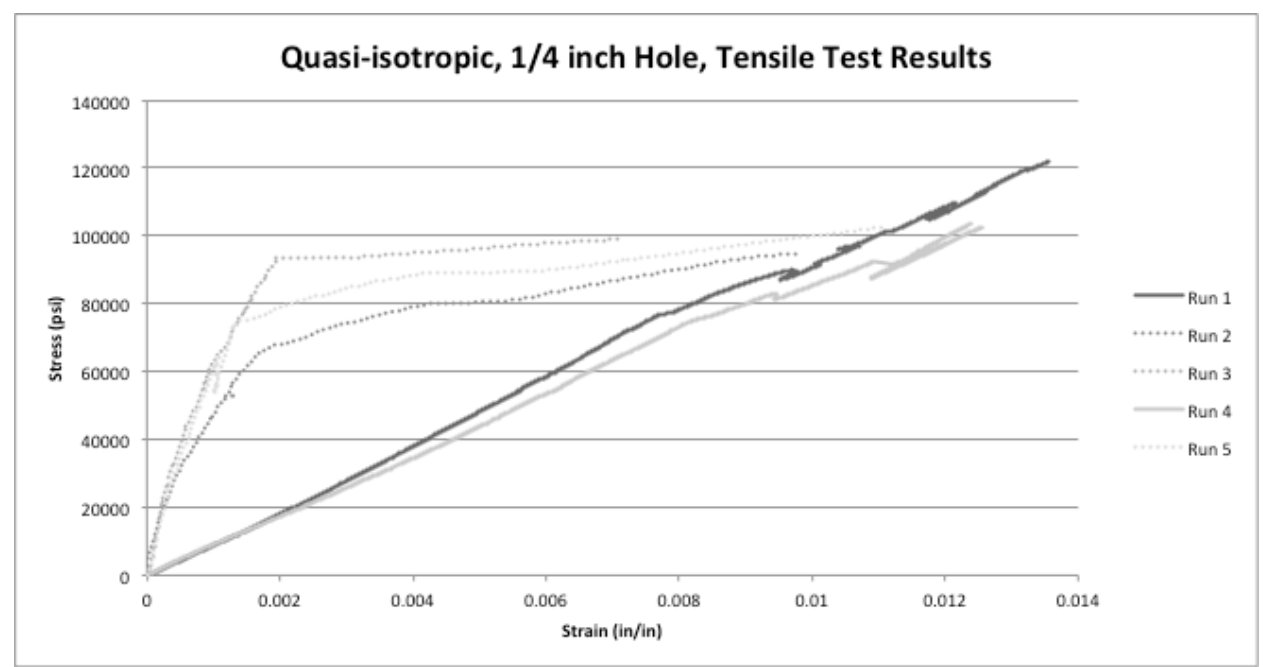

Figure 55 - Quasi-isotropic, centered 1/4" hole, tensile test results at failure

Table17 delineates the tensile test results at 1000 lbf point load. Runs 2, 3, and 5 were discarded.

Table 17 - Quasi-isotropic, centered 1/4" hole, tensile test results at $10001 \mathrm{bf}$

Point Stress Point Strain (psi) (in/in)

\begin{tabular}{lll} 
Run 1 & 13617 & 0.00203 \\
Run 2 & 13609 & 0.00022 \\
Run 3 & 13607 & 0.00020 \\
Run 4 & 13610 & 0.00212 \\
Run 5 & 13606 & 0.00025 \\
\hline
\end{tabular}

Figure 56 graphically delineates the differences of the expected analytical stress/strain curve at $10001 \mathrm{bf}$. With slippage apparent for Runs 2, 3, and 5, the resulting curve is an average of Runs 1 and 4, resulting in a $1 \% \mathrm{FEA}$ to analytical strain error and a $3 \% \mathrm{FEA}$ to test error. 


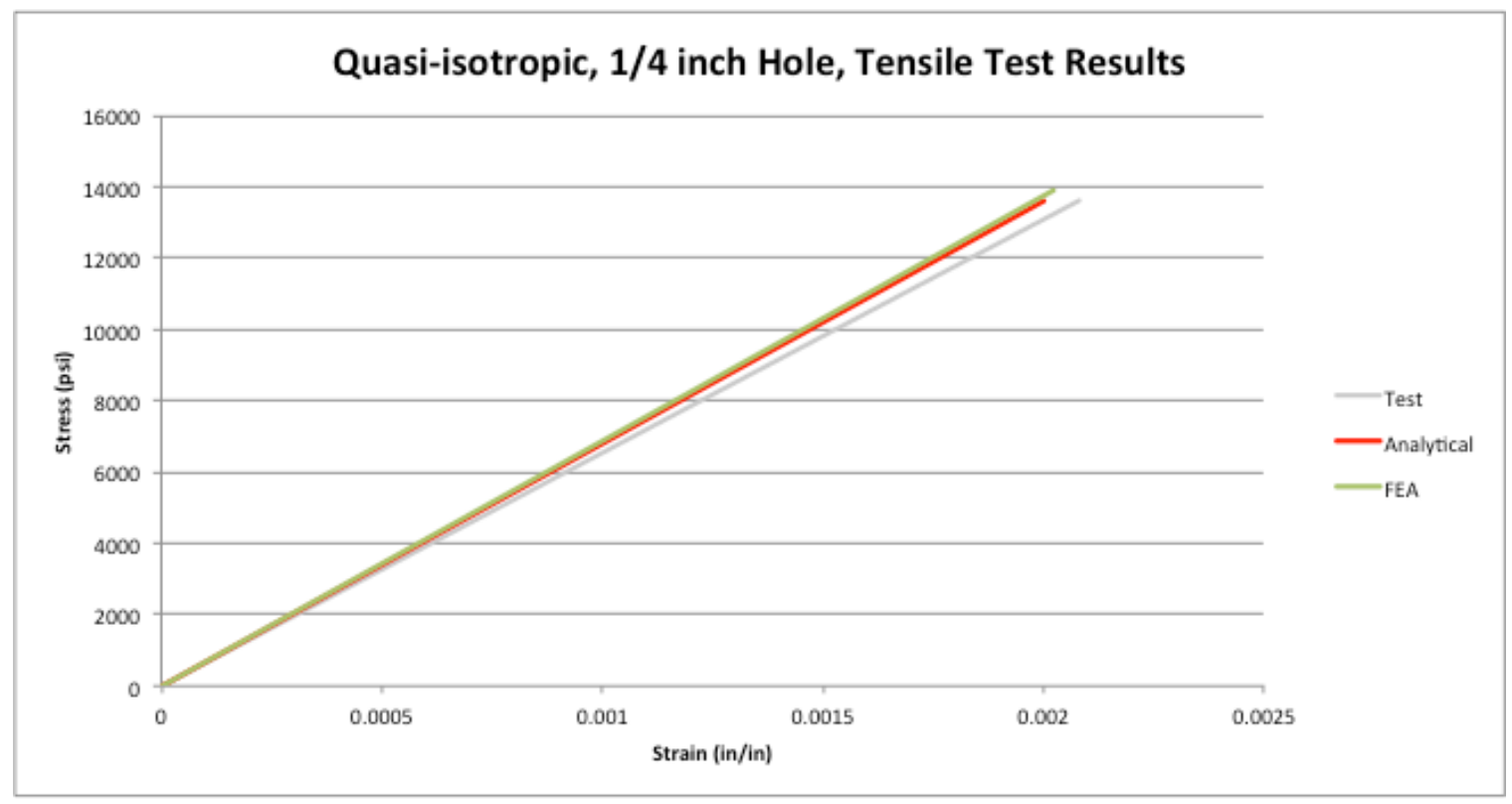

Figure 56 - Quasi-isotropic, Centered 1/4" hole, FEA compared with test and analytical at $1000 \mathrm{lbf}$

Figures 57 and 58 portray failure mode examples for the cross-ply and quasi-isotropic substrates, respectively. 


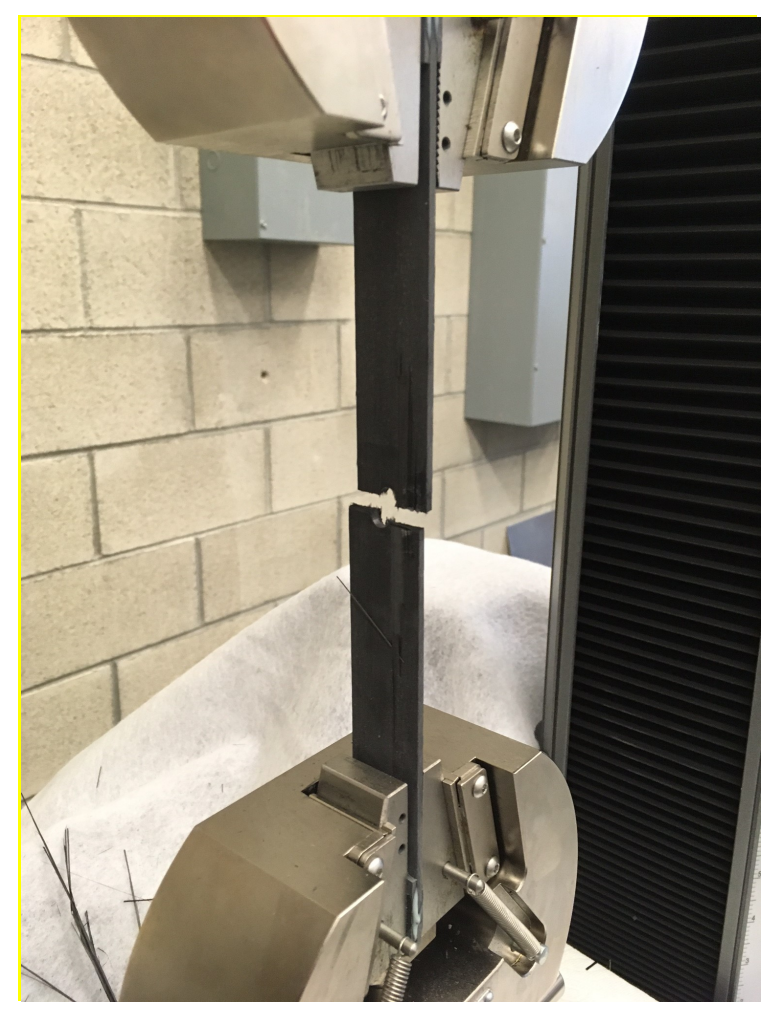

Figure 57 - Cross-ply failure mode example

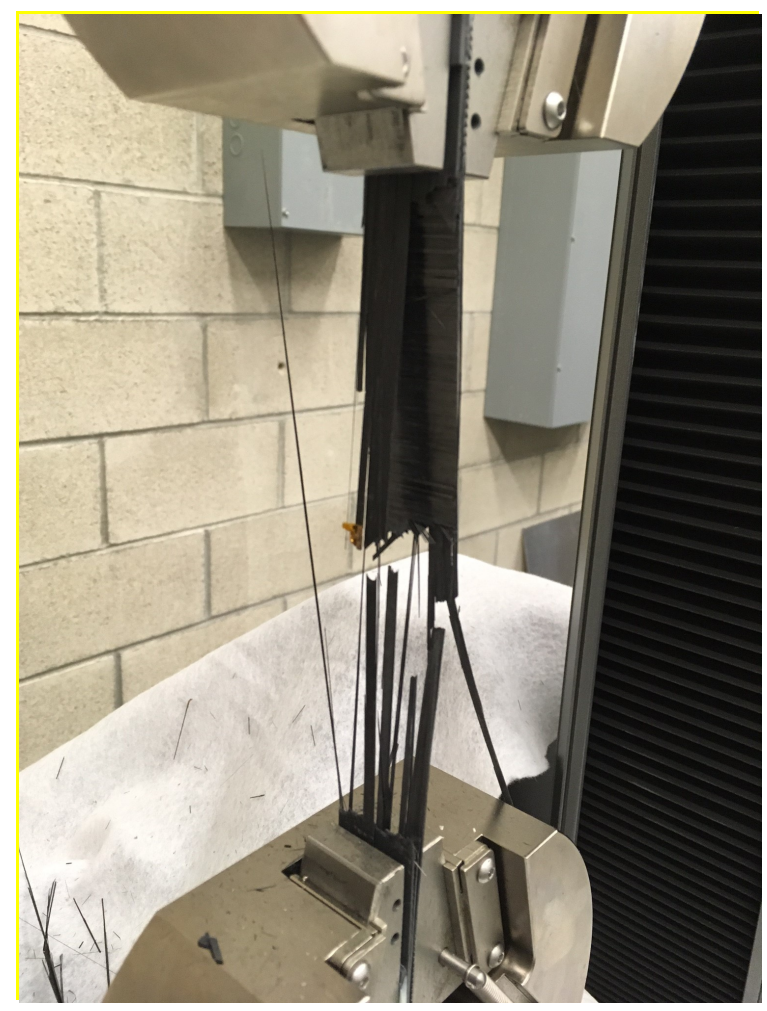

Figure 58 - Quasi-isotropic failure mode example 
For the purposes of this thesis, a global seed size of 0.020 , or on the order of magnitude of 30,000 nodes per substrate, was identified as the ideal number of nodes for analysis; "ideal" defined as the node count that provides the most accurate results in the most reasonable time, and importantly, completion of FEA. If the exhibited error rates in this thesis is deemed unacceptable, it is possible to revisit these analyses with a higher node count to try to reduce the error rates between FEA and analytical, or FEA and test.

Additionally, 0.020 may not be the ideal node count for specimens of different materials, different layups, geometries, hole configurations, imperfections, loading, boundary conditions, etc. As an example, for the homogenous baseline, a global seed size of 1 was analyzed, but only after an analysis time of 144 minutes at a global seed size of 0.020 , which still failed to produce a result. Perhaps an equation can be derived, that per given cross-sectional area, a certain order-ofmagnitude of global seed size should be used as a starting point; it would be prudent for the engineer to then toggle between several mesh configurations, prior to running the actual analysis, to understand what node count would be optimum for the structure at hand.

Figure 59 juxtaposes the strain results from the FEA, tensile tests, and the analytical calculations. Figure 60 juxtaposes the respective stress results. 


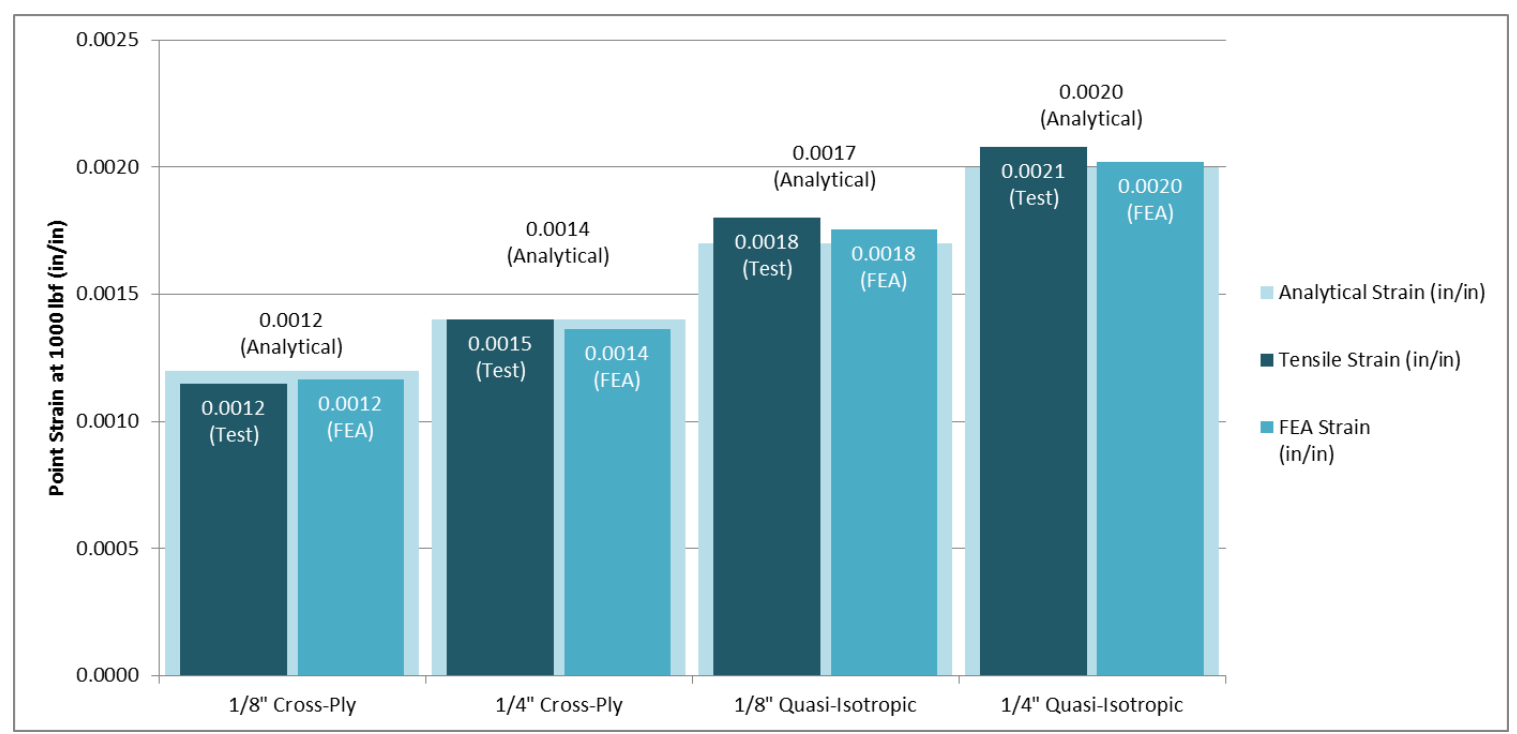

Figure 59 - Juxtaposition of analytical strain with tensile and FEA strain at $1000 \mathrm{lbf}$

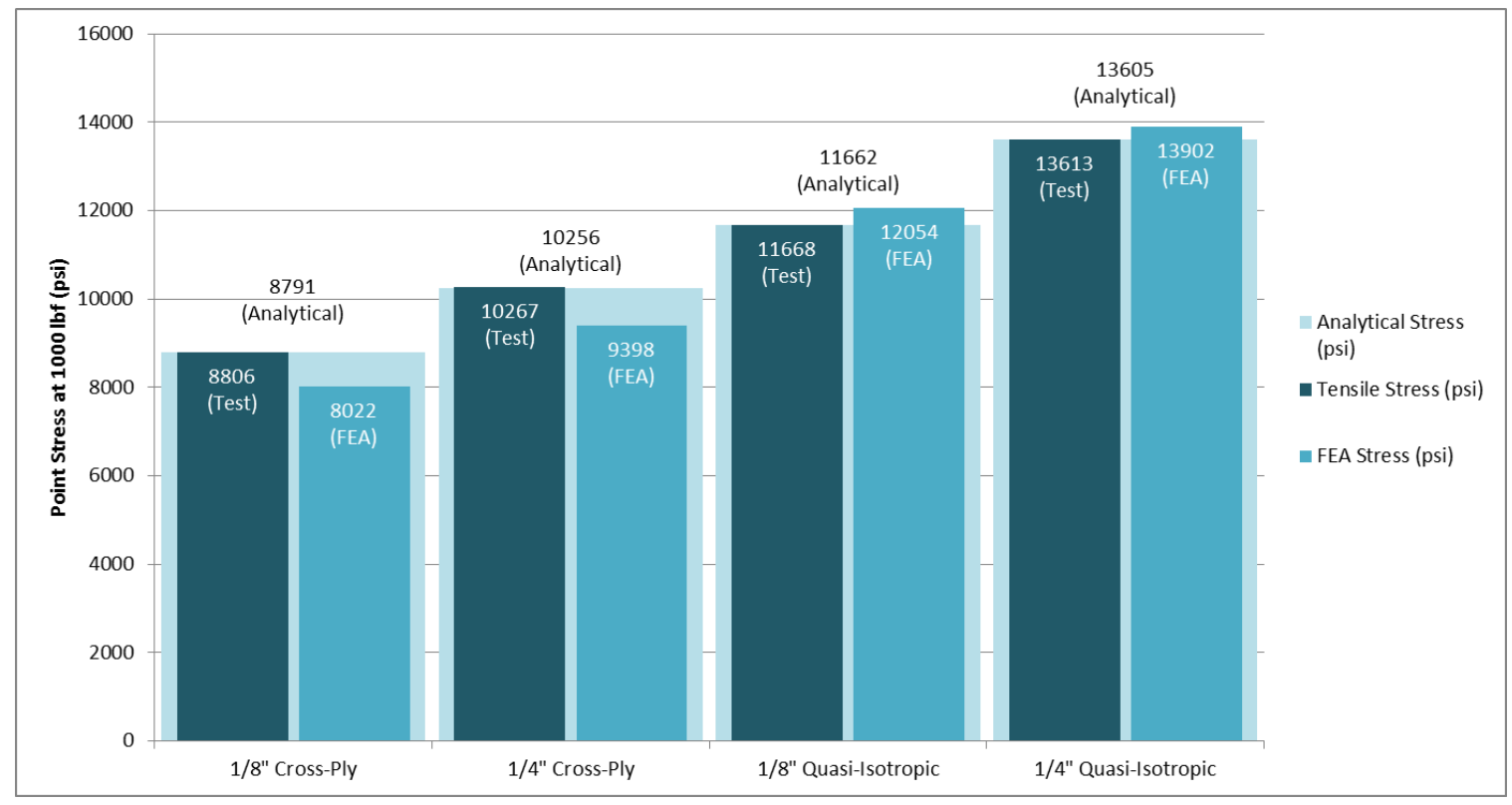

Figure 60 - Juxtaposition of analytical stress with tensile and FEA stress at $1000 \mathrm{lbf}$ 
With the known slippage issues throughout the tensile tests, discarding the known anomalous results helped align the tensile test results more closely with the predicted values from the analytical.

As previously mentioned, variability in the FEA results could be attributed to which nodes had been selected in determining the FEA average, however, both FEA stress and strain values trended closely with the predicted analytical values, averaging a $6 \%$ error in stress and a $2 \%$ error in strain. This would be expected given that stress and strain are correlated by E, therefore, one would expect their respective error ranges to be similar; reference Table 18 .

Table 18 - FEA results compared with analytical

\begin{tabular}{|c|c|c|c|c|c|c|}
\hline & $\begin{array}{l}\text { FEA } \\
\text { Stress } \\
\text { (psi) }\end{array}$ & $\begin{array}{l}\text { Analytical } \\
\text { Stress } \\
\text { (psi) }\end{array}$ & $\begin{array}{l}\text { Error } \\
(\%)\end{array}$ & $\begin{array}{l}\text { FEA } \\
\text { Strain } \\
(\text { in/in })\end{array}$ & $\begin{array}{l}\text { Analytical } \\
\text { Strain } \\
\text { (in/in) }\end{array}$ & $\begin{array}{l}\text { Error } \\
(\%)\end{array}$ \\
\hline 1/8" Cross-Ply & 8022 & 8791 & $10 \%$ & 0.0012 & 0.0012 & $3 \%$ \\
\hline 1/4" Cross-Ply & 9398 & 10256 & $9 \%$ & 0.0014 & 0.0014 & $3 \%$ \\
\hline $\begin{array}{l}\text { 1/8" Quasi- } \\
\text { Isotropic }\end{array}$ & 12054 & 11662 & $-3 \%$ & 0.0018 & 0.0017 & $-3 \%$ \\
\hline $\begin{array}{l}\text { 1/4" Quasi- } \\
\text { Isotropic }\end{array}$ & 13902 & 13605 & $-2 \%$ & 0.0020 & 0.0020 & $-1 \%$ \\
\hline
\end{tabular}


Table 19 delineates a FEA-to-tensile test comparison. The FEA-totensile test stresses experienced a 6\% error, and the FEA-to-adjusted tensile strains averaged an error of $4 \%$

Table 19 - FEA results compared with tensile test

\begin{tabular}{|c|c|c|c|c|c|c|}
\hline & $\begin{array}{l}\text { FEA Stress } \\
\text { (psi) }\end{array}$ & $\begin{array}{l}\text { Tensile } \\
\text { Stress } \\
\text { (psi) }\end{array}$ & $\begin{array}{l}\text { Error } \\
\left(\frac{\%}{0}\right)\end{array}$ & $\begin{array}{l}\text { FEA Strain } \\
\text { (in/in) }\end{array}$ & $\begin{array}{l}\text { Tensile } \\
\text { Strain } \\
\text { (in/in) }\end{array}$ & $\begin{array}{l}\text { Error } \\
(\%)\end{array}$ \\
\hline $\begin{array}{l}1 / 8 " \text { Cross- } \\
\text { Ply }\end{array}$ & 8022 & 8806 & $10 \%$ & 0.0012 & 0.0012 & $-1 \%$ \\
\hline $\begin{array}{l}1 / 4 " \text { Cross- } \\
\text { Ply }\end{array}$ & 9398 & 10267 & $9 \%$ & 0.0014 & 0.0015 & $10 \%$ \\
\hline $\begin{array}{l}\text { 1/8" Quasi- } \\
\text { Isotropic }\end{array}$ & 12054 & 11668 & $-3 \%$ & 0.0018 & 0.0018 & $3 \%$ \\
\hline $\begin{array}{l}\text { 1/4" Quasi- } \\
\text { Isotropic }\end{array}$ & 13902 & 13613 & $-2 \%$ & 0.0020 & 0.0021 & $3 \%$ \\
\hline
\end{tabular}

Table 20 delineates a tensile test-to-analytical comparison. The tensile test and analytical stresses were nearly identical at $0.10 \%$ error, and the adjusted tensile strains averaged an error of $6 \%$

For the discarded test runs: the larger strain errors were attributed to slipping, as at any given value of stress, the correlating strain values were consistently lower than expected. With a consistently lower strain value at a given stress, a higher slope, or E, results, which could potentially question the original set of material properties, however, with the peculiarity in how the responses trended, it is most probable that slippage was experienced with the cross and quasi substrates due to factors such as tab design/configuration and tooling grip errors. It is interesting to note, the analytical-to-tensile-test stress values were more closely aligned than the analytical-to-tensile test strain values. This could be very well due to the natural variables introduced when conducting a tensile test, from strain gauge application methods to tolerance stacks from load cells ( $5 \%$ error) and strain gauge 
readings $(\sim 5 \%)$; it would not be improbable these factors could have contributed to the ten-thousandths to hundred-thousandths of an inch differences.

Table 20 - Tensile results compared with analytical

\begin{tabular}{|l|r|r|r|r|r|r|}
\hline & $\begin{array}{l}\text { Analytical } \\
\text { Stress } \\
\text { (psi) }\end{array}$ & $\begin{array}{l}\text { Tensile } \\
\text { Stress } \\
\text { (psi) }\end{array}$ & $\begin{array}{l}\text { Error } \\
(\%)\end{array}$ & $\begin{array}{l}\text { Analytical } \\
\text { Strain } \\
\text { in/in) }\end{array}$ & $\begin{array}{l}\text { Tensile } \\
\text { Strain } \\
\text { (in/in) }\end{array}$ & $\begin{array}{l}\text { Error } \\
(\%)\end{array}$ \\
\hline $\begin{array}{l}1 / 8 " \text { Cross- } \\
\text { Ply }\end{array}$ & 8791 & 8806 & $0.17 \%$ & 0.0012 & 0.0012 & $-4 \%$ \\
\hline $\begin{array}{l}1 / 4 " \text { Cross- } \\
\text { Ply }\end{array}$ & 10256 & 10267 & $0.11 \%$ & 0.0014 & 0.0015 & $9 \%$ \\
\hline $\begin{array}{l}1 / 8 \text { " Quasi- } \\
\text { Isotropic }\end{array}$ & 11662 & 11668 & $0.05 \%$ & 0.0017 & 0.0018 & $6 \%$ \\
\hline $\begin{array}{l}1 / 4 " \text { Quasi- } \\
\text { Isotropic }\end{array}$ & 13605 & 13613 & $0.06 \%$ & 0.0020 & 0.0021 & $4 \%$ \\
\hline
\end{tabular}

As verification, another set of stress/strain values were analyzed at a point load of 3000lbf; Figure 61 compares the tensile test and FEA results with the analytical. The FEA-to-tensile strain averaged an error of 5\% and the FEA-to-analytical strain averaged an error of $1 \%$

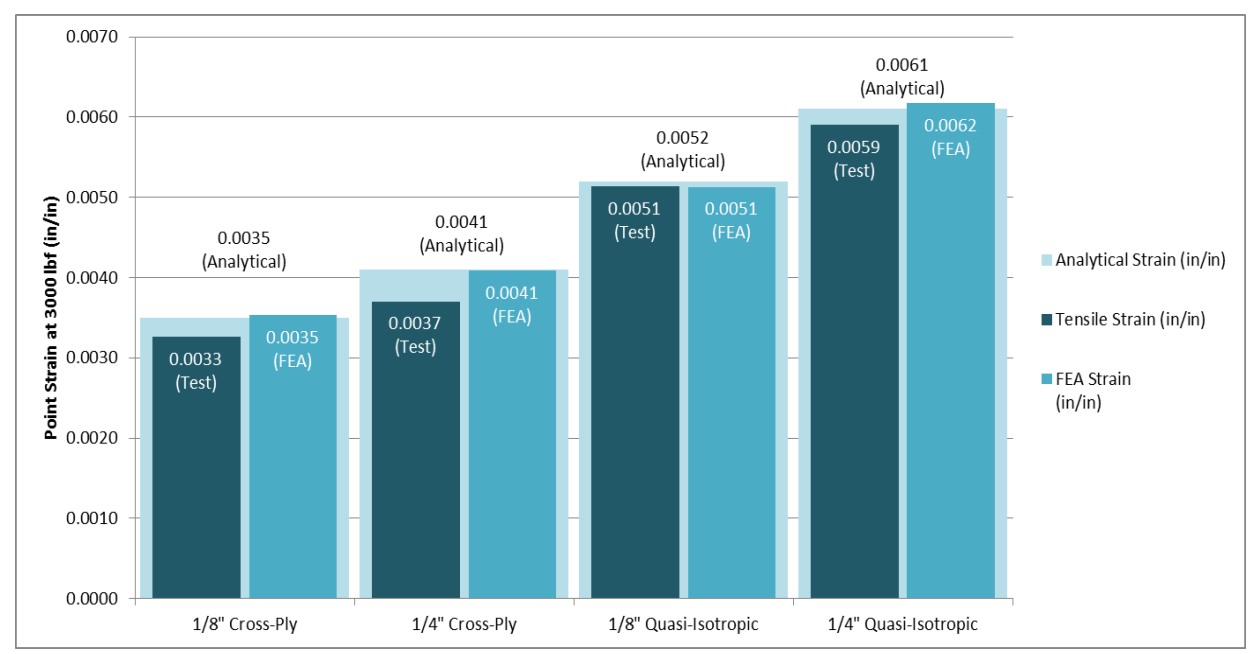

Figure 61 - Juxtaposition of analytical stain with tensile and FEA strain at $30001 \mathrm{bf}$ 
VIII. Closing Discussion

Conclusion

The objective of this thesis was to determine whether the advancements in numerical methods have progressed enough such that its results could be accurate enough to deem experimental testing redundant in validating structural design. Based on the conducted research, certain numerical methods, such as the shell element numerical approximations through ABAQUS, coupled with sufficient mesh designs, have historically shown strong correlations between numerical and experimental test results, as was validated through the results of this thesis.

Additionally, the investigation of variables to test design, such as varied ply orientations and hole configurations, further provided validation that error rates between numerical and experimental results remained unaffected, regardless of ply orientations or hole configurations. With FEA-to-analytical strains averaging an error of $2 \%$, FEA-to-tensile strains averaging an error of $4 \%$, and strain values accurate up to ten-thousandths and hundred-thousandths of an in/in, Table 21 further summarizes the average FEA-to-analytical and average FEA-toaverage-tensile-test strain values at $1000 \mathrm{lbf}$ point load; Table 22 summarizes the correlating stress values, showing a $6 \%$ error for both FEA-to-analytical and FEA-to-experimental test results. With design margins and factors of safety incorporated into every design as an industry standard, the acceptability of these error rates could depend on how those margins are already being leveraged in the design, particularly for mission critical components, though margins are generally sufficient to be able to cover the error rates in analysis.

Additionally, it has been observed through this thesis that a denser, more intricate mesh design could provide a greater level of accuracy for numerical solutions, which proves the notion that if lower 
error rates were necessitated, continued research with a more powerful processor should be able to provide the granularity and accuracy in output that would further minimize error rates between FEA and experimental and FEA and analytical results.

Table 21 - FEA-to-analytical and FEA-to-tensile test strain, with correlating error rates

\begin{tabular}{|l|r|r|r|r|r|}
\hline & $\begin{array}{l}\text { FEA Strain } \\
\text { (in/in) }\end{array}$ & $\begin{array}{l}\text { Analytical } \\
\text { Strain } \\
\text { (in/in) }\end{array}$ & $\begin{array}{l}\text { Error } \\
(\%)\end{array}$ & $\begin{array}{l}\text { Tensile } \\
\text { Strain } \\
\text { (in/in) }\end{array}$ & \multicolumn{1}{|l|}{$\begin{array}{l}\text { Error } \\
(\%)\end{array}$} \\
\hline $\begin{array}{l}1 / 8 " \text { Cross- } \\
\text { Ply }\end{array}$ & 0.0012 & 0.0012 & $-3 \%$ & 0.0012 & $1 \%$ \\
\hline $\begin{array}{l}1 / 4 " \text { Cross- } \\
\text { Ply }\end{array}$ & 0.0014 & 0.0014 & $-2 \%$ & 0.0015 & $-9 \%$ \\
\hline $\begin{array}{l}1 / 8 " \text { Quasi- } \\
\text { Isotropic }\end{array}$ & 0.0018 & 0.0017 & $3 \%$ & 0.0018 & $-3 \%$ \\
\hline $\begin{array}{l}\text { 1/4" Quasi- } \\
\text { Isotropic }\end{array}$ & 0.0020 & 0.0020 & $1 \%$ & 0.0021 & $-3 \%$ \\
\hline
\end{tabular}

Table 22 - FEA-to-analytical and FEA-to-tensile test stress, with correlating error rates

\begin{tabular}{|c|c|c|c|c|c|}
\hline & $\begin{array}{l}\text { FEA } \\
\text { Stress } \\
\text { (psi) }\end{array}$ & $\begin{array}{l}\text { Analytical } \\
\text { Stress (psi) }\end{array}$ & $\begin{array}{l}\text { Error } \\
(\%)\end{array}$ & $\begin{array}{l}\text { Tensile } \\
\text { Stress } \\
\text { (psi) }\end{array}$ & $\begin{array}{l}\text { Error } \\
(\%)\end{array}$ \\
\hline $\begin{array}{l}\text { 1/8" Cross- } \\
\mathrm{Ply}\end{array}$ & 8022 & 8791 & $-9 \%$ & 8806 & $-9 \%$ \\
\hline $\begin{array}{l}1 / 4 " \text { Cross- } \\
\mathrm{Ply}\end{array}$ & 9398 & 10256 & $-8 \%$ & 10267 & $-8 \%$ \\
\hline $\begin{array}{l}\text { 1/8" Quasi- } \\
\text { Isotropic }\end{array}$ & 12054 & 11662 & $3 \%$ & 11668 & $3 \%$ \\
\hline $\begin{array}{l}\text { 1/4" Quasi- } \\
\text { Isotropic }\end{array}$ & 13902 & 13605 & $2 \%$ & 13613 & $2 \%$ \\
\hline
\end{tabular}

The lessons-learned from the conducted research were successfully folded into the design and approach of this thesis: a point load was examined (1000lbf and 3000lbf) by combining the shell element model approach through ABAQUS, as discussed in Wang's research, with the ply- 
stack sequence study from Hallett's and Haque's research, resulting in numerical results with error rates under $10 \%$.

Compared to Wang's $1.5 \%$ error in peak stress prediction between FEA and test, the results of this thesis's error for stress at a $10001 b f$ point load was calculated to be $3 \%$. However, with the sensitivity analysis conducted in this thesis to study how mesh densities affect stress/strain results, it can be concluded with full confidence that this $3 \%$ error could be minimized with a greater node count.

In comparison to Hallett's experiment, utilizing the shell element model through ABAQUS as discussed in Wang's study, proved to be a much more accurate numerical method as predicted: a $10 \%$ error from Hallett's study compared to a $6 \%$ error in stress for this thesis. Bringing Haque's study into the fold, the $6 \%$ error rate from this thesis was a vast improvement from the 29\% error from Haque's, which also provided an insight different from Haque's conclusion: lay-up sequences are, indeed, significant, and notch configurations do, indeed, have an effect on local stresses-and subsequently, stress concentrations, even at smaller hole sizes (hole-diameter-to-specimen width ratios: 0.2-0.3, as quoted by Haque's study) .

Although a sub-6\% error rate across all experiments conducted in this thesis can be seen as a success, the following section identifies some adjustments that could be made to further investigate the nuances of composite behavior and properties, while minimizing error rates.

Future Work

Future work could involve an FEA, analytical, and tensile test study focused specifically on stress concentrations based on growing hole sizes (diameter-to-width ratios ranging from 0.05 to 0.5 ), utilizing several types of pre-preg, and maintaining the varied ply sequences, at a node count per specimen on the order of magnitude of 100,000 s of nodes; this 
would essentially combine Wang's, Hallett's, and Haque's studies with the thesis conducted here, at a higher granularity in FEA. This should provide a tighter correlation between FEA, test, and analytical, resulting in error rates more consistently within the $1.5 \%$ seen in Wang's research. Furthermore, other load types, such as compression and bending, may also provide further insight into how these materials behave under loading, thus furthering the discussion of whether testing could one day be completely replaced by numerical analysis for validating structural design .

Finally, some of the higher error-rate case studies presented in the Previous Works section of this thesis could be recreated using analytical and numerical models that are known to have more accurate predictions, such as CLPT and the shell element numerical approximation method. 


\section{Bibliography}

3M. (2017). 3M Scotch-Weld Epoxy Adhesives DP460 Off-White and DP460NS. St. Paul, MN: 3M Industrial Adhesives and Tapes Division. Retrieved from:

http: //multimedia.3m.com/mws/media/661220/3mtm-scotch-weld-tmepoxy-adhesive-dp460-ns-and-off-white.pdf

Abisset, E., Daghia, F., Ladeveze, P. (2011). On the Validation of a Damage Mesomodel for Laminated Composites by Means of Open-hole Tensile Tests on Quasi-isotropic Laminates. Elsevier Composites: Part A, Applied Science and Manufacturing, 42, 15151524 .

Achard, V., Bouvet, C., Castanie, B. (2014). Discrete Ply Modeling of Open Hole Tensile Tests. Elsevier - Composites: Part A, Applied Science and Manufacturing, 113, 369-381.

Arslan, H.M., Kaltakci, M.Y., Yerli, H.R. (2009). Effect of Circular Holes on Cross-ply Laminated Composite Plates. The Arabian Journal for Science and Engineering, Vol 34, Number 2B.

ASTM. (2014). Standard Test Method for Tensile Properties of Polymer Matrix Composite Materials. ASTM: D3039/D3039M-14, pg. 6 . Retrieved from: https: //subscriptions-techstreetcom.ezproxy.lib.calpoly.edu/products/667211

Atas, A., Arslan, N., Sen, F. (2008). Failure Analysis of Laminated Composite Plates with Two Parallel Pin-Loaded Holes. Journal of Reinforced Plastics and Composites.

Chen, B.Y., Tay, T.E., Baiz, P.M. (2013). Numerical Analysis of Size Effects on Open-Hole Tensile Composite Laminates. Elsevier Composites: Part A, Applied Science and Manufacturing, 47, 52-62.

Dan-Jumbo, E., Keller, R., Chan, W.S. (2009). Strength of Composite Laminate with Multiple Holes. University of Texas at Arlington \& The Boeing Company.

Ercin, G.H., Camanho, P.P., Xavier, J. (2013). Size Effects on the Tensile and Compressive Failure of Notched Composite Laminates. Elsevier - Composites: Part A, Applied Science and Manufacturing, $96,736-744$.

Falco, O., Mayugo, J.A., Lopes, C.S. (2014). Variable-stiffness Composite Panels: Defect Tolerance Under In-plane Tensile Loading. Elsevier - Composites: Part A, Applied Science and Manufacturing, 63, 21-31.

Gan, K.W., Wisnom, M.R., Hallett, S.R. (2013). Effect of High ThroughThickness Compressive Stress on Fibre Direction Tensile Strength of Carbon/Epoxy Composite Laminates. Elsevier - Composites Science and Technology, 90, 1-8.

Hallett, S.R., Green, B.G., Giang, W.G. (2009). The Open Hole Tensile Test: A Challenge for Virtual Testing of Composites. Int $J$ AdV Manuf Techol, 158: 169-181. 
Hallett, S.R., Jiang, W.G., Wisnom, M.R. (2007). The Effect of Stacking Sequence on Thickness Scaling of Tests on Open Hole Tensile Composite Specimens. 48th AIAA/ASME/ASCE/AHS/ASC Structures, Structural Dynamics, and Materials Conference, 23-26 April 2007, Honolulu, Hawaii.

Haque, A., Ahmed, L., Ramasetty, A. (2005). Stress Concentrations and Notch Sensitivity in Woven Ceramic Matrix Composites Containing a Circular Hole-An Experimental, Analytical, and Finite Element Study. Journal of the American Ceramic Society, Vol. 88, No. 8.

Hatta, H., Denk, L., Watanabe, T. (2004). Fracture Behavior of CarbonCarbon Composites with Cross-ply Lamination. Journal of Composite Materials, Vol. 38, No. 17/2004.

Henderson, James. VHR. (29 July 2014). Electron is the World's First Carbon-Composite Launch Vehicle. Retrieved from: http://v-hr.com/news/news/electron-is-the-world-first-carboncomposite-launch-vehicle-a-mere-5-million-to-deliver-a-satelliteinto-orbit-withrocket-lab/

Hermann, T.M., Locke, J.E. (2005). Failure Analysis of Anisotropic Composites Utilizing Commercial FEA Software. 43rd AIAA Aerospace Sciences Meeting and Exhibit, 10-13 January 2005, Reno, Nevada.

Hu, F.z., Soutis, C., Edge, E.C. (2007). Interlaminar Stresses in Composite Laminates with a Circular Hole. Elsevier - Composites: Part A, Applied Science and Manufacturing, 37, 223-232.

Faridmehr, I., Hanim Osman, M. (2014). Correlation Between Engineering Stress-Strain and True Stress-Strain. American Journal of Civil Engineering and Architecture, Vol. 2, No. 1, pages 53-59. http: / /www.academia.edu/11249427/Correlation_between_Engineering_ Stress-Strain_and_True_Stress-Strain_Curve

Iarve, E.V., Mollenhauer, D., Kim, R. (2005). Theoretical and Experimental Investigation of Stress Redistribution in Open Hole Composite Laminates Due to Damage Accumulation. Elsevier Composites: Part A, Applied Science and Manufacturing, 36, 163171 .

Ko, William L. (1985). Stress Concentration Around a Small Circular Hole in the HimAT Composite Plate. Edwards, CA: Ames Research Center, Dryden Flight Research Facility. Retrieved from: https : / /www.nasa.gov/centers/dryden/pdf/88004main_H-1235.pdf

Lin, S.C., Chen, I.K. (1996). Drilling Carbon Fiber-Reinforced Composite Material at High Speed. Retrieved from:

https://www.researchgate.net/publication/223169102_Drilling_Carbo n_Fiber-reinforced_Composite_Material_at_High_Speed

Liu, G., Tang, K. (2015). Study on Stress Concentration in Notched Cross-ply Laminates Under Tensile Loading. Journal of Composite Materials, Vol. 50(3), 283-296.

Mechanical Engineering. University of Washington: College of Engineering Retrieved from:

http: //courses.washington.edu/mengr450/CLT_Summary.pdf 
Morais, A.B. (2000). Open-Hole Tensile Strength of Quasi-Isotropic Laminates. Elsevier - Composites Science and Technology, 60, 1997-2004.

Moure, M.M., Otero, F., Garcia-Castillo, S.K. (2015). Damage Evolution in Open-Hole Laminated Composite Plates Subjected to In-plane Loads. Elsevier - Composites: Part A, Applied Science and Manufacturing, 133, 1048-1057.

Palucka, T., Bensaude-Vincent, B. (19 October 2002). Composites Overview. Retrieved from: http: //authors.library.caltech.edu/5456/1/hrst.mit.edu/hrs/materi als/public/composites/Composites_Overview.htm

Pierron, F., Green, B., Wisnom, M.R. (2007). Full-field Assessment of the Damage Process of Laminated Composite Open-Hole Tensile Specimens. Elsevier - Composites: Part A, Applied Science and Manufacturing, 38, 2307-2320.

Pilkey, W.D., Pilkey, D.F. (2008). Peterson's Stress Concentration Factors, 3rd Edition. Wiley.

Rahmani H., Najafi, S.H.M., Saffarzadeh-Matin, S. (2013). Mechanical Properties of Carbon Fiber/Epoxy Composites: Effects of Number of Plies, Fiber Contents, and Angle-ply Layers. Polymer Engineering and Science - 2014.

Roylance, D. (2000). Constitutive Equations. Department of Materials Science and Engineering: MIT. Retrieved from: http://web.mit.edu/course/3/3.11/www/modules/const.pdf

Sakai, K., Nassar, S. (2016). Failure Analysis of Composite-Based Lightweight Multimaterial Joints in Tensile-Shear Tests After Cyclic Heat at High-Relative Humidity. Journal of Manufacturing Science and Engineering, April 2017, Vol. 139.

Sharma, D.S., Ukadgaonker, V.G. (2008). Stress Intensity Factors for Cracks Emenating from a Circular Hole in Laminated Composite Infinite Plate Under Different Loading Conditions. First International Conference on Emerging Trends in Engineering and Technology, Pg. 781-786.

Shokrieh, M.M., Ghasemi, A.R. (2006). Simulation of Central Hole Drilling Process for Measurement of Residual Stresses in Isotropic, Orthotropic, and Laminated Composite Plates. Journal of Composite Materials, Vol. 41, No. 4/2007.

Singh, I., Bhatnagar, N. (2005). Drilling-induced Damage in UniDirectional Glass Fiber Reinforced Plastic (UD-GFRP) Composite Laminates. Int $J$ Adv Manuf Techol, 27: 877-882.

Staab, George. (1999). Laminar Composites, Ch. 6. ButterworthHeinemann. 
Wang, J., Callus, P.J. (2003). Experimental and Numerical Investigation of the Tension and Compression Strength of Un-Notched and Notched Quasi-isotropic Laminates. Elsevier: Composite Structures.

Retrieved from: http://www.sciencedirection.com

Watanabe, S., Shindo, Y., Takeda, T. (2011). Evaluation of Tensile Strength of Woven Carbon/Epoxy Composite Laminates at Cryogenic Temperatures Using the Open Hole Specimens. Journal of Testing and Evaluation, Vol. 39, No. 4.

West System. (2014). Six10 Epoxy Adhesive. Bay City, MI: Gougeon Brothers, Inc. Retrieved from: http://www.westsystem.com/wpcontent/uploads/Six10-1.pdf

Xu, W., Thorsson, S., Waas, A. (2015). Experimental and Numerical study on Cross-ply Woven Textile Composite with Notches and Cracks. Elsevier - Composites: Part A, Applied Science and Manufacturing, $132,816-824$.

Yn, X., Ding, S., Tong, J.W. (2009). Numerical Elastic-Plastic Simulation of Interlaminar Stresses in a Notched Angle-ply Thermoplastic Composite Laminate. Mechanics of Composite Materials, Vol. 45, No. 3.

Young, W., Budynas, R. (2001). Roark's Formulas for Stress and Strain, 7th Edition, Ch. 5, 6, 7, 11, 17, Appendix C. McGraw-Hill Professional.

Zhen, W., Chen, W. (2009). Stress Analysis of Laminated Composite Plates with a Circular Hole According to a Single-layer Higherorder Model. Elsevier - Composites: Part A, Applied Science and Manufacturing, 90, 122-129. 
Appendix

Classical Laminated Plate Theory Equations

$$
\begin{aligned}
& \boldsymbol{Q}_{i j}=\left[\begin{array}{ccc}
Q_{11} & Q_{12} & 0 \\
Q_{12} & Q_{22} & 0 \\
0 & 0 & Q_{66}
\end{array}\right] \\
& Q_{11}=\frac{E_{11}^{2}}{\left(E_{11}-v_{12} \cdot E_{22}\right)} \\
& Q_{12}=\frac{v_{12} E_{11} E_{22}}{E_{11}-v_{12}^{2} E_{22}} \\
& Q_{22}=\frac{E_{11} E_{22}}{E_{11}-v_{12}^{2} E_{22}} \\
& Q_{66}=G_{12} \\
& \overline{Q_{11}}=Q_{11} \cos (\theta)^{4}+2\left(Q_{12}+2 Q_{66}\right) \cos (\theta)^{2} \cdot \sin (\theta)^{2}+Q_{22} \sin (\theta)^{4}{ }_{\text {(Eq . 6) }} \\
& \overline{Q_{12}}=\overline{Q_{21}}=Q_{12}\left(\cos (\theta)^{4}+\sin (\theta)^{4}\right)+\left(Q_{11}+Q_{22}-4 Q_{66}\right) \cos (\theta)^{2} \sin (\theta)^{2} \quad \text { (Eq. 7) } \\
& \overline{Q_{16}}=\overline{Q_{61}}=\left(Q_{11}-Q_{12}-2 Q_{66}\right) \cos (\theta)^{3} \sin (\theta)-\left(Q_{22}-Q_{12}-2 Q_{66}\right) \cos (\theta) \sin (\theta)^{3} \\
& \text { (Eq. 8) } \\
& \overline{Q_{22}}=Q_{11} \sin (\theta)^{4}+2\left(Q_{12}+2 Q_{66}\right) \cos (\theta)^{2} \sin (\theta)^{2}+Q_{22} \cos (\theta)^{4} \text { (Eq. 9) } \\
& \overline{Q_{26}}=\overline{Q_{62}}=\left(Q_{11}-Q_{12}-2 Q_{66}\right) \cos (\theta) \sin (\theta)^{3}-\left(Q_{22}-Q_{12}-2 Q_{66}\right) \cos (\theta)^{3} \sin (\theta) \\
& \text { (Eq. } 10) \\
& \overline{Q_{66}}=\left(Q_{11}+Q_{22}-2 Q_{12}-2 Q_{66}\right) \cos (\theta)^{2} \sin (\theta)^{2}+Q_{66}\left(\cos (\theta)^{4}+\sin (\theta)^{4}\right) \\
& \overline{\boldsymbol{Q}_{i j}}=\begin{array}{lll}
\overline{Q_{11}} & \overline{Q_{12}} & \overline{Q_{16}} \\
\overline{Q_{16}} & \overline{Q_{22}} & \overline{Q_{26}} \\
\overline{Q_{26}} & \overline{Q_{66}}
\end{array}
\end{aligned}
$$

(Eq. 12) 
Step 1: Creating a Part

Starting Abaqus, under menu heading Create Model Database, click With Standard/Explicit Model.

- Sketch \& Extrude

Start by creating a part. Click on the Create Part icon; by default, the options should be set to the following:

- Modeling Space: 3D

- Type: Deformable

- Base Feature: Shape: Solid

- Base Feature: Shape: Type: Extrusion

- Approximate Size: 200

\section{Click: Continue}

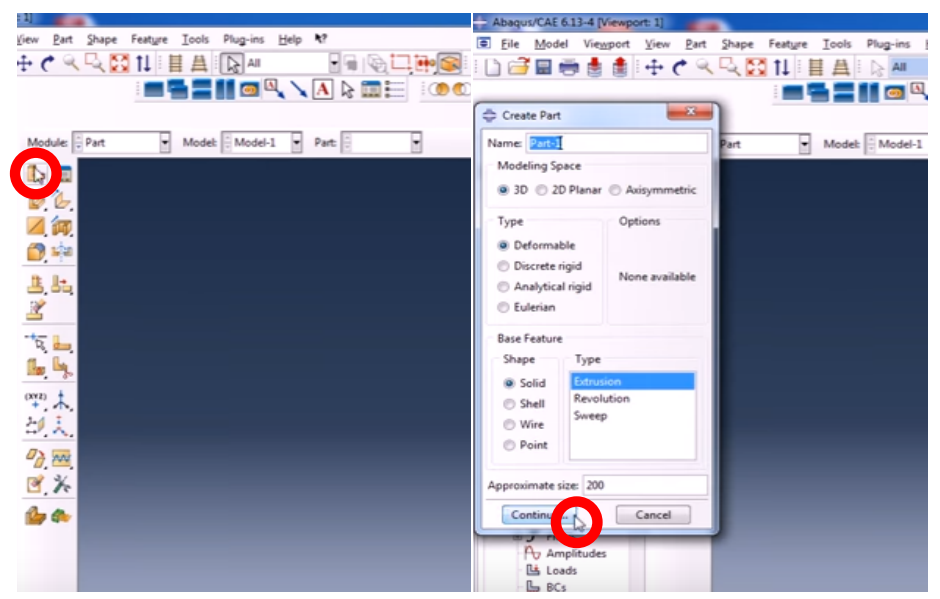

From here, the entire upper left module becomes a tool bar to sketch the specimen profile. Generally, one may start with the Create Isolated Point or the Create Lines: Connected buttons. When the sketch is complete, click Done at the bottom of the screen, and extrude the sketch to the appropriate depth. 




- Partition

Modeled specimens can be partitioned to improve FEA solver performance; with more complicated geometries, and depending on which mesh type the user is utilizing-hexahedral or tetrahedral, partitioning of a part breaks down the complicated geometries to ensure the mesh design is being applied to every part of the specimen. To do this, hold down the Partition Cell: Define Cutting Plane button, select Partition Cell: Extrude/Sweep Edges, identify on the model where the partitions should be made, and finally, which direction each respective sweep should be made:






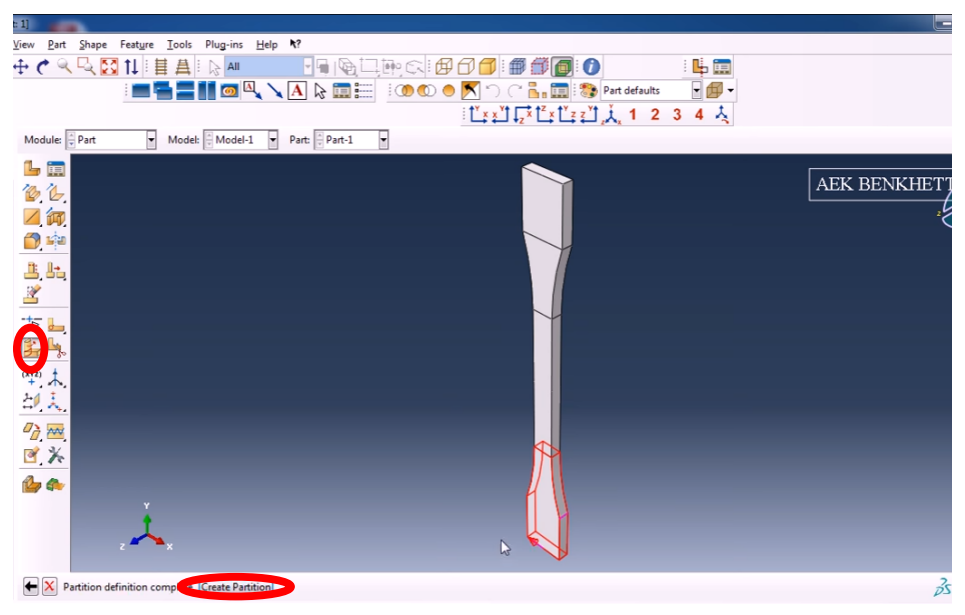

- Create Reference Point

Like any other analysis, a reference point will need to be established. Hold down the Create Datum Point: Enter Coordinates icon, and move the cursor over to the Create Datum Point: Midway Between 2 Points icon. This will display all datum points. Click on the two middle datum points along the top edges of the specimen, and an unfilled point will appear between them. Go to the Tools dropdown menu, click on the Reference Point selection, and click on the newly appeared, unfilled datum point to establish it as the specimen's Reference Point. An " $x$ " with "RP" will appear over the point when completed successfully.

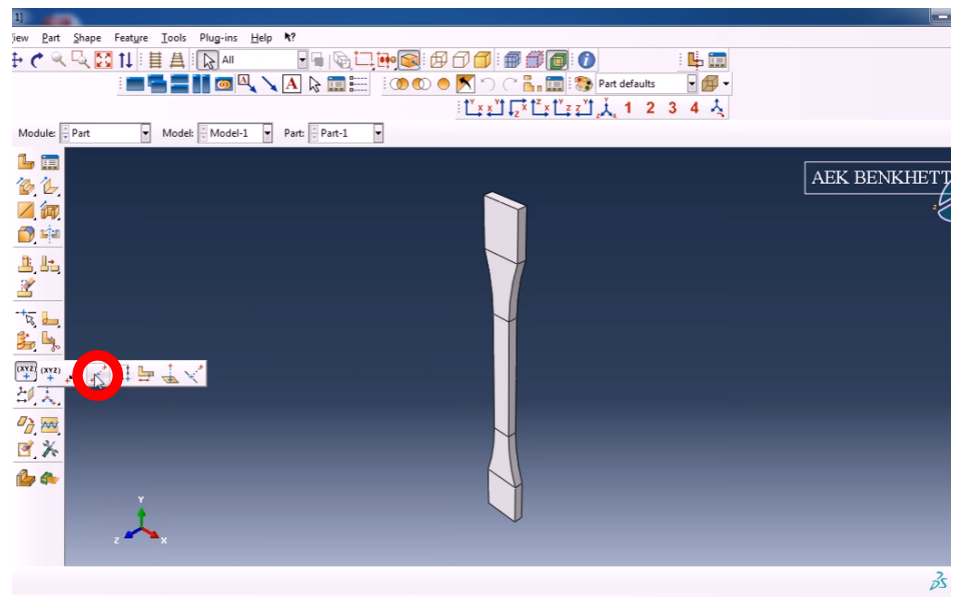



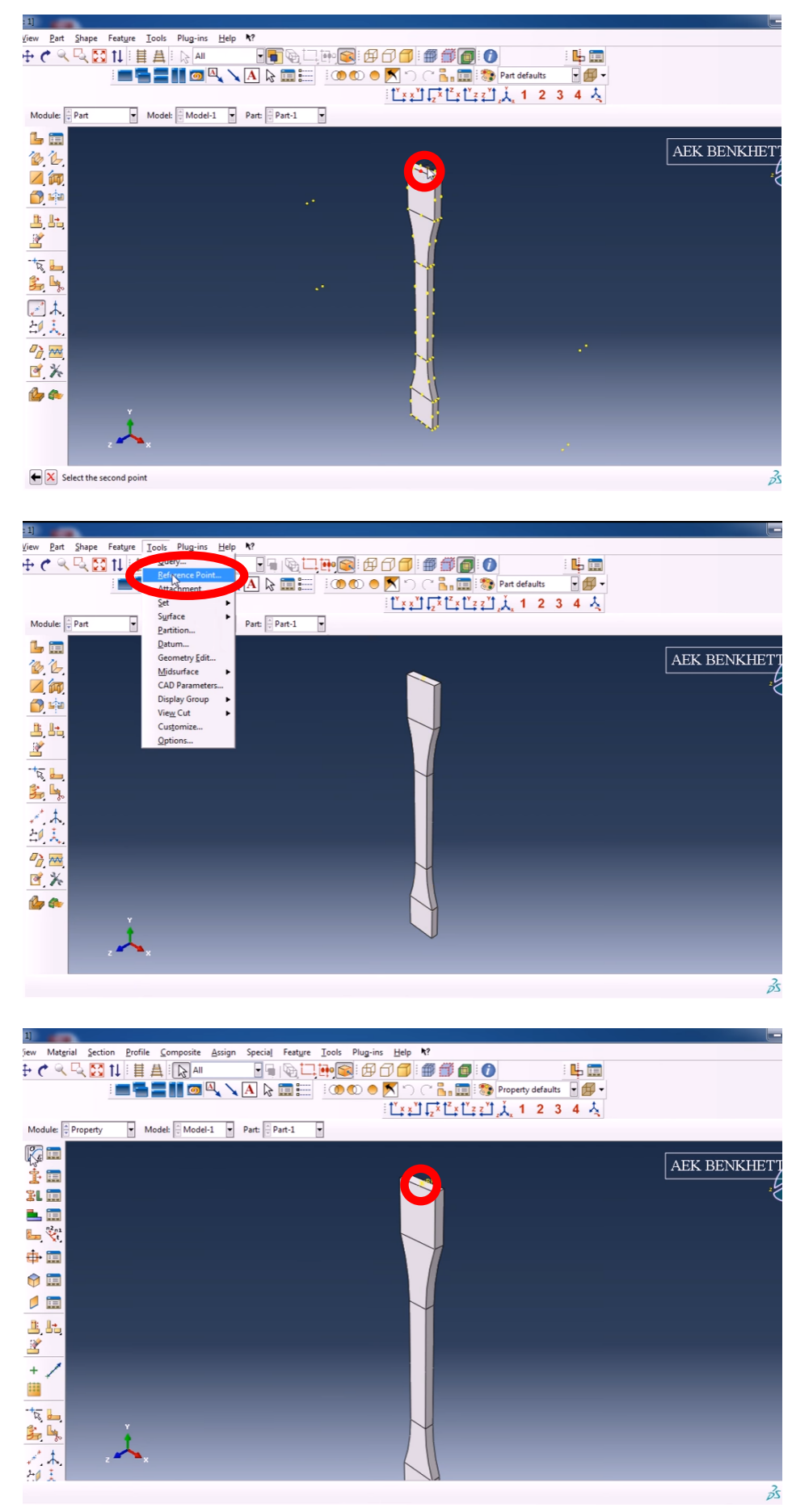

- Establish Material Properties

Under the Module dropdown, select Property. This will update the main left module to selections those that would manage options related to the properties of the part. From here, click on the Create Material icon: at the prompt, determine a name and 
description for the material to be defined (defaults to "Material1"), click on the Mechanical dropdown, select Elasticity, Elastic, and subsequently complete the Young's Modulus and Poisson's Ratio data fields. The Type selection should remain as Isotropic for this instance.
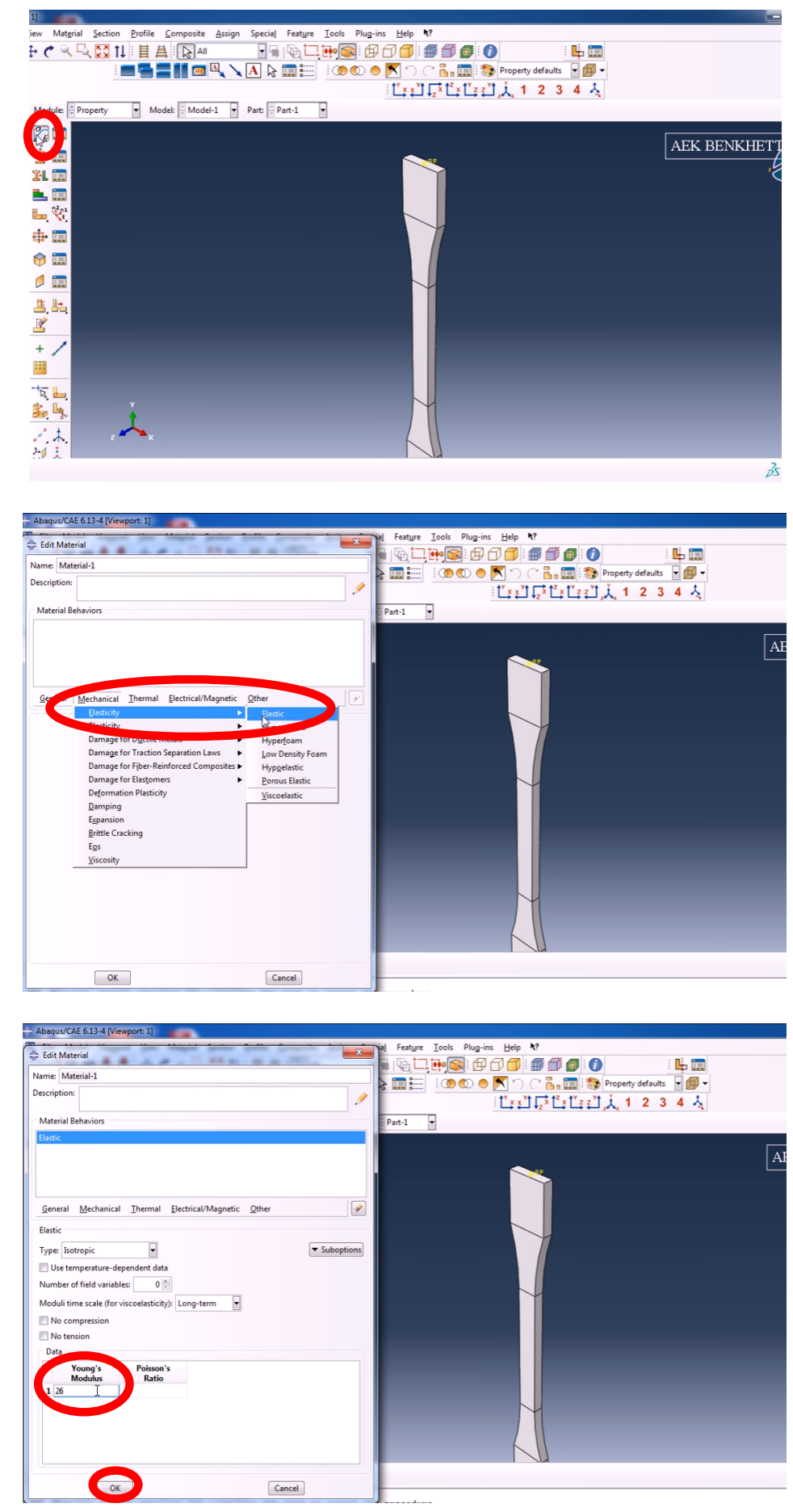
- Assign Material Properties to Defined Sections

Click on the Create Section icon. Again, determine a name for the section to be created-default is "Section-1". For the homogenous baseline, Category: Solid, Type: Homogenous will be used. Click Continue. For the Edit Section popup, Material-1 should be defaulted in the dropdown; click ok to continue.
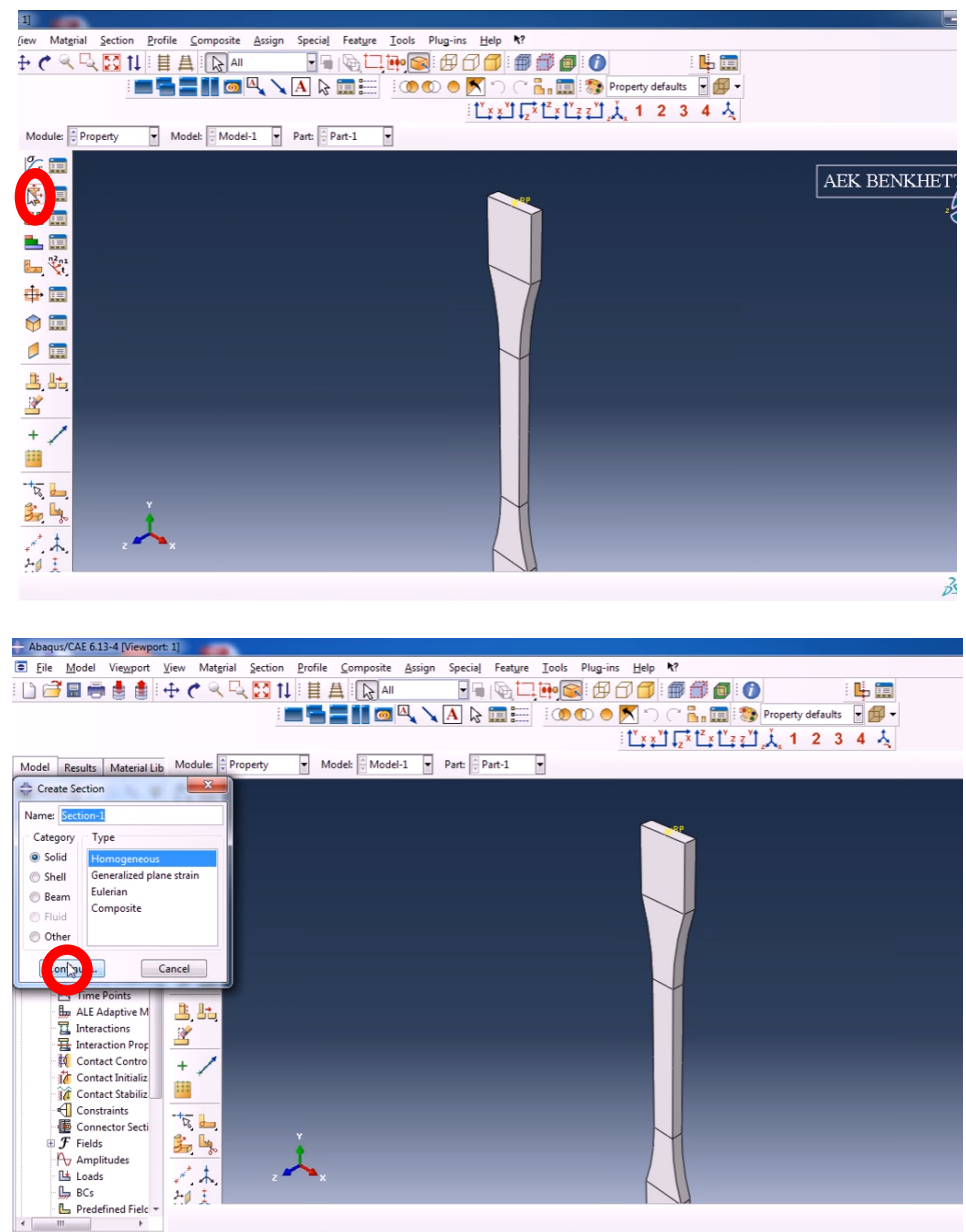


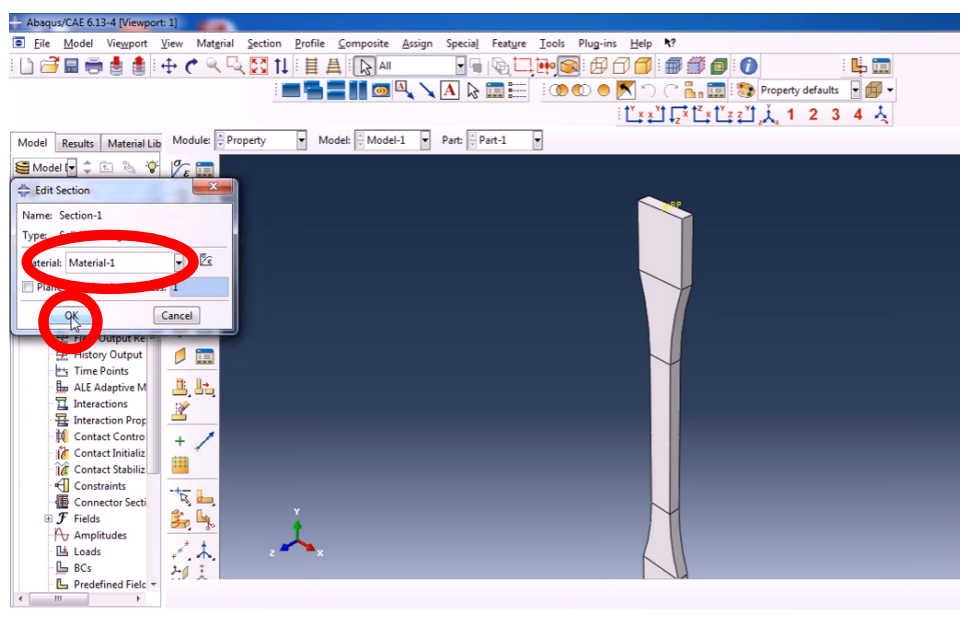

Click on the Assign Section icon; select the entire specimen with the cursor. When the entire specimen's frame is selected red, ensure the "Create set" box is unchecked at the bottom of the screen, and click Done. An Edit Section Assignment popup will appear; click Ok to proceed. The model will now have turned a blue-green.

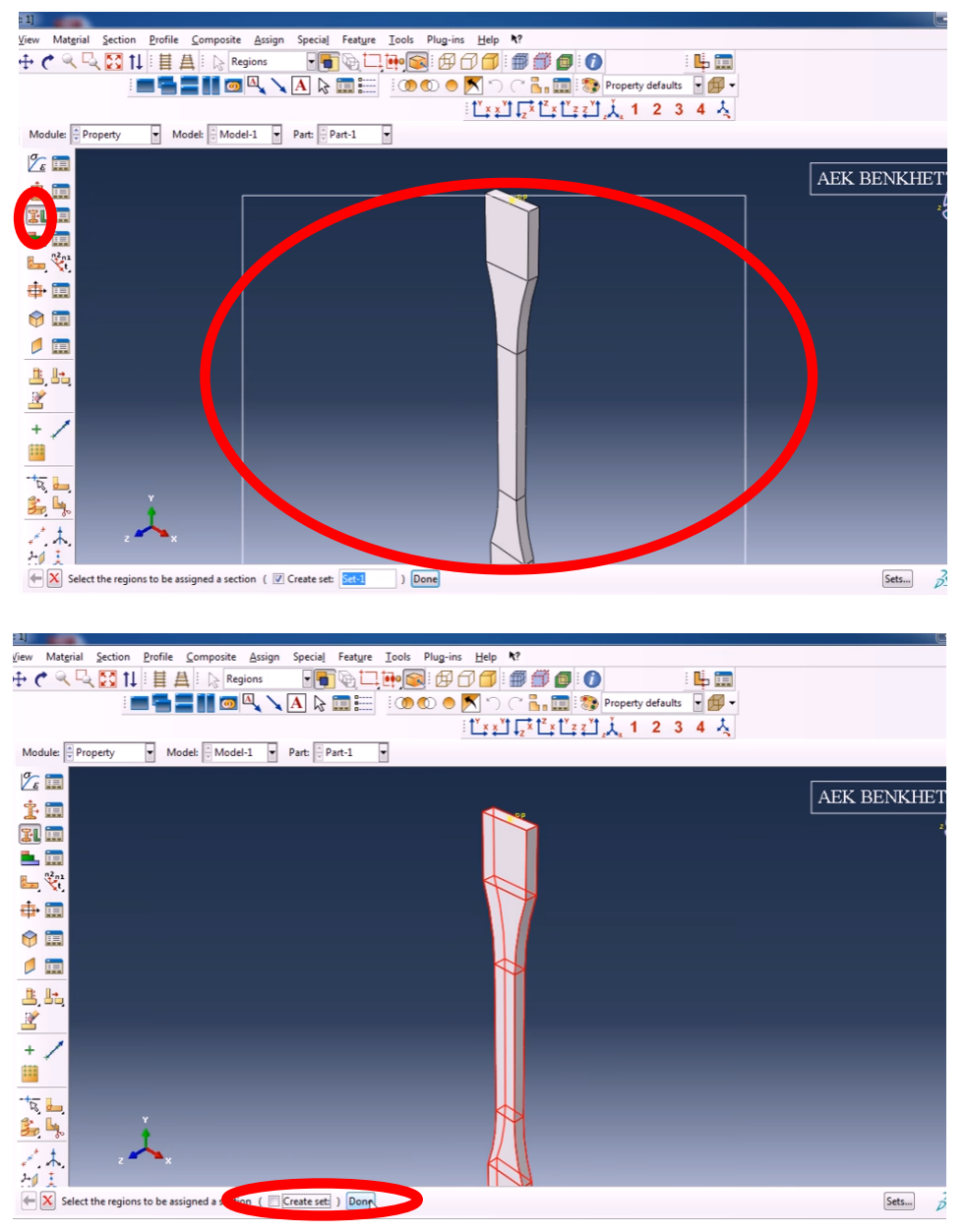









\section{Step 2: Defining the Test Parameters}

- Creating an Instance

Under the Module dropdown, select Assembly. Do not be alarmed if the part disappears. Find and click on the Create Instance icon. On the ensuing popup, select Create instances from: Parts; verify "Part-1" is selected; confirm the Instance Type is Dependent (mesh on part); click ok to continue.
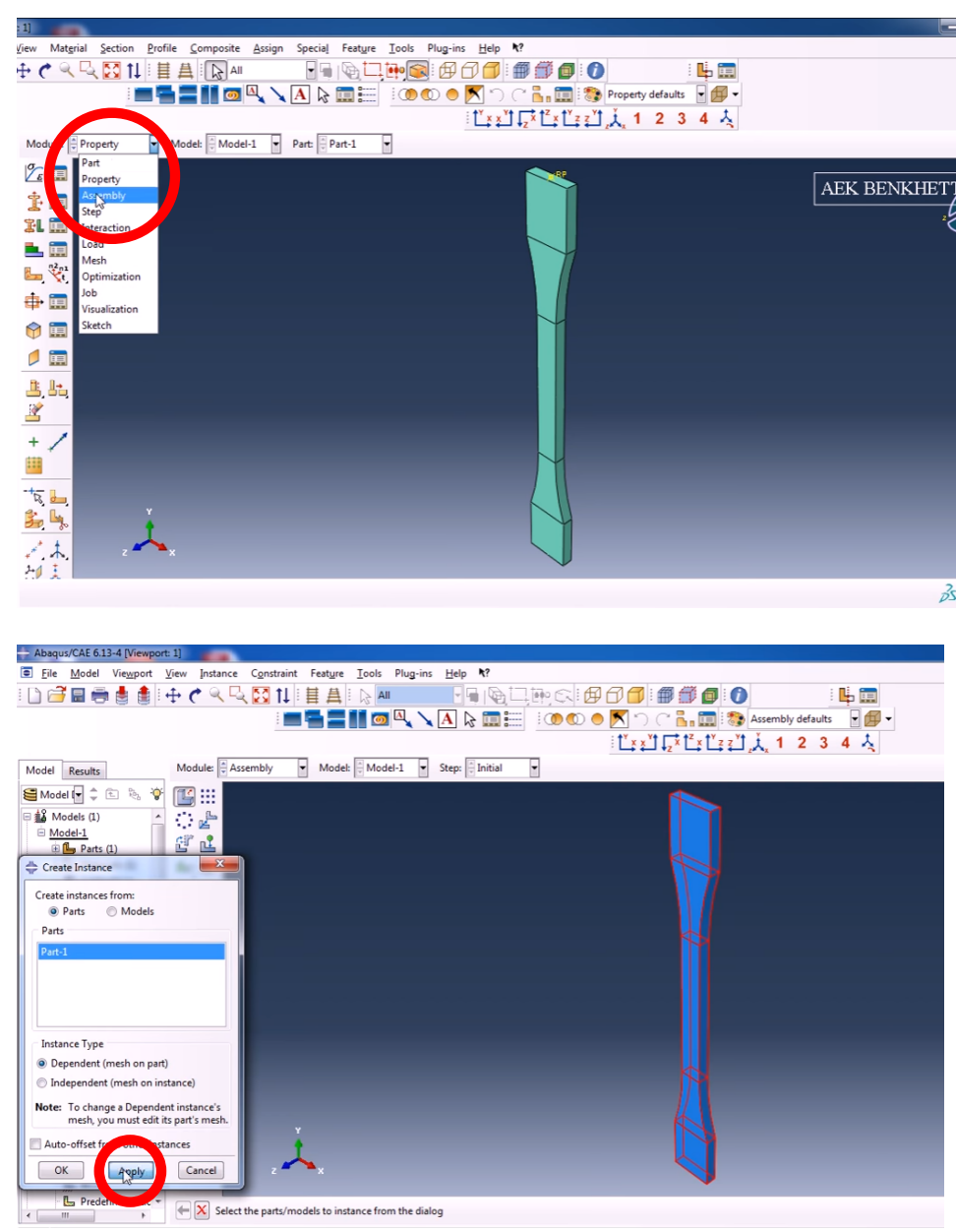

- Defining Steps

Under the Module dropdown, select Step. Find and click on the Create Step icon. Confirm Procedure type is General > Static, General; click Continue. An Edit Step popup will appear. Under the Basic tab, enter a description as desired, define the time period as 1 (default); leave NIgeom in the off state; do not apply any automatic 
stabilization. Under the Incrementation tab: Type: Automatic; Maximum number of increments: 100, Increment size: Initial: 0.1, Minimum: 1E-005; Maximum: 1; click Ok to continue.
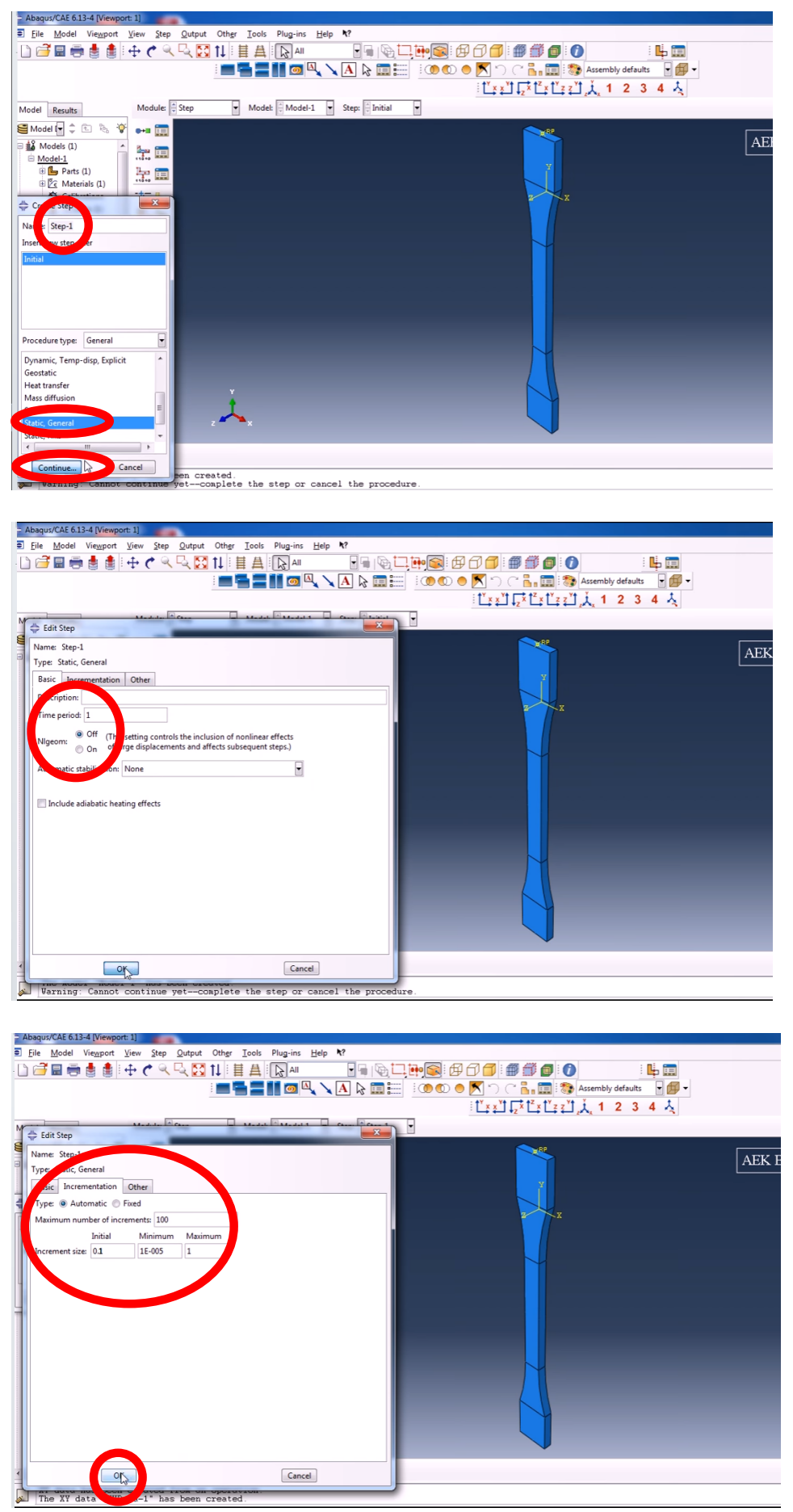
- Defining Constraints

Under the Module dropdown, select Interaction. Select the Create Constraint icon to get started. Name the constraint characteristics as desired (default: "Constraint-1"), and select the Type to be Coupling. Selecting Continue will initiate a request to define the constraint control point; select the Reference Point here, click Done; for the constraint region type, select: Node Region; for selecting points for the surface nodes, navigate up to the dropdown menu in the upper menu, and change Enable Selection from All to Cells. Clicking on the cell regions to constrain will turn the wireframe of that section magenta. Clicking Done will prompt the Edit Constraints popup. From here, define the constraints to be Kinematic and constrain all degrees of freedom. Click ok.

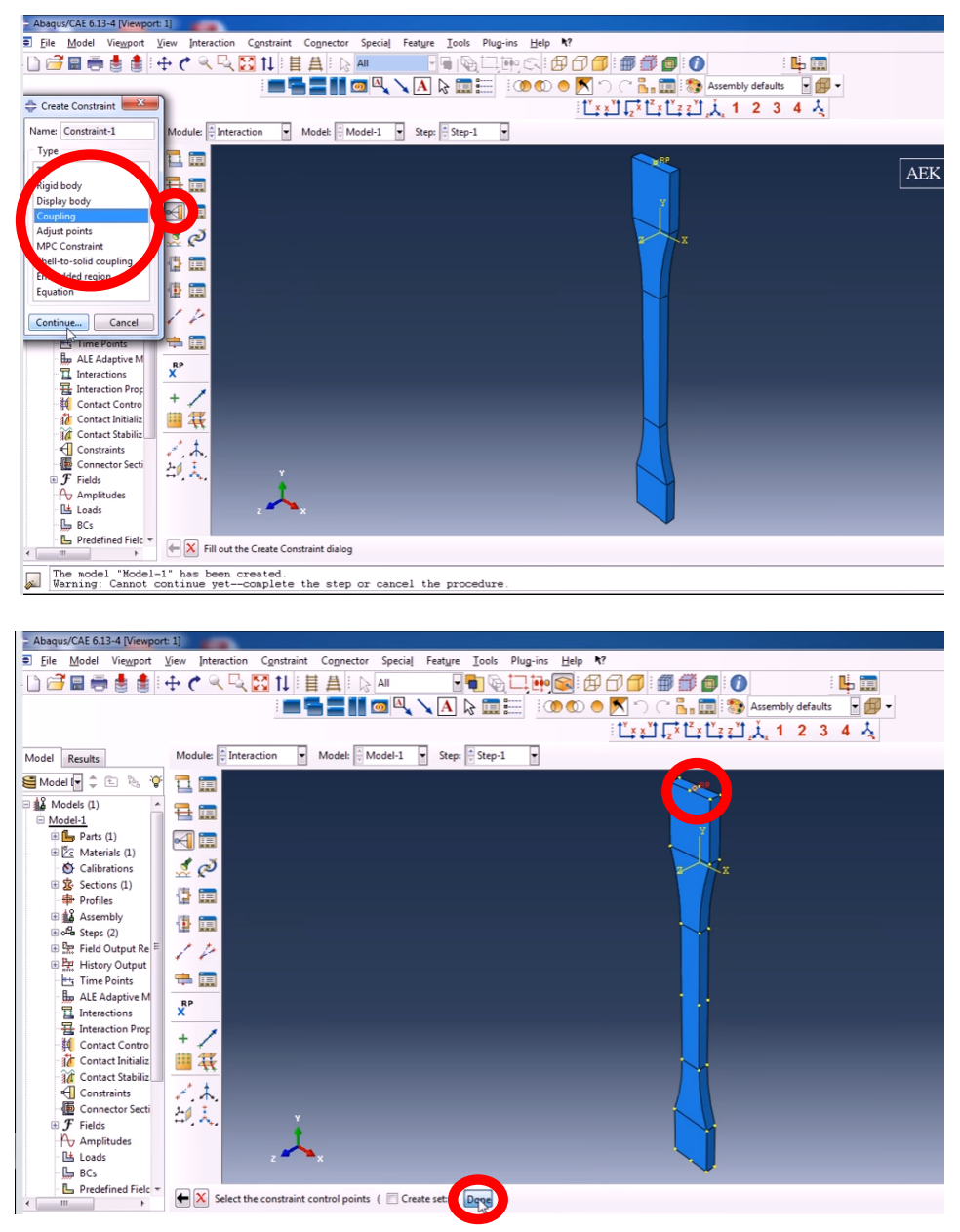




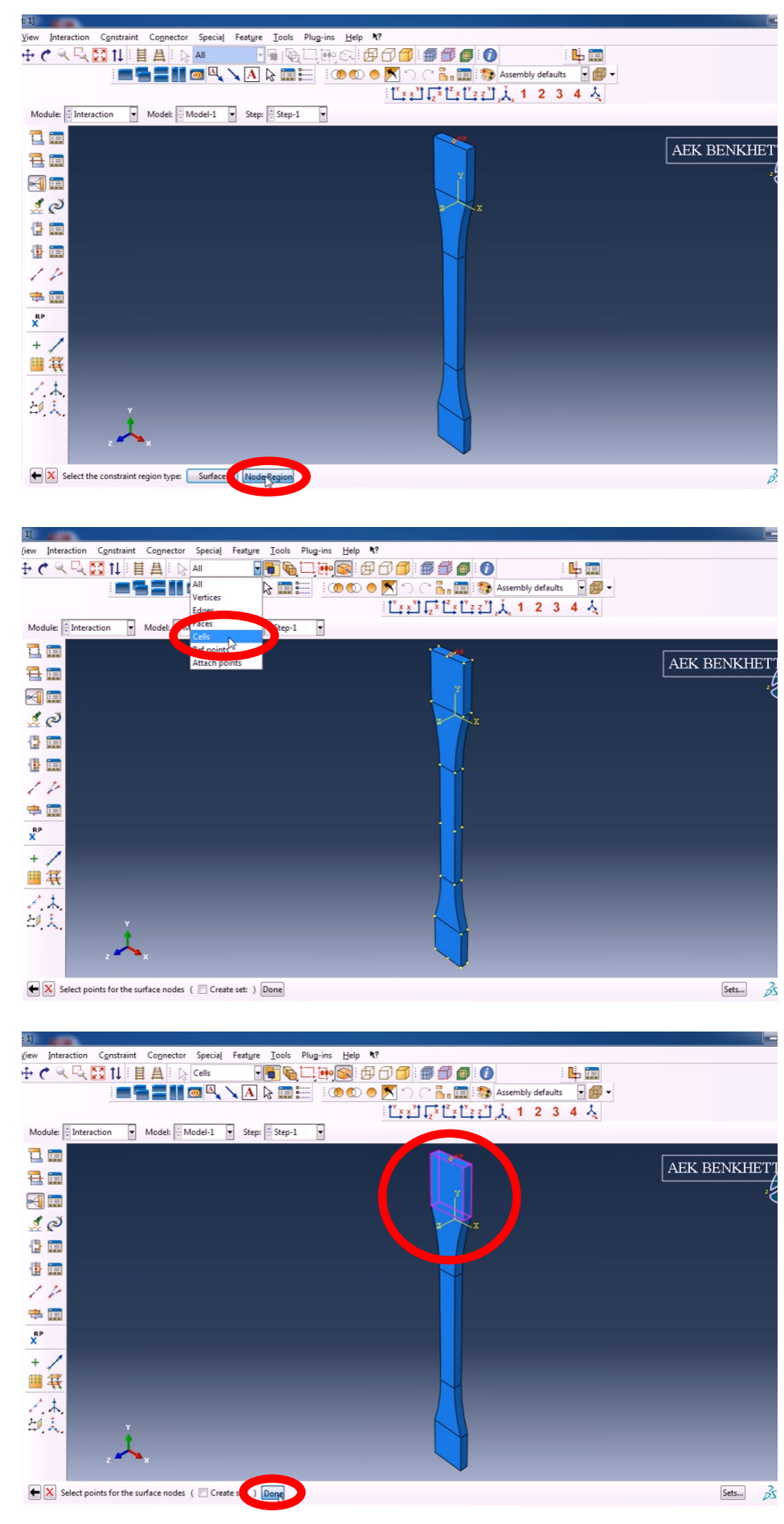




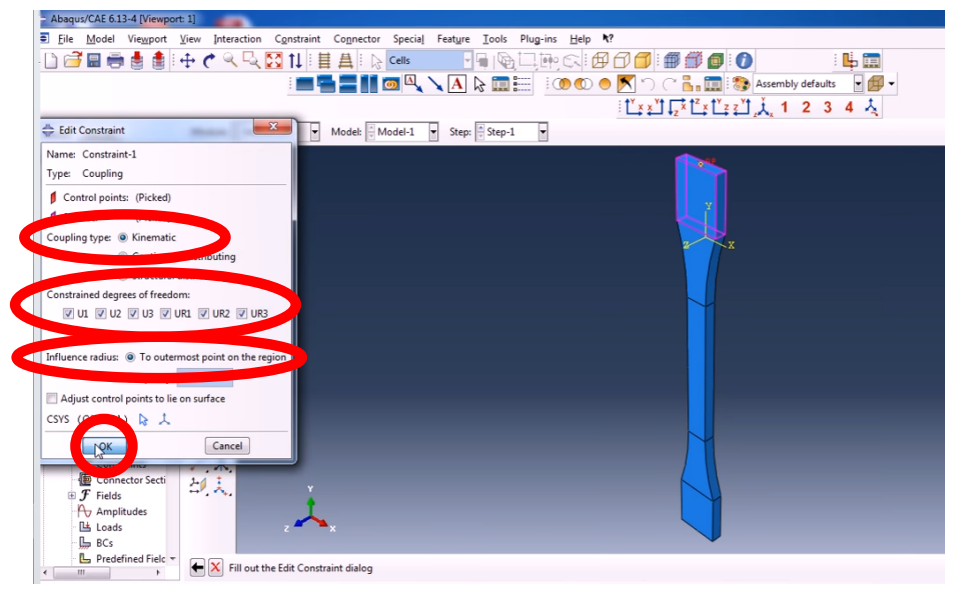

- Defining Boundary Conditions

Under the Module dropdown, select Load, and then the Create Boundary Condition icon. Name the boundary condition accordingly, and select the following: Step: Step-1 (or equivalently named); Category: Mechanical; Types for Selected Step: Symmetry/Antisymmetry/Encastre. Click Continue. Enable Selection may need to be changed from All to Cells once again. Select the region to apply the Boundary Condition on the model, click Done, and then Encastre. Click $O k$, and then proceed to create a secondary Boundary Condition to limit the Displacement/Rotation of the specimen. The same settings will apply until the Edit Boundary Condition popup, where the following axes should be selected to lock: U1, U3, U4, UR1, UR2, and UR3. Click ok to finalize the second set of Boundary Conditions. 

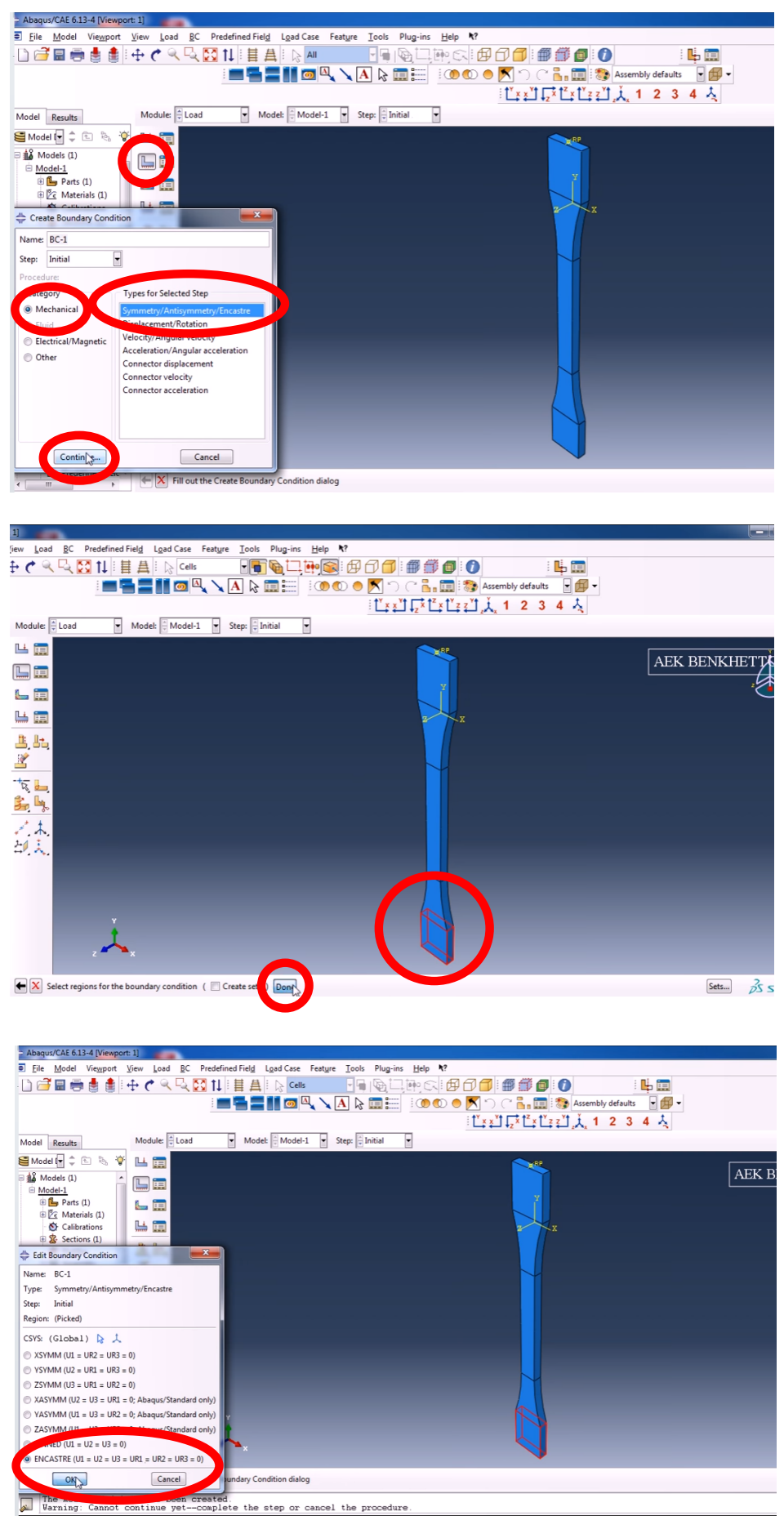



- Defining the Test Load

The Test Load is defined by category-mechanical, acoustic, thermal, etc., and type-concentrated force, pressure, gravity, etc. The manner in how a load is distributed is defined by the Amplitude 
settings, where a user is able to dictate at which frequency and profile a load may be introduced to a specimen.

With the Module set to "Load", select the Load Manager icon.

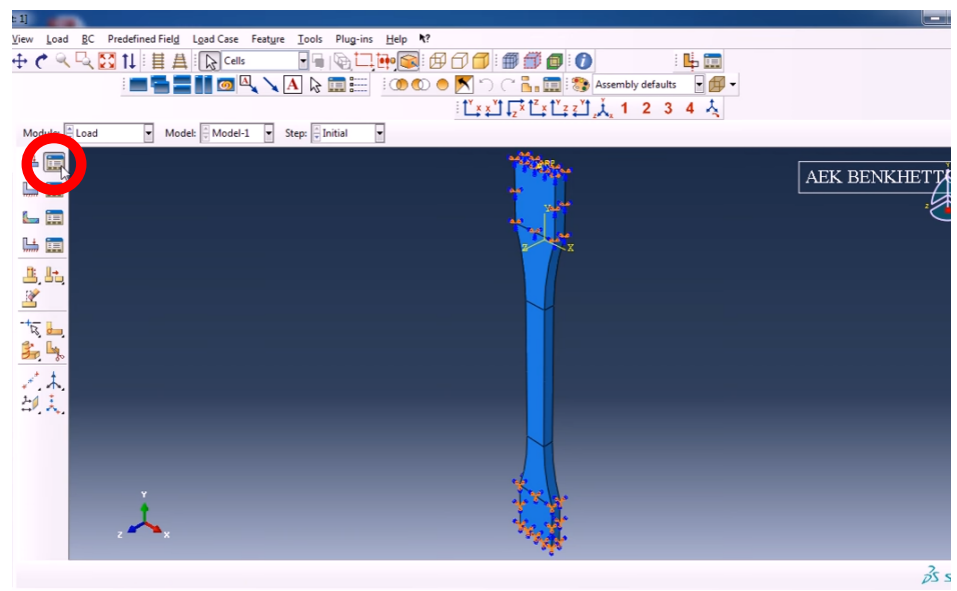

At the prompt, Create a load, defining it as a Mechanical, Concentrated force.

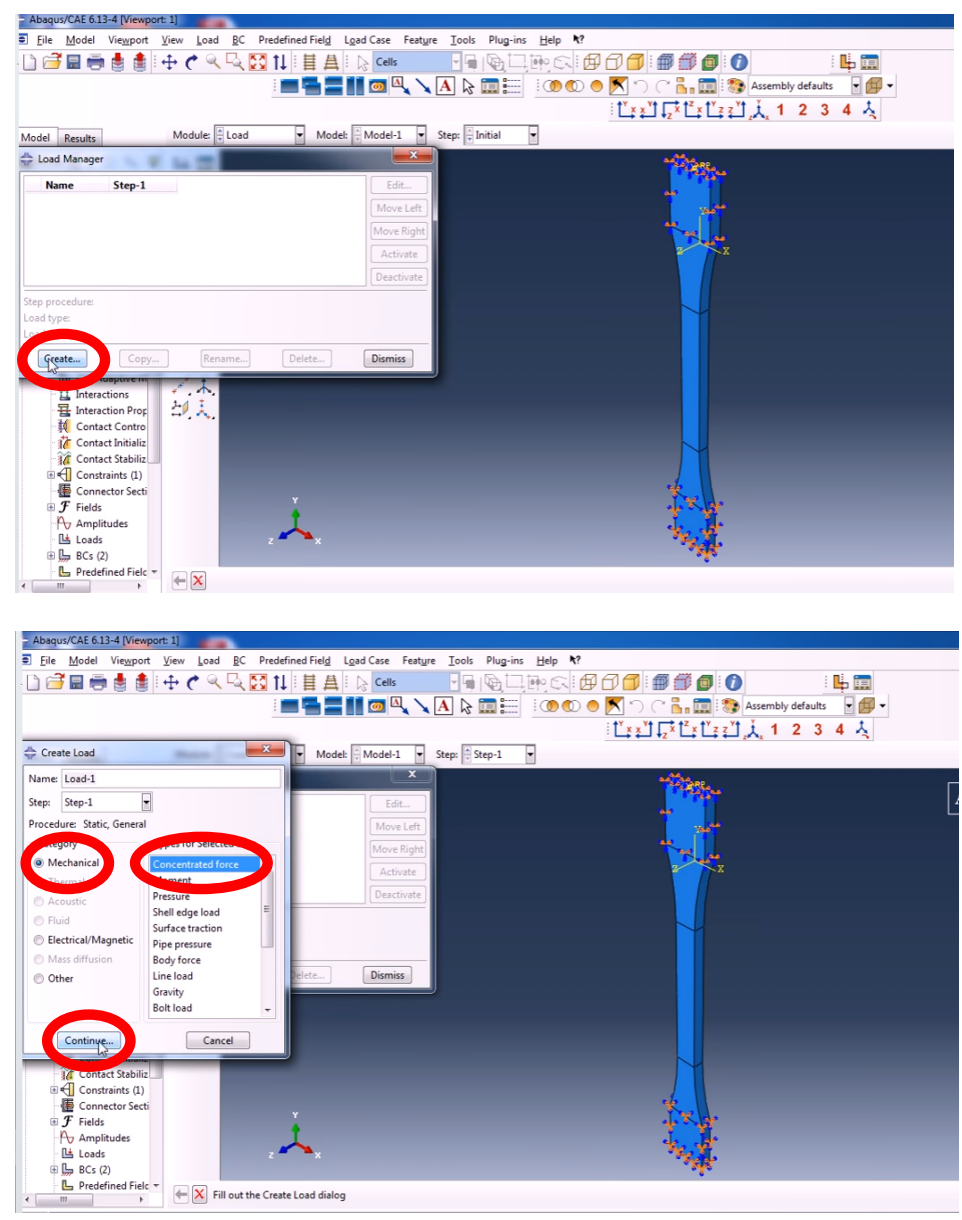


Select a point, or a set of points, on the FEM for the load to be applied.



At the Edit Load prompt, define a uniformly distributed load at a magnitude of choice, and define the Amplitude as a tabular ramp. By default, the Amplitude will be named Amp-1.




Define the ramping characteristic frequencies.

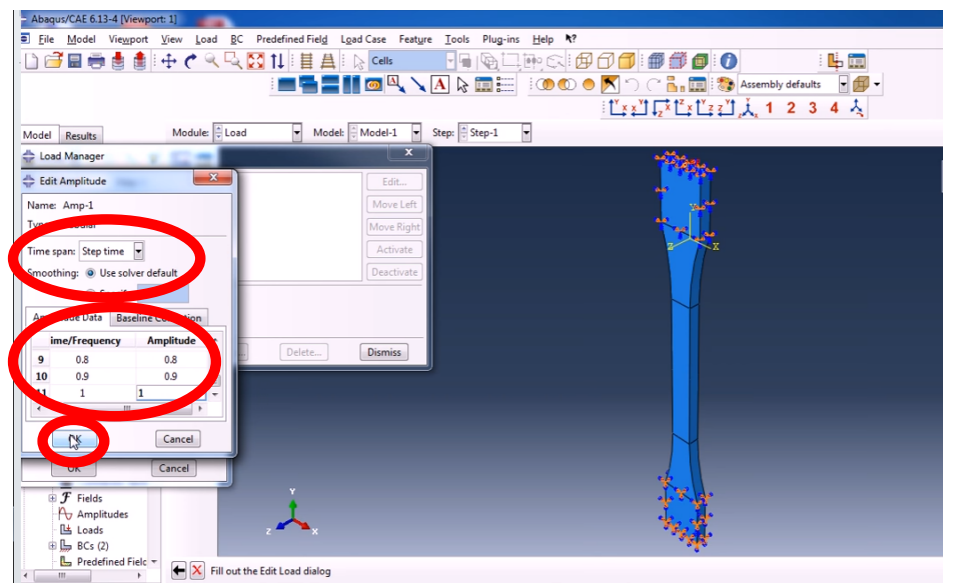

From the dropdown, select the newly created Amp-1.




- Mesh

Properly setting up the Mesh is one of the most important steps to FEA. With the Module set to Mesh and object set to Part: [part name], click on the Global Seeds icon.



The Approximate global size determines the number of elements utilized in the finite element calculations; the greater the Approximate global size, the less number of nodes; the smaller the Approximate global size, the more nodes-the more nodes, theoretically, more accuracy in results. The initial global size was set to 10 .

Curvature control determines the shape of each element: the smaller the Maximum deviation factor, the more quadrilateral each respective node will be. The initial curvature control was set to 0.1 (default).

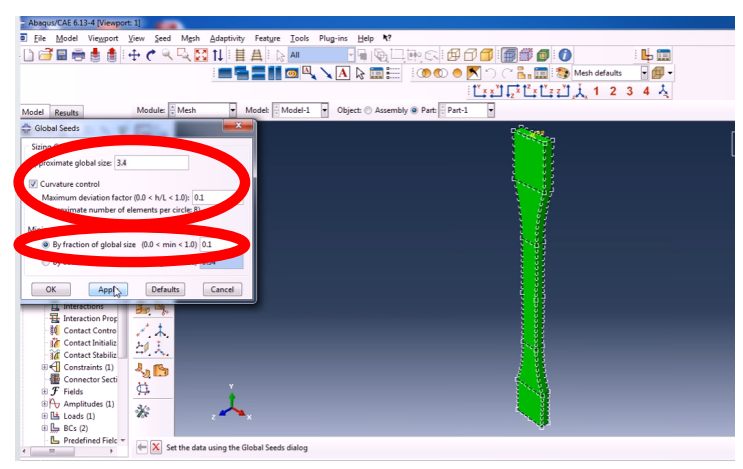


When completed, ensuring the object is selected as Part > [Name of Part], click Yes when prompted Ok to Mesh Part? The model will now turn blue with the meshed nodes visible.

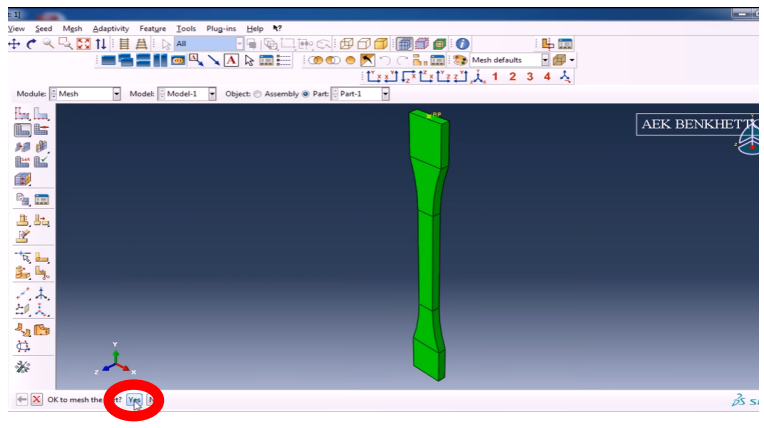

- Submit for Test

Set the Module dropdown to Job. Select Job Manager $>$ Create..., a popup will appear. Name the job (defaults to "Job-1"), select Source: Model: Model-1 (or equivalent), add a description as necessary, and click Ok. Back on the Job Manager screen, highlight Job-1 and click Submit. The model is now being analyzed. Once the job is complete, click Results to review the finite element analysis. 
Finite Element Models

\section{Cross-ply, 1/8" Hole}
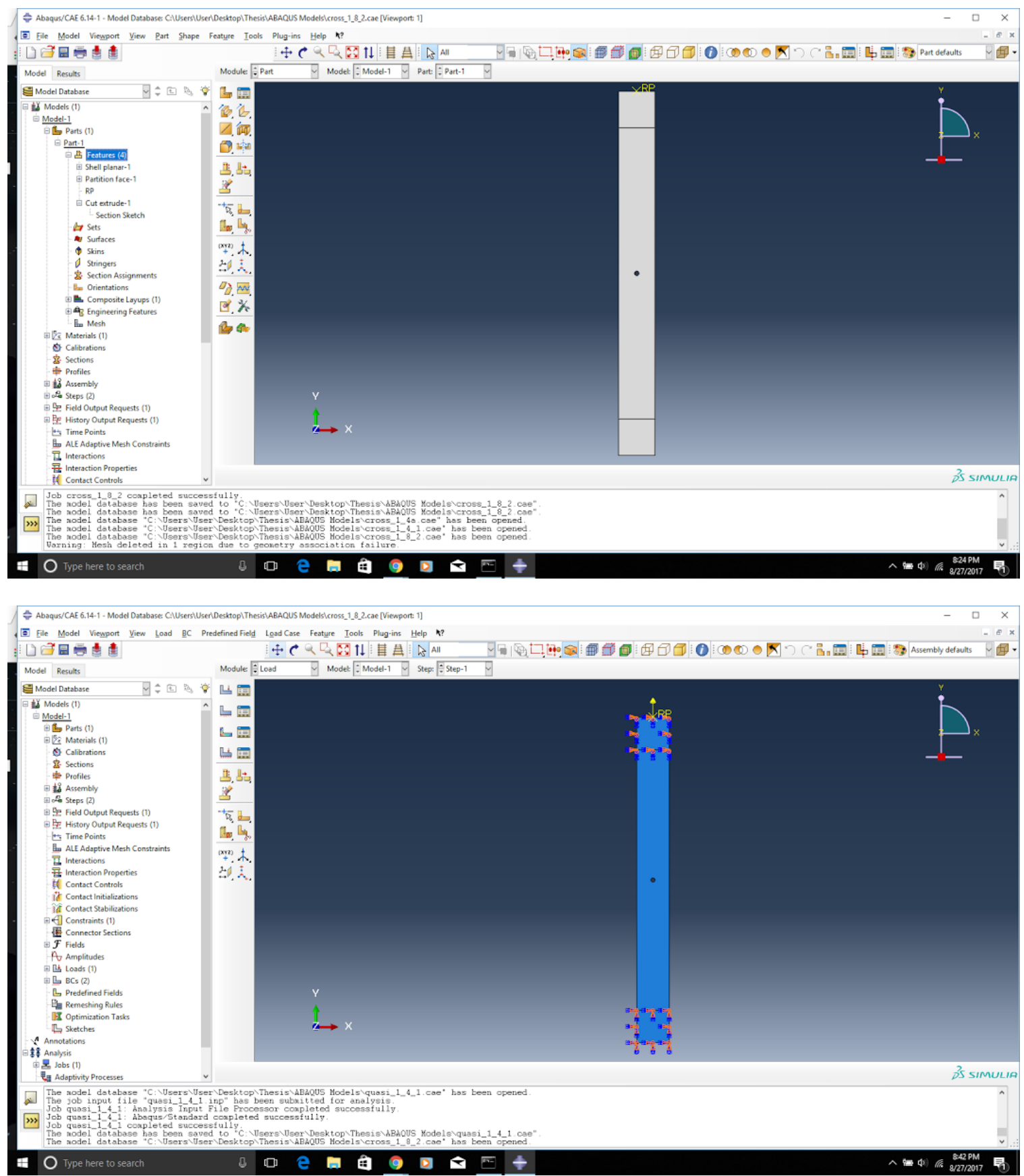



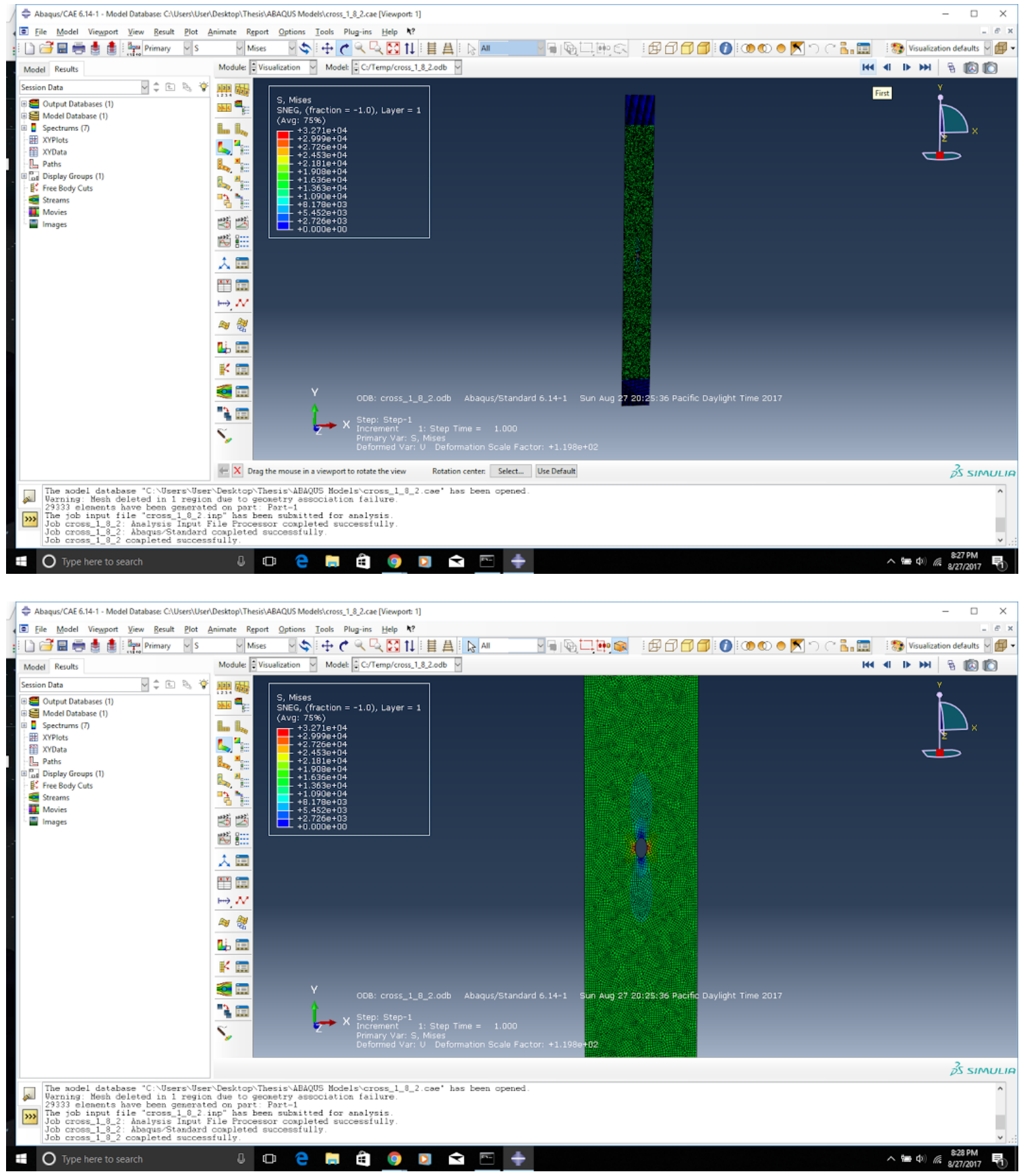





Cross-ply, 1/4" Hole


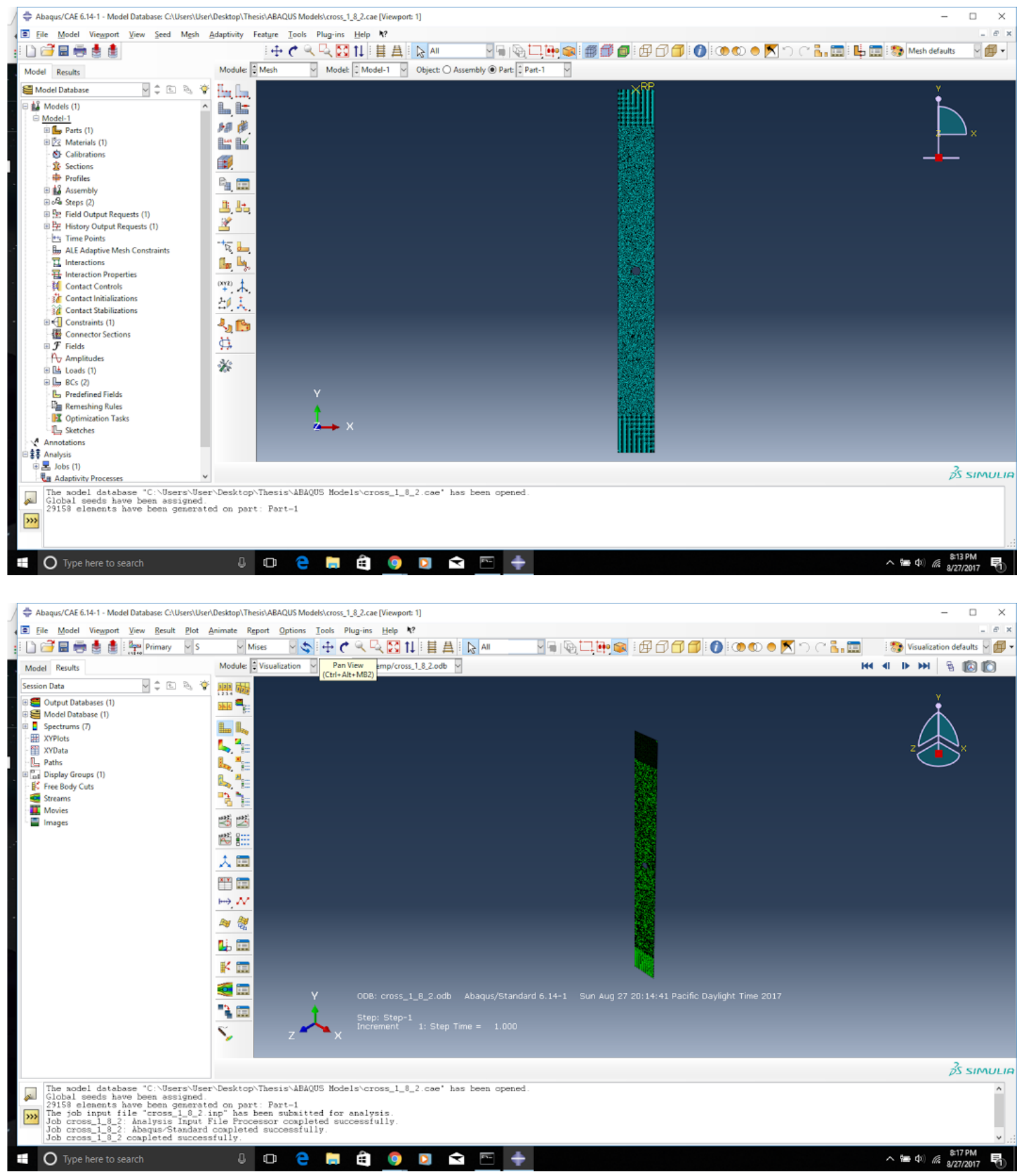

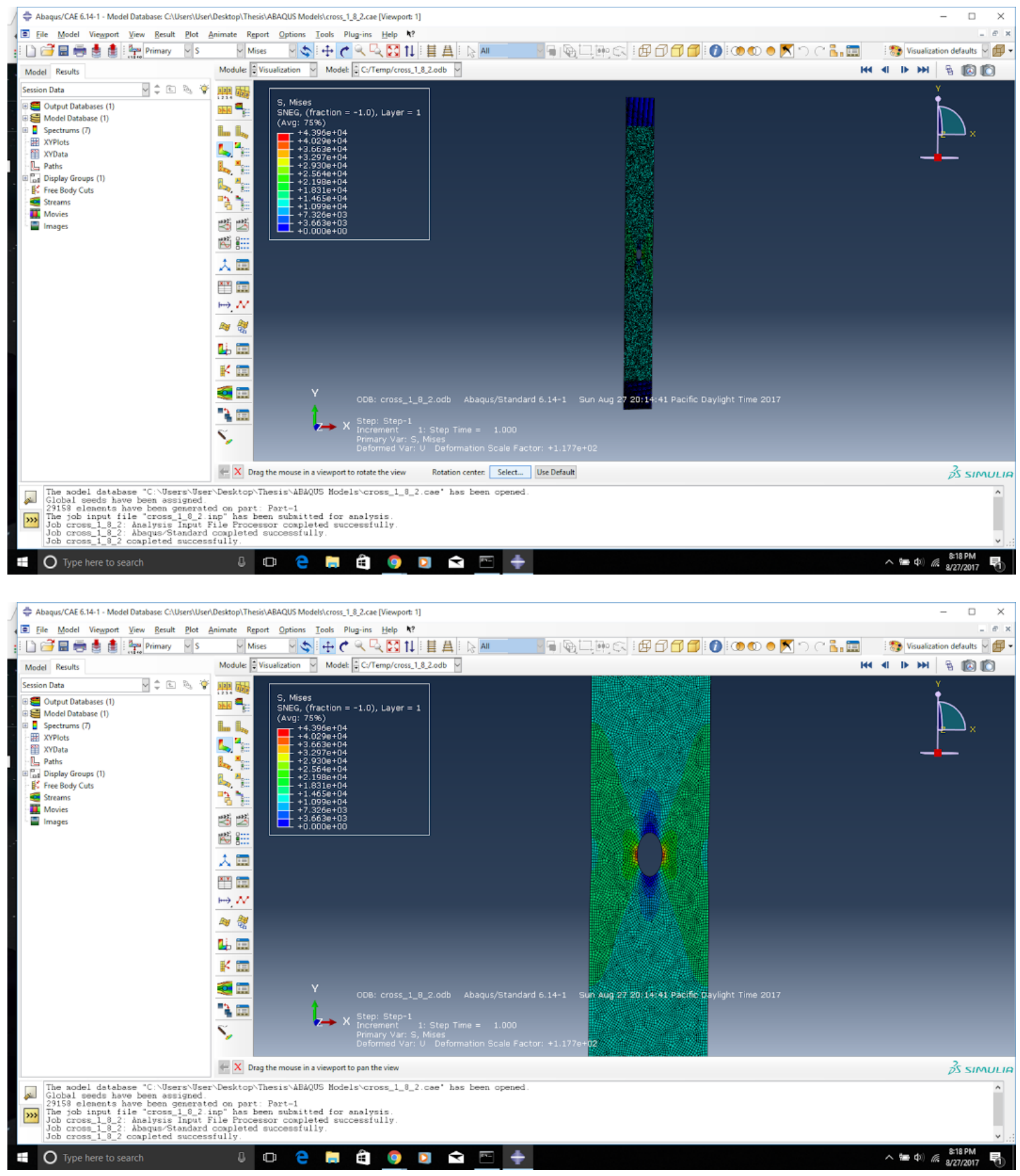


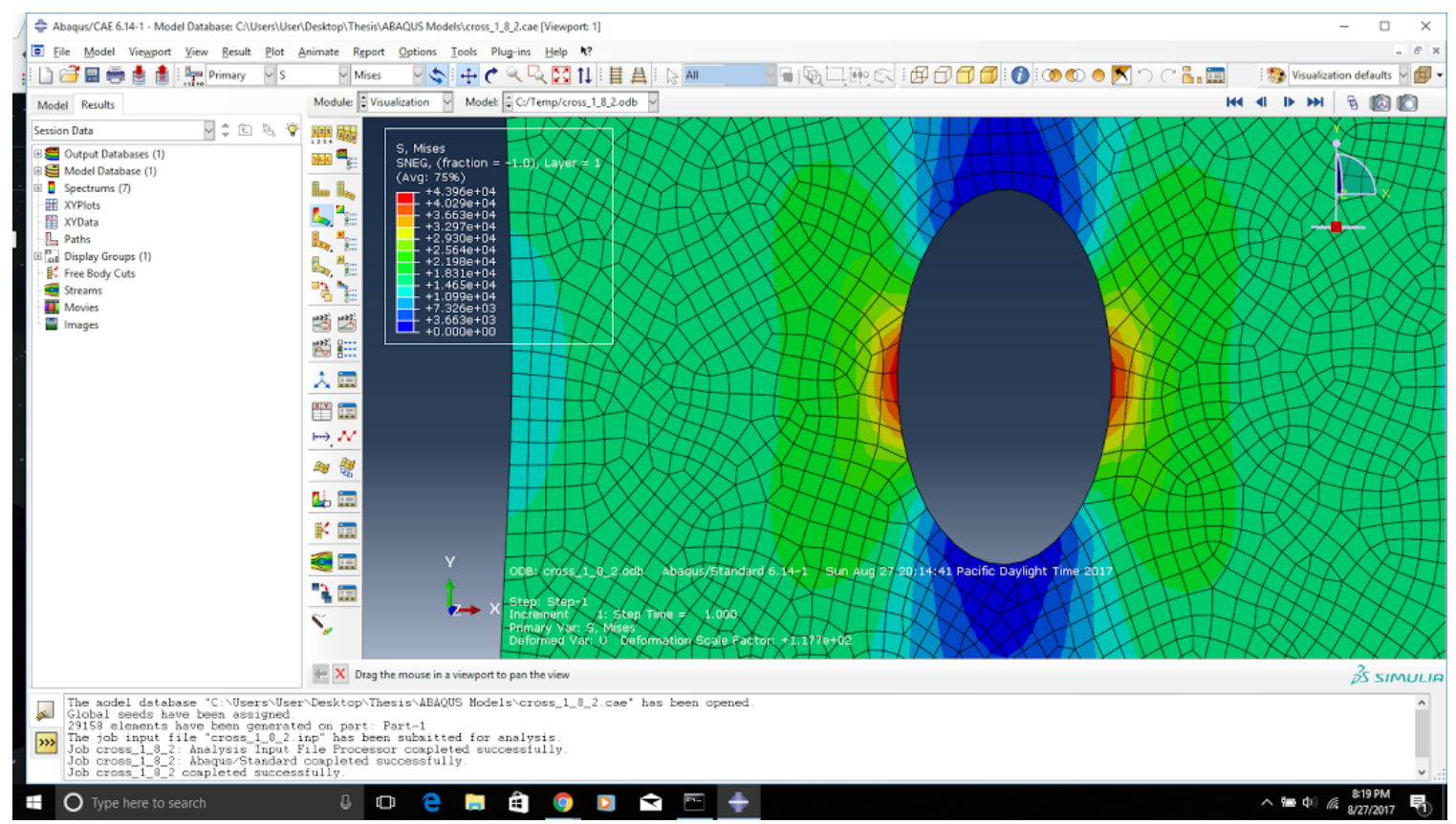




\section{Quasi-isotropic, 1/8" Hole}
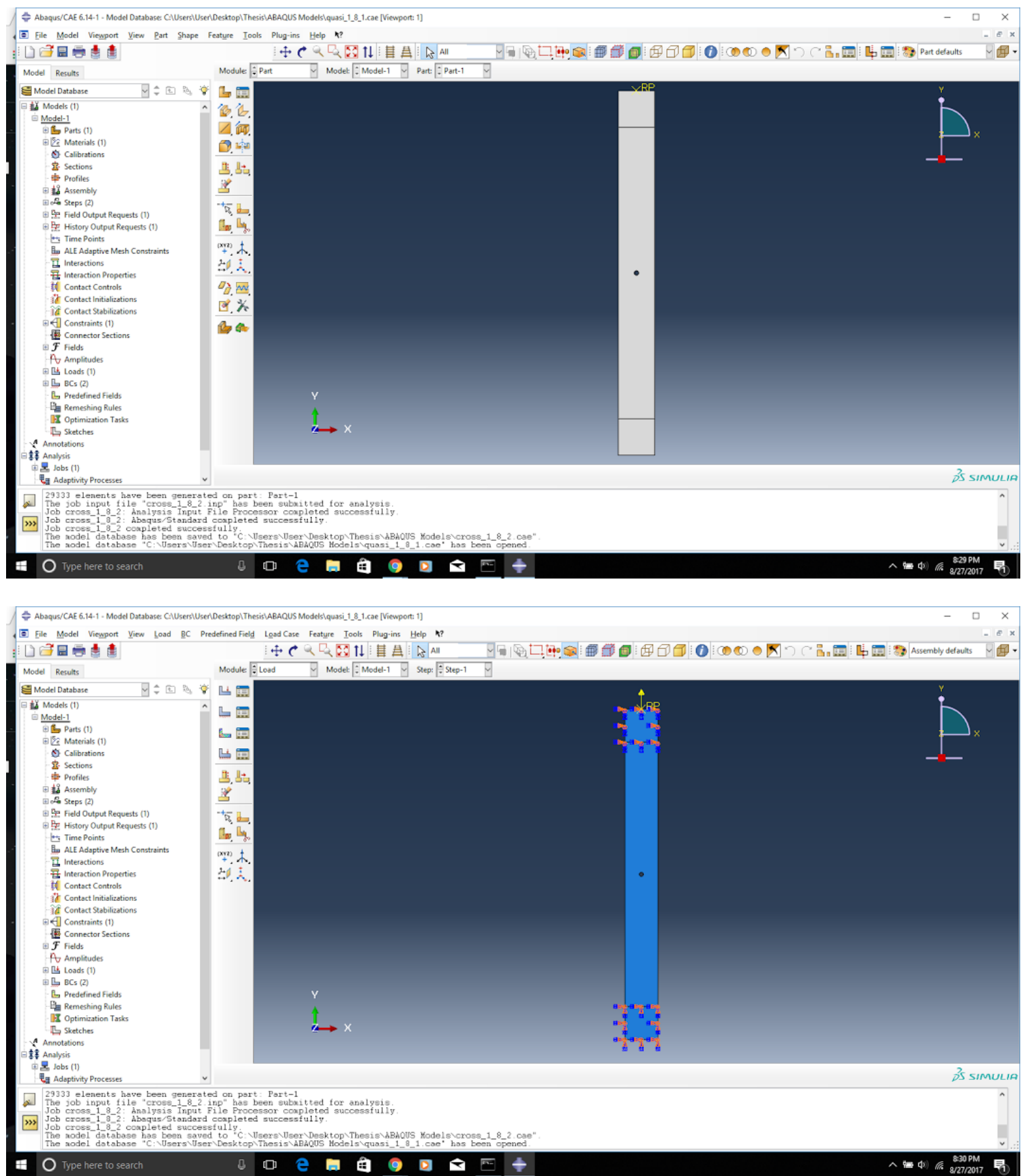

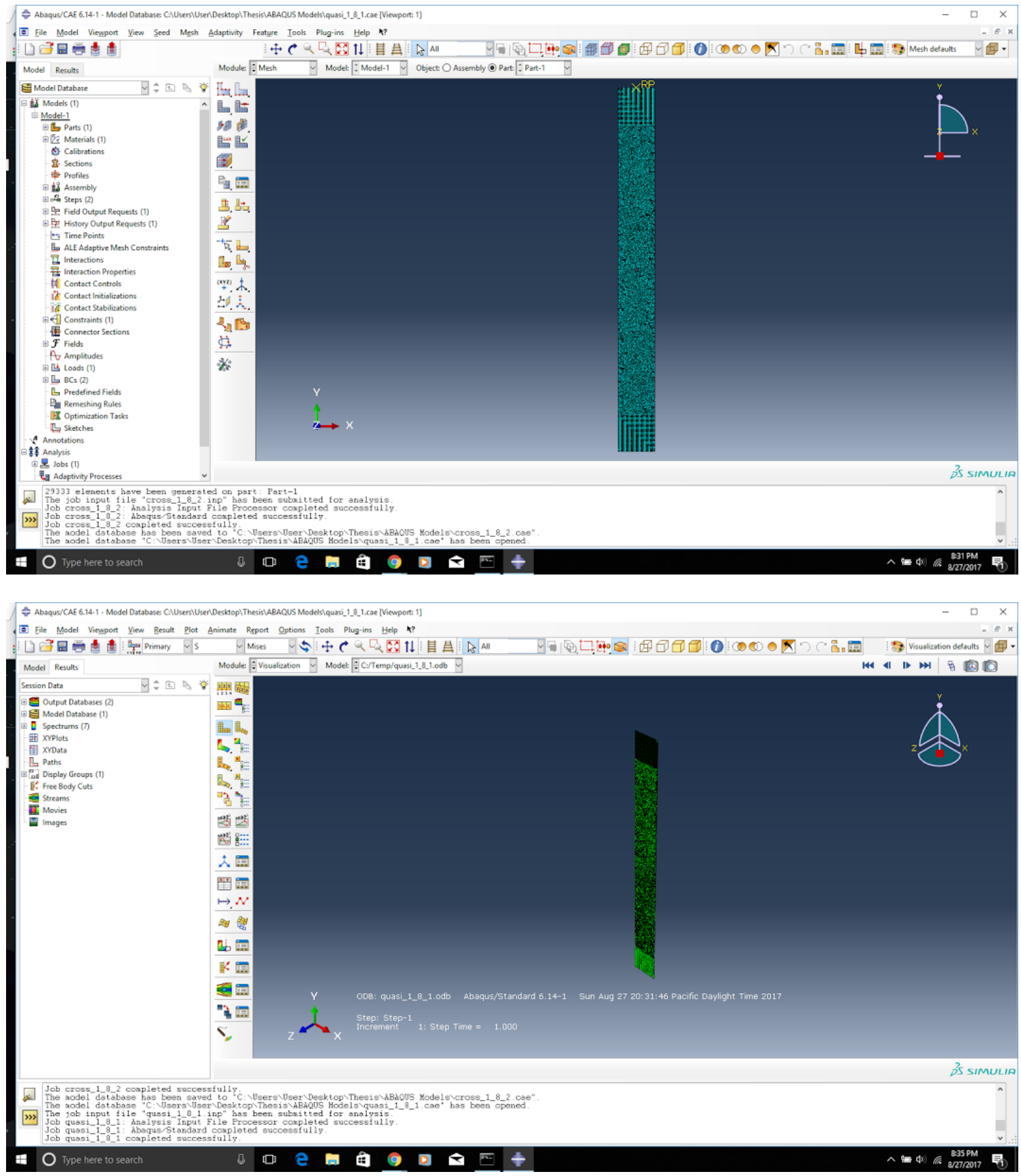









\section{Quasi-isotropic, 1/4" Hole}
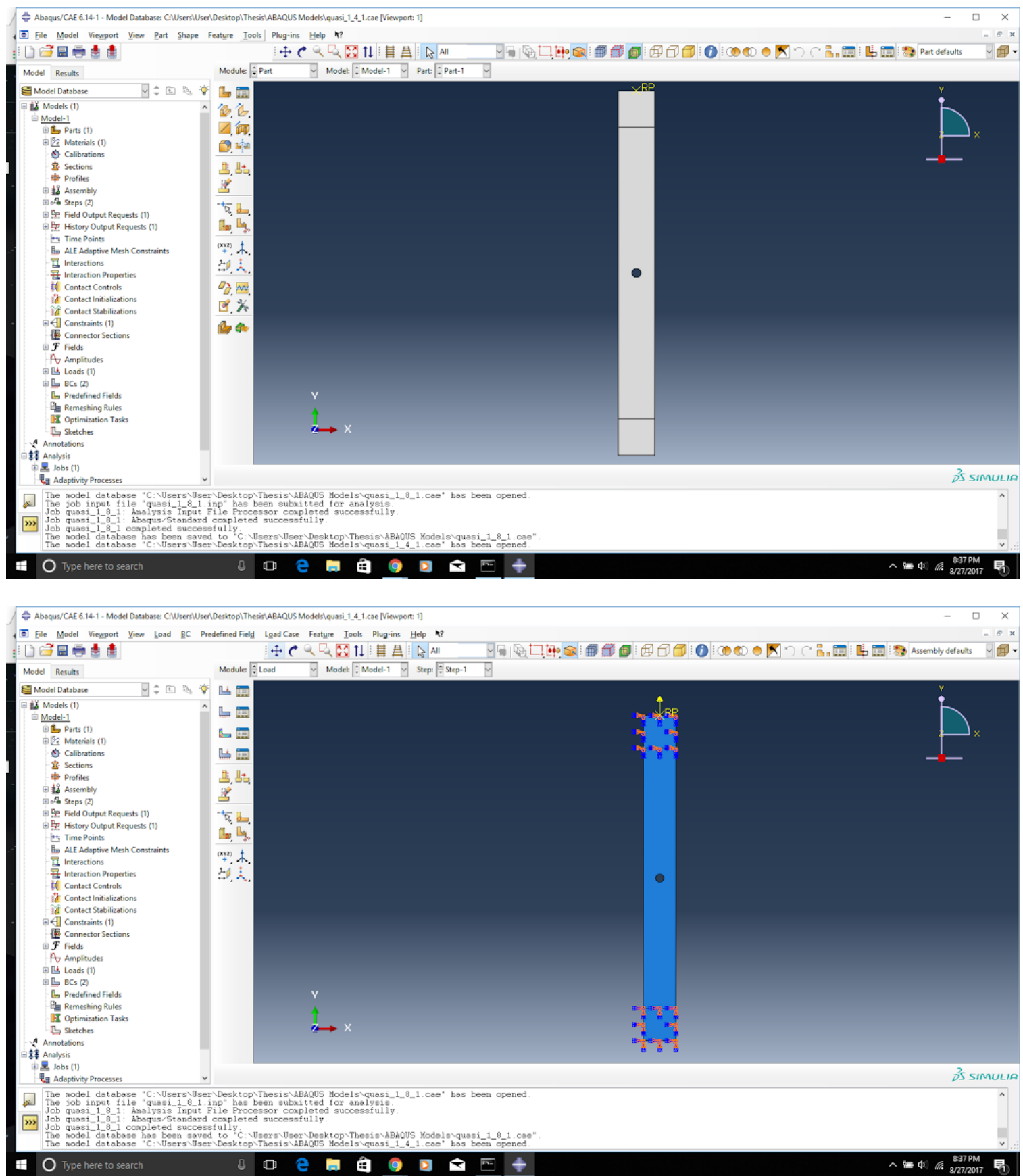

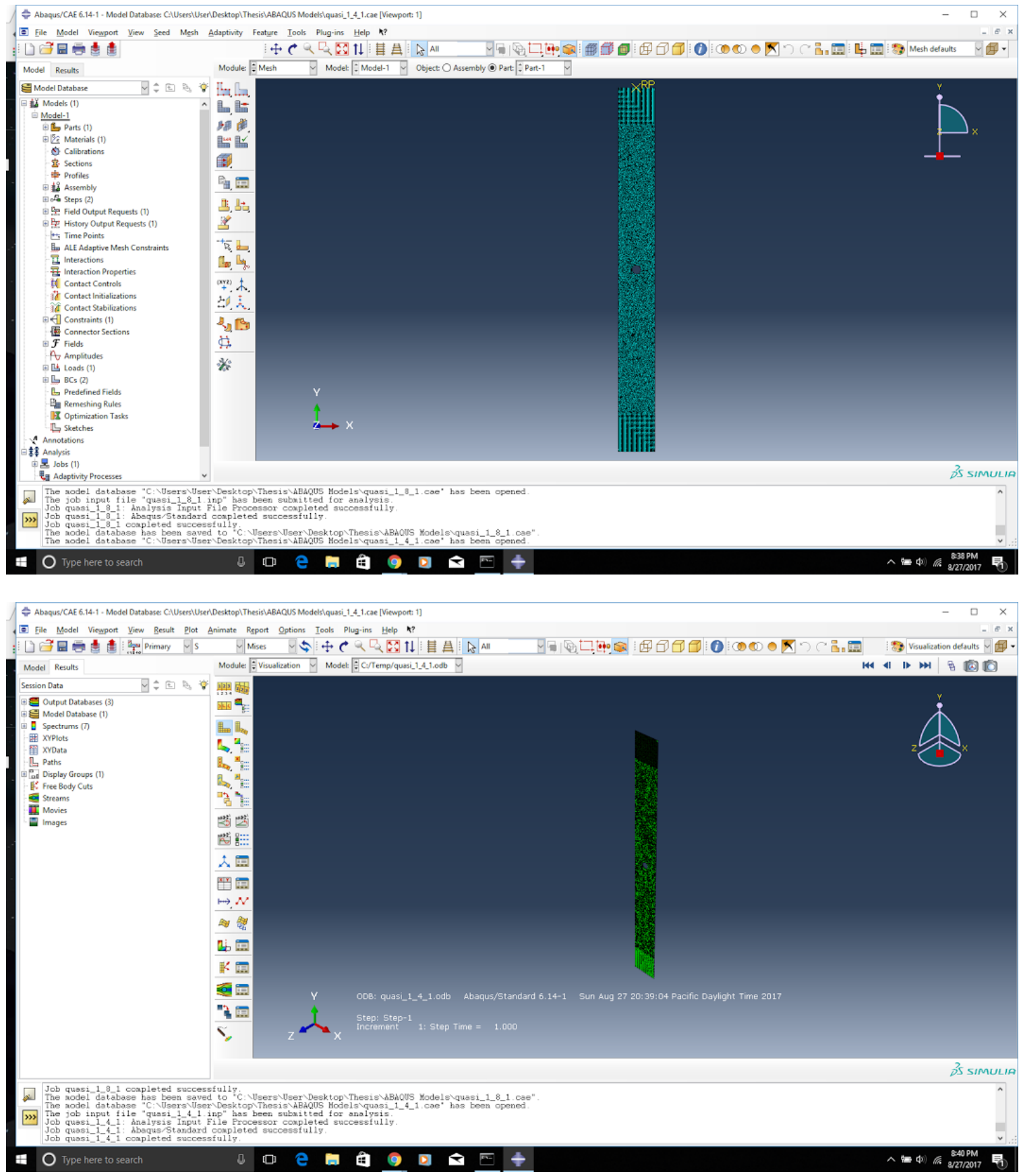

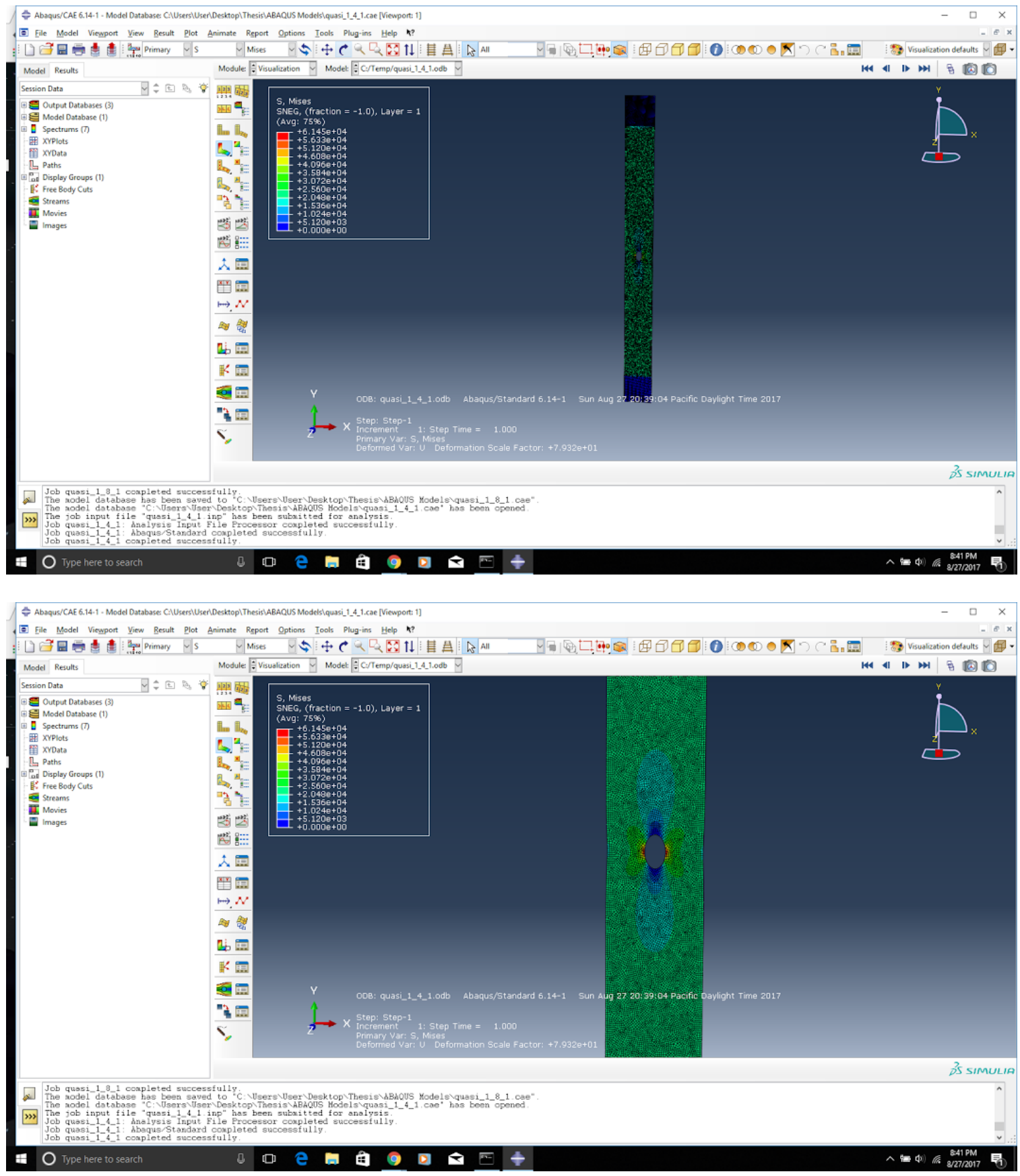


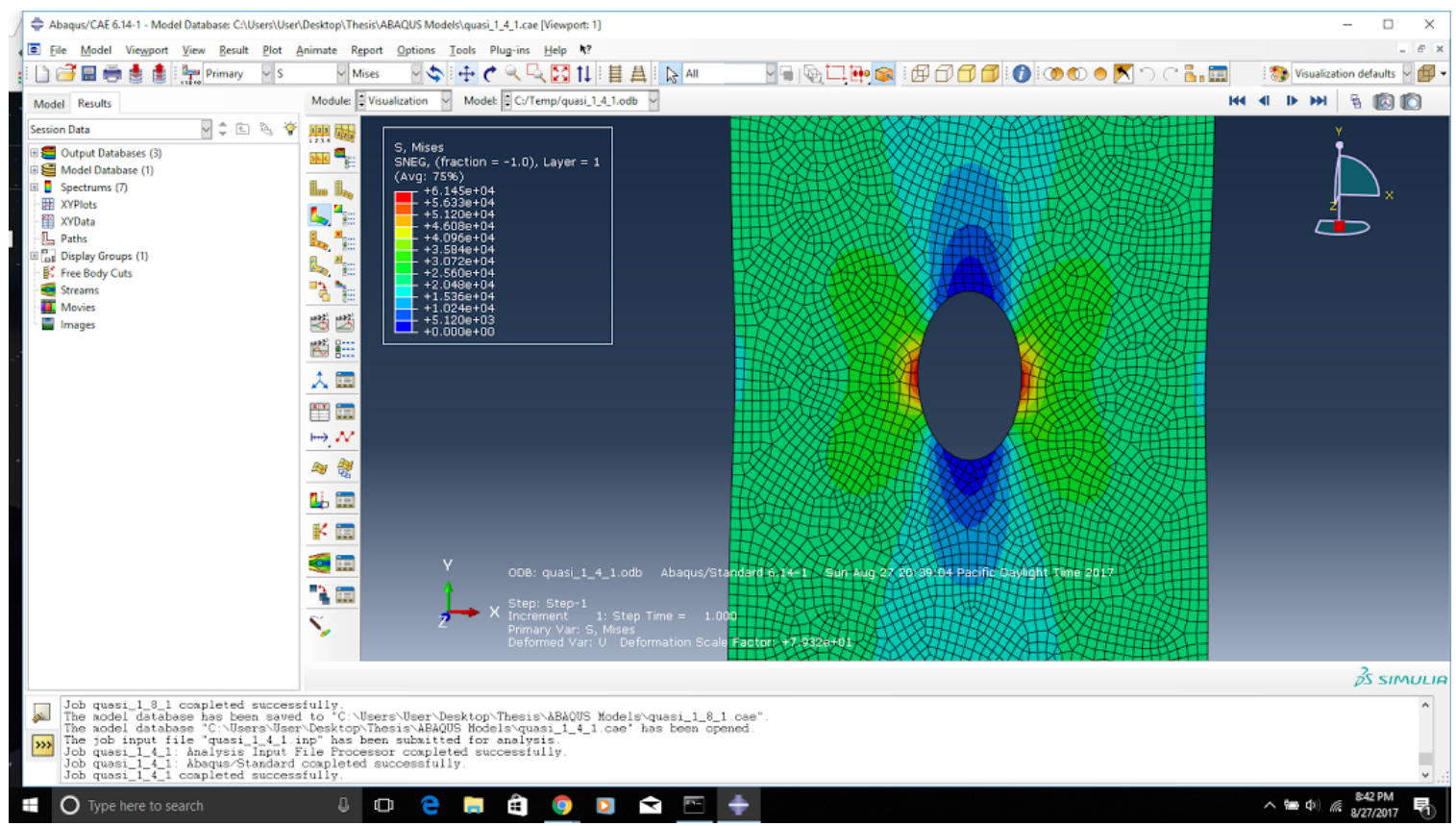


Previous Works Summary

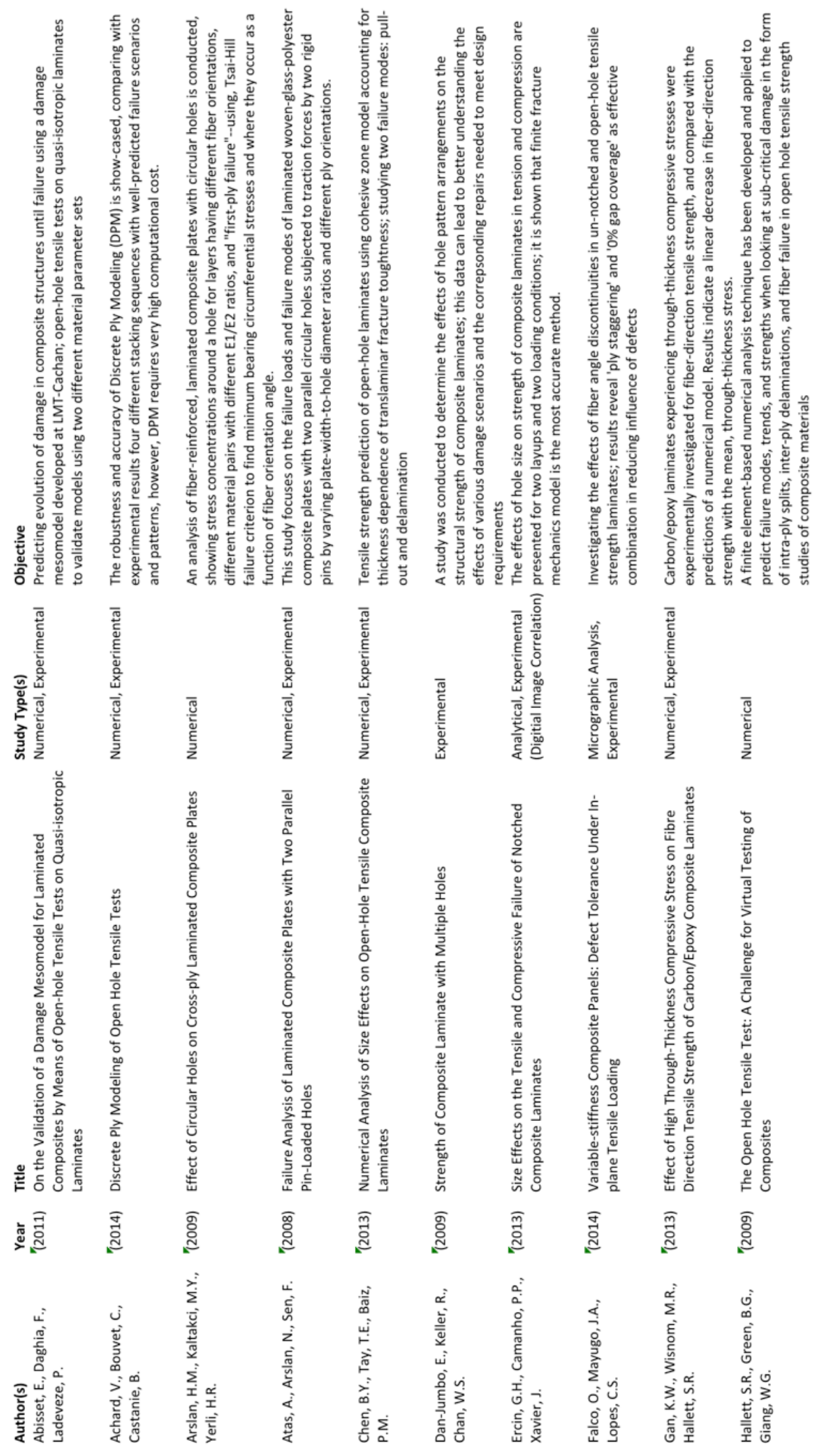



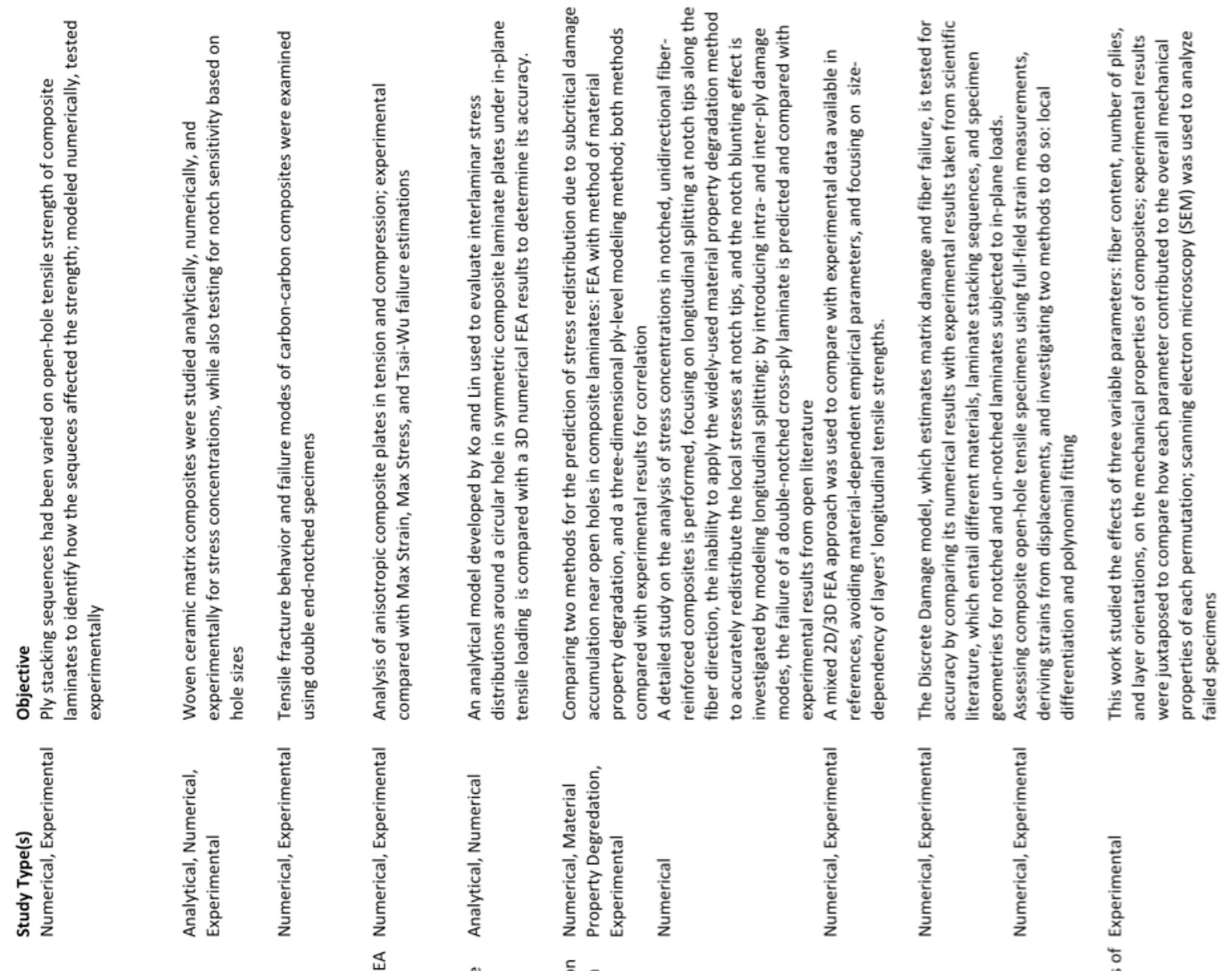

衰
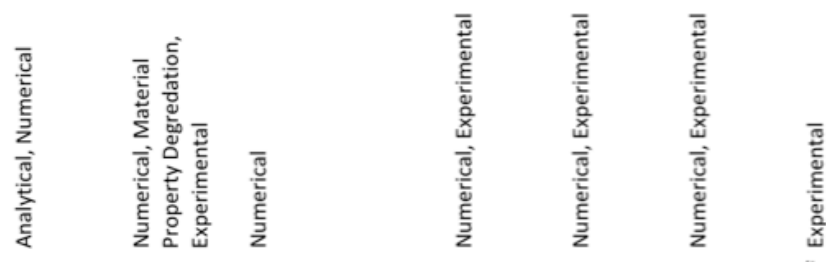

敦営

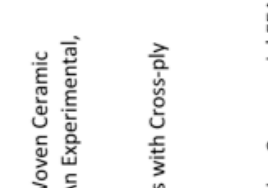

응
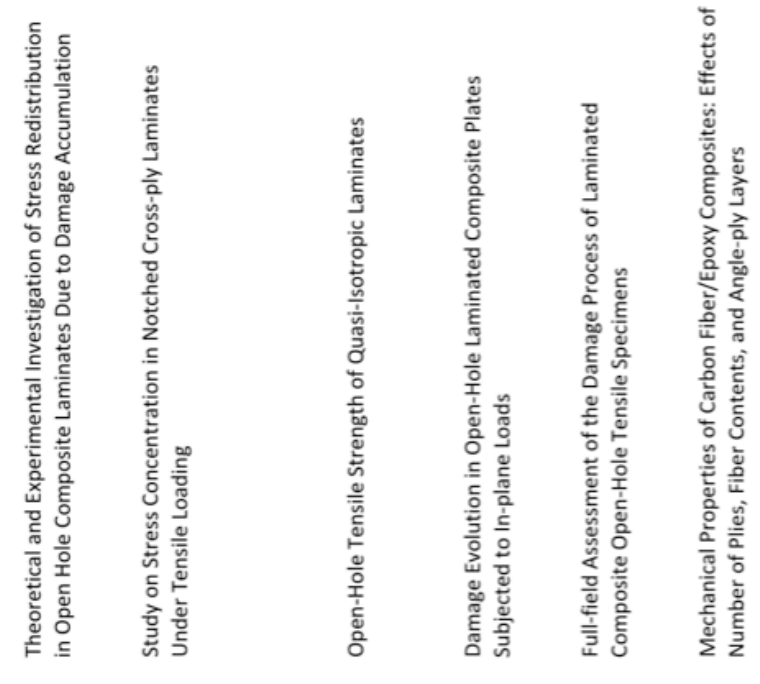

愛

商 愛

屁



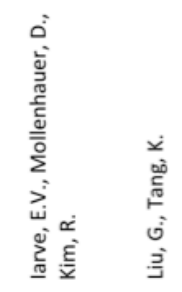

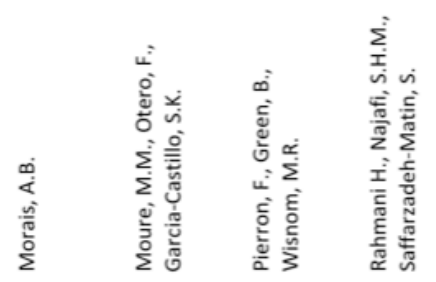



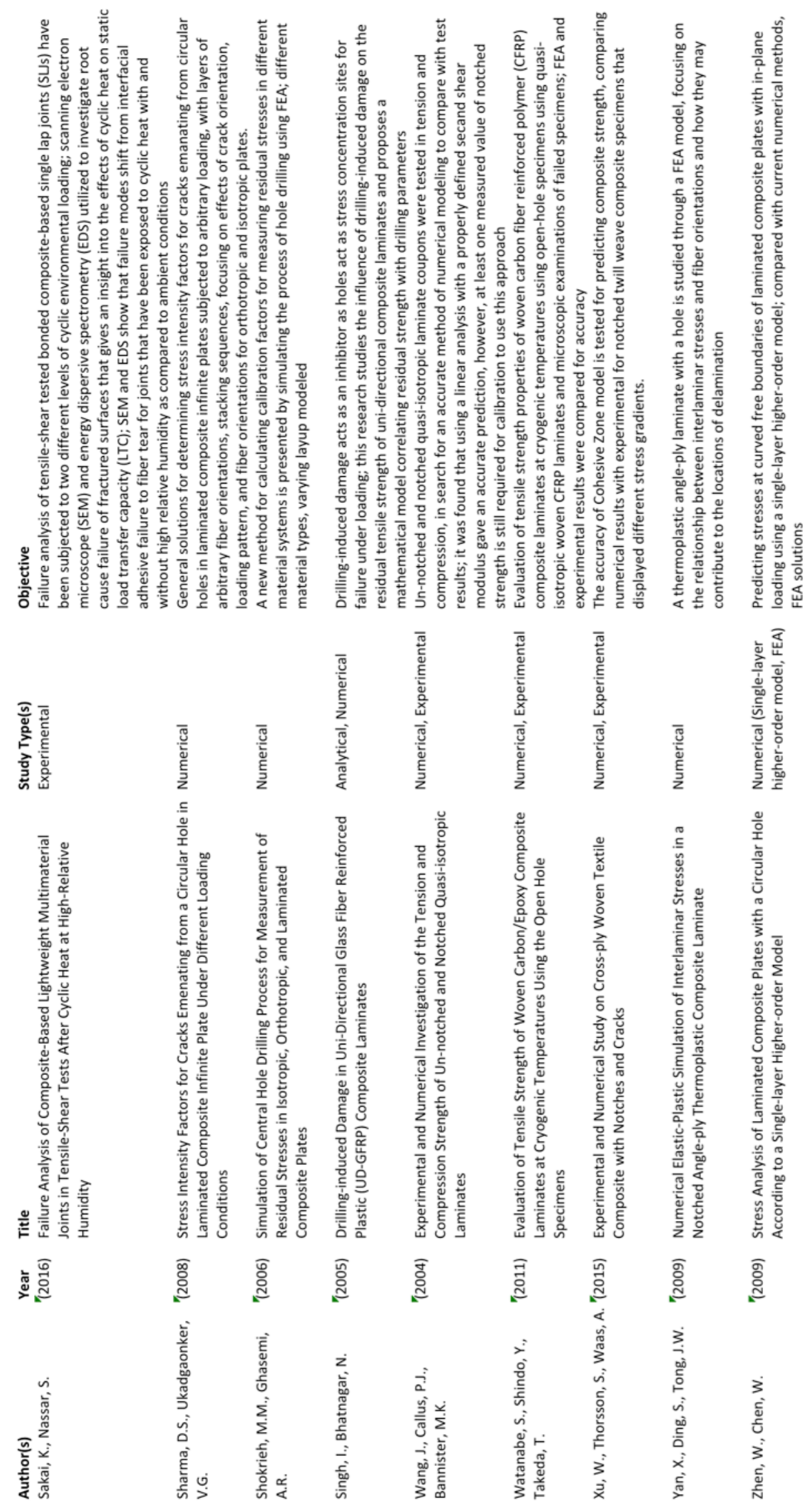